\title{
Metal-Free Synthetic Shortcut to Octahydro-Dipyrroloquinoline Skeletons from 2,5-Cyclohexadienone derivatives and L-Proline
}

Can Zhang, Jianbin Li, Xin Wang, Xuan Shen, Dunru Zhu and Ruwei Shen*

State Key Laboratory of Materials-Oriented Chemical Engineering, College of Chemical Engineering, Nanjing Tech University, Nanjing 211800, China.

E-mail: shenrw@njtech.edu.cn

\section{Table of Contents}

1. Single crystal $X$-ray diffraction analysis of $\mathbf{3 a}$ and $\mathbf{3 b}$

S2-S3

2. Deuterated experiment

S4-S5

3. Copies of ${ }^{1} \mathrm{H}$ and ${ }^{13} \mathrm{C}\left\{{ }^{1} \mathrm{H}\right\}$ NMR spectra

S6-S57 


\section{X-ray single crystal diffraction analysis of $3 \mathrm{a}$ and $3 \mathrm{~b}$}

The well-shaped single crystals of 3a and $\mathbf{3 b}$ were selected for X-ray diffraction study. The unit cell parameters and intensity data were collected at 296(2) K on a Bruker SMART APEX II CCD diffractometer using a graphite-monochromated Mo $\mathrm{K} \alpha(\lambda=0.71073 \AA)$ radiation. The structure was solved by direct methods and refined on $\mathrm{F} 2$ by full-matrix least squares procedures using SHELXTL software. All non-hydrogen atoms were refined anisotropically. All $\mathrm{H}$ atoms were located from a difference map and refined isotropically.

Crystallographic data for $\mathbf{3 a}$ and $\mathbf{3 b}$ are listed in Table S1. Figure S1 and Figure S2 show the ORTEP drawings of compounds $\mathbf{3 a}$ and $\mathbf{3 b}$ (ellipsoid contour 50\% probability). CCDC 2057583 and 2057584 include the crystallographic data of $\mathbf{3 a}$ and $\mathbf{3 b}$ for this article. These data can be obtained free of charge from the Cambridge Crystallographic Date Center via www.ccdc.cam.ac.uk.

Table S1 Crystallographic data for compound 3a and $\mathbf{3 b}$

\begin{tabular}{lll}
\hline Compound & 3a & 3b \\
\hline Empirical formula & $\mathrm{C}_{22} \mathrm{H}_{26} \mathrm{~N}_{2} \mathrm{O}_{2}$ & $\mathrm{C}_{44} \mathrm{H}_{52} \mathrm{~N}_{4} \mathrm{O}_{4}$ \\
Formula weight & 350.45 & 700.89 \\
Crystal system & Triclinic & Triclinic \\
Space group & $P-1$ & $P-1$ \\
$a(\AA)$ & $7.511(4)$ & $8.814(15)$ \\
$b(\AA)$ & $10.104(5)$ & $13.601(2)$ \\
$c(\AA)$ & $12.064(6)$ & $17.015(3)$ \\
$\alpha\left({ }^{\circ}\right)$ & $83.595(7)$ & $98.714(2)$ \\
$\beta\left(^{\circ}\right)$ & $88.531(7)$ & $101.738(2)$ \\
$\gamma\left({ }^{\circ}\right)$ & $88.891(8)$ & $107.063(2)$ \\
$V\left(\AA^{3}\right)$ & $909.4(8)$ & $1860(6)$ \\
$Z$ & 2 & 2 \\
$D_{\mathrm{c}}\left(\mathrm{g} \cdot \mathrm{cm}^{-3}\right)$ & 1.280 & 1.251 \\
$\left.\mu(\mathrm{mm})^{-1}\right)$ & 0.082 & 0.08 \\
$F(000)$ & 376 & 752 \\
Crystal size $\left.(\mathrm{mm})^{3}\right)$ & $0.19 \times 0.14 \times 0.10$ & $0.16 \times 0.12 \times 0.10$ \\
$\theta$ Range & $1.699-25.002$ & $1.255-25.005$ \\
Reflections collected & 6428 & 13621 \\
Independent reflections & $3135\left[R_{\text {int }}=0.0335\right]$ & $6513\left[R_{\text {int }}=0.0310\right]$ \\
Reflections observed $[I>2 \sigma(I)]$ & 2224 & 4298 \\
Data/restraints/parameters & $3135 / 6 / 238$ & $6513 / 0 / 473$ \\
Goodness-of-fit on $F^{2}$ & 1.059 & 1.016 \\
$R_{1} / w R_{2}[I>2 \sigma(I)]$ & $0.0786 / 0.2311$ & $0.0472 / 0.1128$ \\
$R_{1} / w R_{2}($ all data) & $0.1021 / 0.2485$ & $0.0802 / 0.1273$ \\
Max., Min. $\Delta \rho\left(\mathrm{e} \cdot \AA^{-3}\right)$ & $0.320,-0.275$ & $0.177,-0.222$ \\
\hline
\end{tabular}




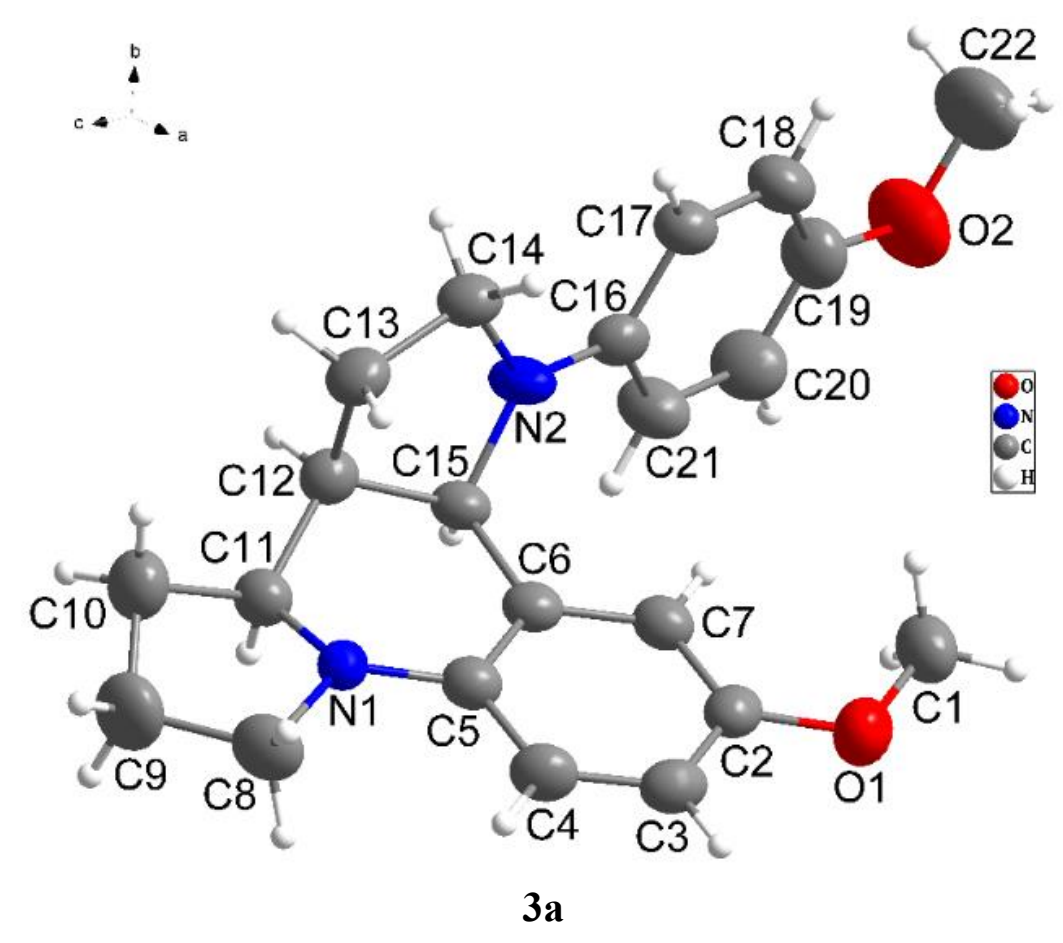

Figure S1. ORTEP drawing of compound 3a (ellipsoid contour 50\% probability; CCDC 2057583): crystal sample was obtained from a clear solution of the compound 3a disolved in PE/DCE (5/1) by slow evaporation at room temperature

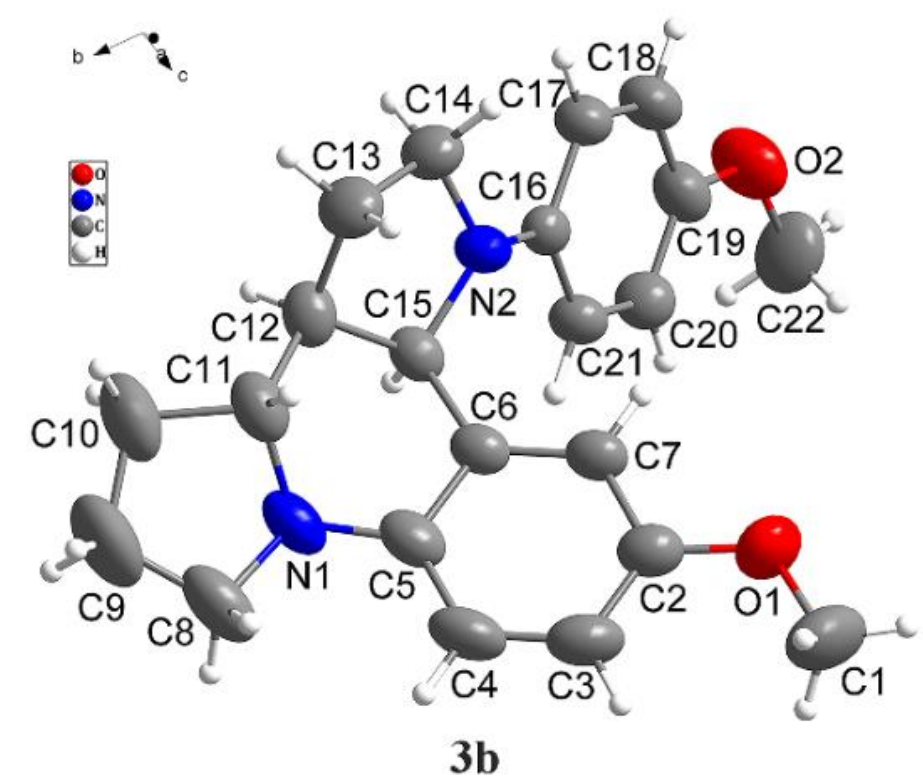

Figure S2. ORTEP drawing of compound $\mathbf{3 b}$ (ellipsoid contour 50\% probability; there are two molecules per unit cell, and one molecule was omitted for clarity; CCDC 2057584): crystal sample was obtained from a clear solution of the compound $\mathbf{3 b}$ disolved in PE/DCE (5/1) by slow evaporation at room temperature 


\section{Deuterated experiment}
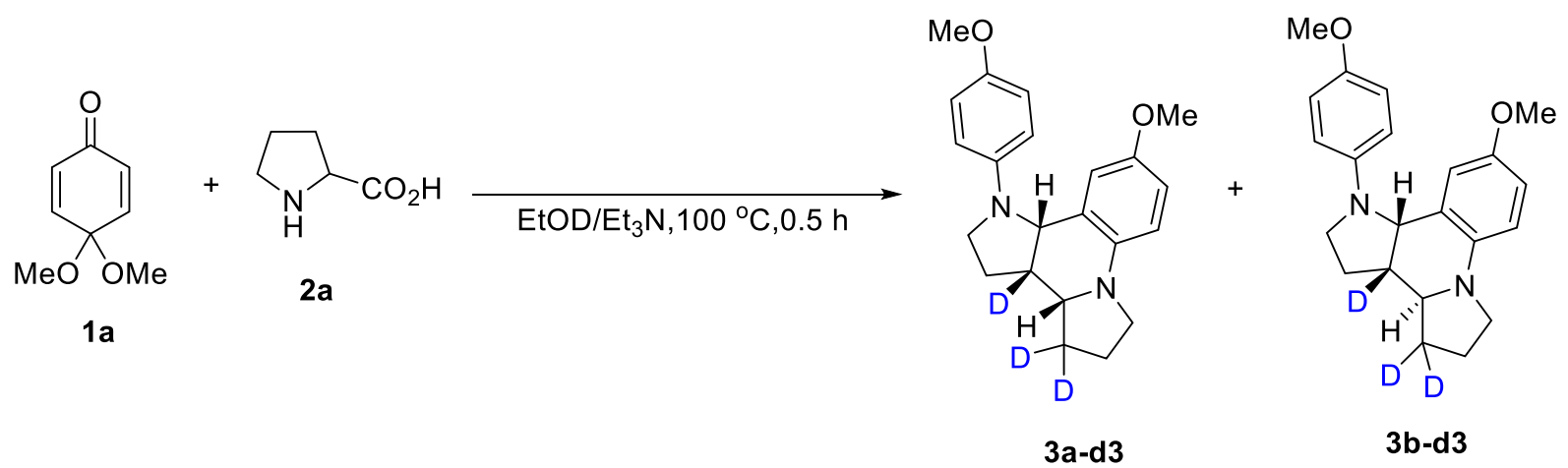

Following the general procedure, the reaction of $1 \mathbf{a}(30.9 \mathrm{mg}, 0.2 \mathrm{mmol})$ and $\mathbf{2 a}(28.1 \mathrm{mg}$, $0.24 \mathrm{mmol})$ in EtOD $(1 \mathrm{~mL})$ and $\mathrm{Et}_{3} \mathrm{~N}(0.25 \mathrm{~mL})$ at $100{ }^{\circ} \mathrm{C}$ for $1 \mathrm{~h}$ afforded 3a-d3 $(13.2 \mathrm{mg}, 38 \%)$ and 3b-d3 (11.8 mg, 33\%), which were purified by column chromatography (pretreated with 1\% $\left.\mathrm{Et}_{3} \mathrm{~N}\right)$ using PE/EtOAc (50/1 v/v) as eluent. 3a-d3: ${ }^{1} \mathrm{H} \mathrm{NMR}\left(\mathrm{CDCl}_{3}, 400 \mathrm{MHz}\right): \delta=6.95(\mathrm{~d}, J=$ $4.0 \mathrm{~Hz}, 1 \mathrm{H}), 6.87(\mathrm{~d}, J=8.8 \mathrm{~Hz}, 2 \mathrm{H}), 6.76(\mathrm{~d}, J=8.8 \mathrm{~Hz}, 2 \mathrm{H}), 6.71-6.68(\mathrm{~m}, 1 \mathrm{H}), 6.36(\mathrm{~d}, J=$ $8.8 \mathrm{~Hz}, 1 \mathrm{H}), 5.02(\mathrm{~s}, 1 \mathrm{H}), 3.78(\mathrm{~s}, 3 \mathrm{H}), 3.59(\mathrm{~s}, 3 \mathrm{H}), 3.55(\mathrm{~s}, 1 \mathrm{H}), 3.45-3.36(\mathrm{~m}, 2 \mathrm{H}), 3.22-3.12$ (m, 2H), 2.09-2.03 (m, 1H), 1.98-1.87 (m, 3H). 3b-d3: ${ }^{1} \mathrm{H}$ NMR $\left(\mathrm{CDCl}_{3}, 400 \mathrm{MHz}\right): \delta=6.83(\mathrm{~d}$, $J=8.4 \mathrm{~Hz}, 2 \mathrm{H}), 6.74-6.72(\mathrm{~m}, 2 \mathrm{H}), 6.65-6.61(\mathrm{~m}, 3 \mathrm{H}), 4.33(\mathrm{~s}, 1 \mathrm{H}), 3.76(\mathrm{~s}, 3 \mathrm{H}), 3.64(\mathrm{~s}, 3 \mathrm{H})$, $3.64-3.61(\mathrm{~m}, 1 \mathrm{H}), 3.43\left(\mathrm{td}, J_{1}=8.8 \mathrm{~Hz}, J_{2}=2.8 \mathrm{~Hz}, 1 \mathrm{H}\right), 3.27-3.24(\mathrm{~m}, 1 \mathrm{H}), 2.81-2.74(\mathrm{~m}, 1 \mathrm{H})$, $2.35(\mathrm{~s}, 1 \mathrm{H}), 2.20-2.10(\mathrm{~m}, 2 \mathrm{H}), 1.97-1.92(\mathrm{~m}, 1 \mathrm{H}), 1.78-1.71(\mathrm{~m}, 1 \mathrm{H})$. A comparison on the ${ }^{1} \mathrm{H}$ NMR spectra is shown in Figure S3 and Figure S4. Detailed spectra can be found in Part 3 Copies of ${ }^{1} \mathrm{H}$ and ${ }^{13} \mathrm{C}$ NMR spectra (pages S6, S8, S10 and S11).
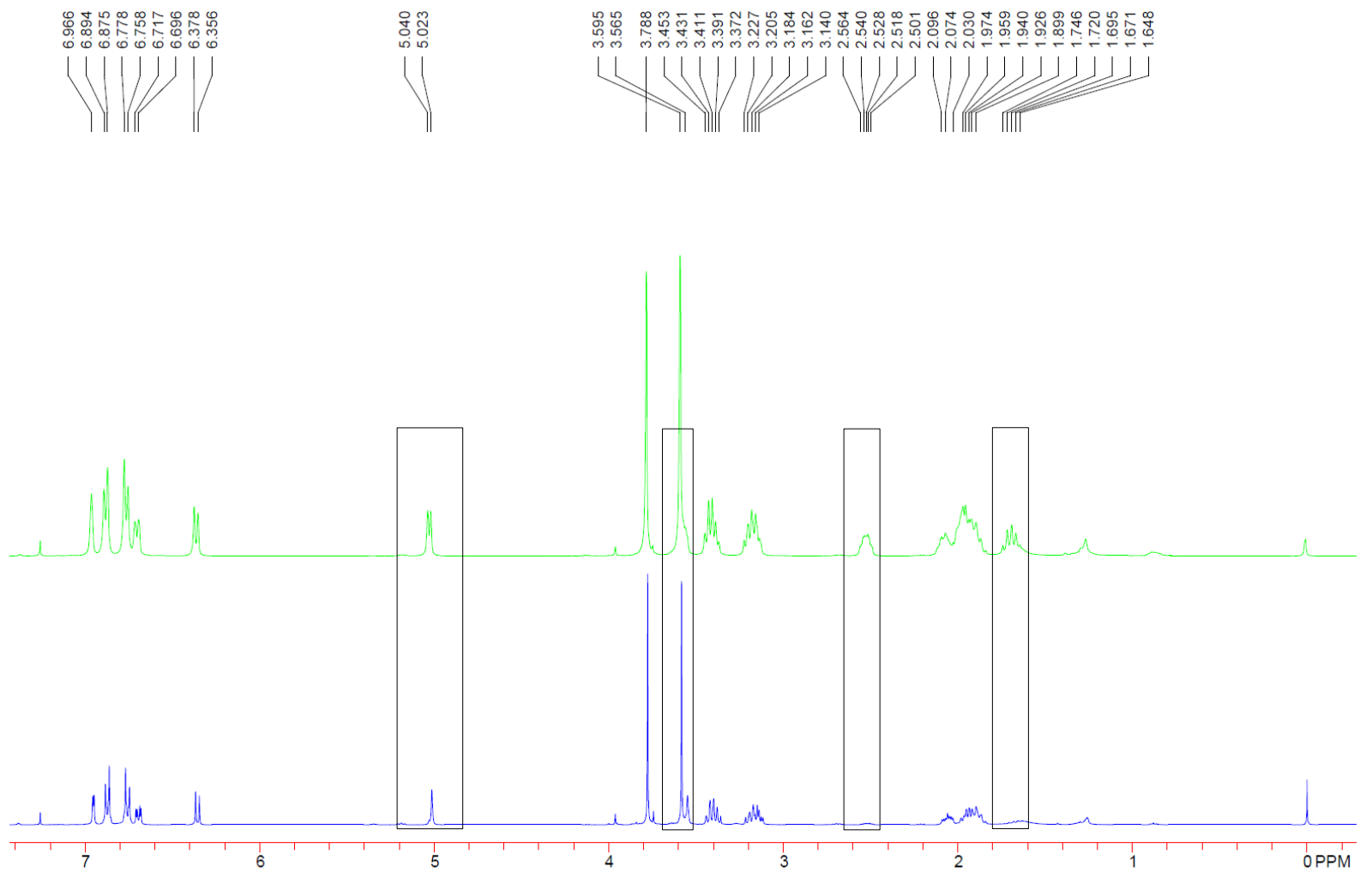

Figure S3 ${ }^{1} \mathrm{H}$ NMR of $\mathbf{3 a}$ (green) and 3a-d3 (blue) 


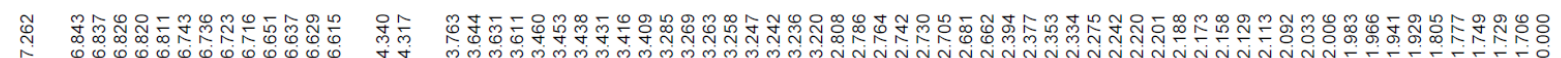

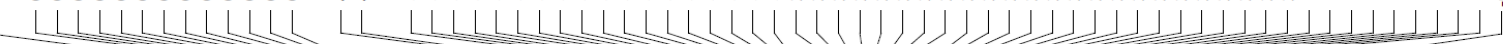

Tा IाI

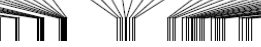

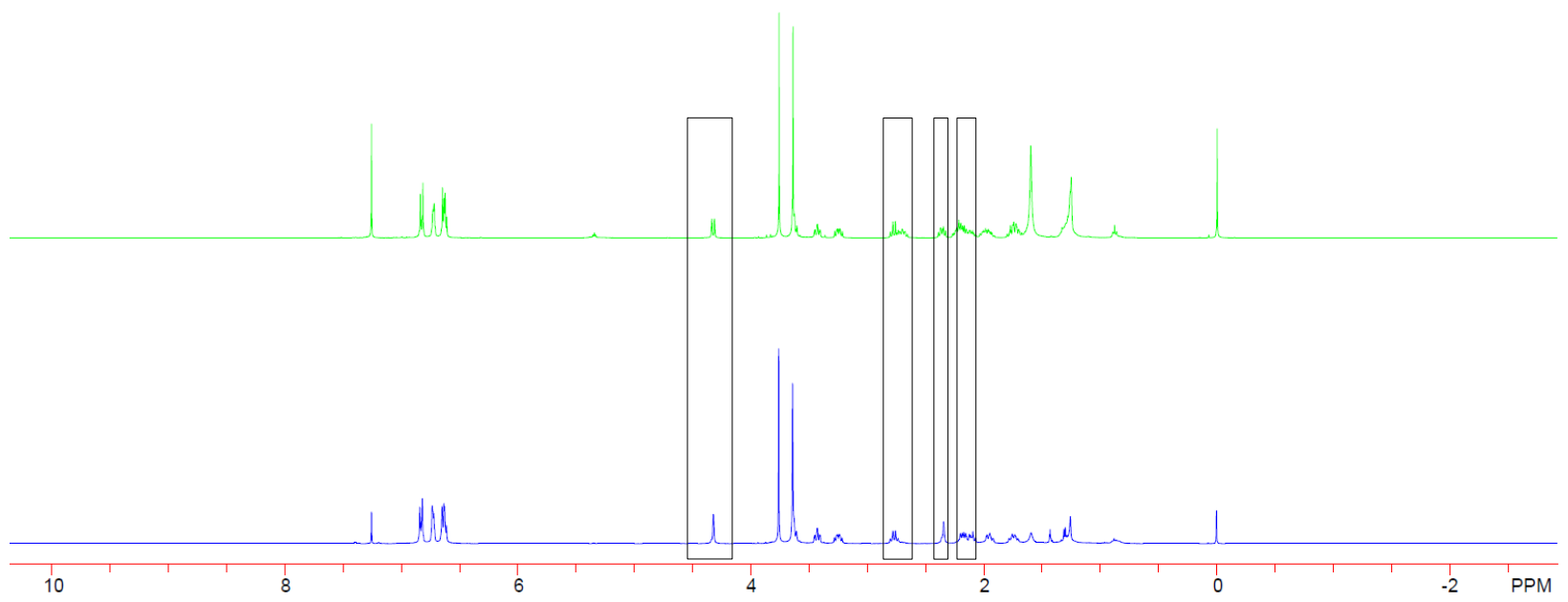

Figure $\mathbf{S} 4{ }^{1} \mathrm{H}$ NMR of $\mathbf{3 b}$ (green) and $\mathbf{3 b - d 3}$ (blue)

3. Copies of ${ }^{1} \mathrm{H}$ and ${ }^{13} \mathrm{C}\left\{{ }^{1} \mathrm{H}\right\}$ NMR spectra 
${ }^{1} \mathrm{H} \mathrm{NMR}$ of $\mathbf{3 a}\left(\mathrm{CDCl}_{3}, 400 \mathrm{MHz}\right)$
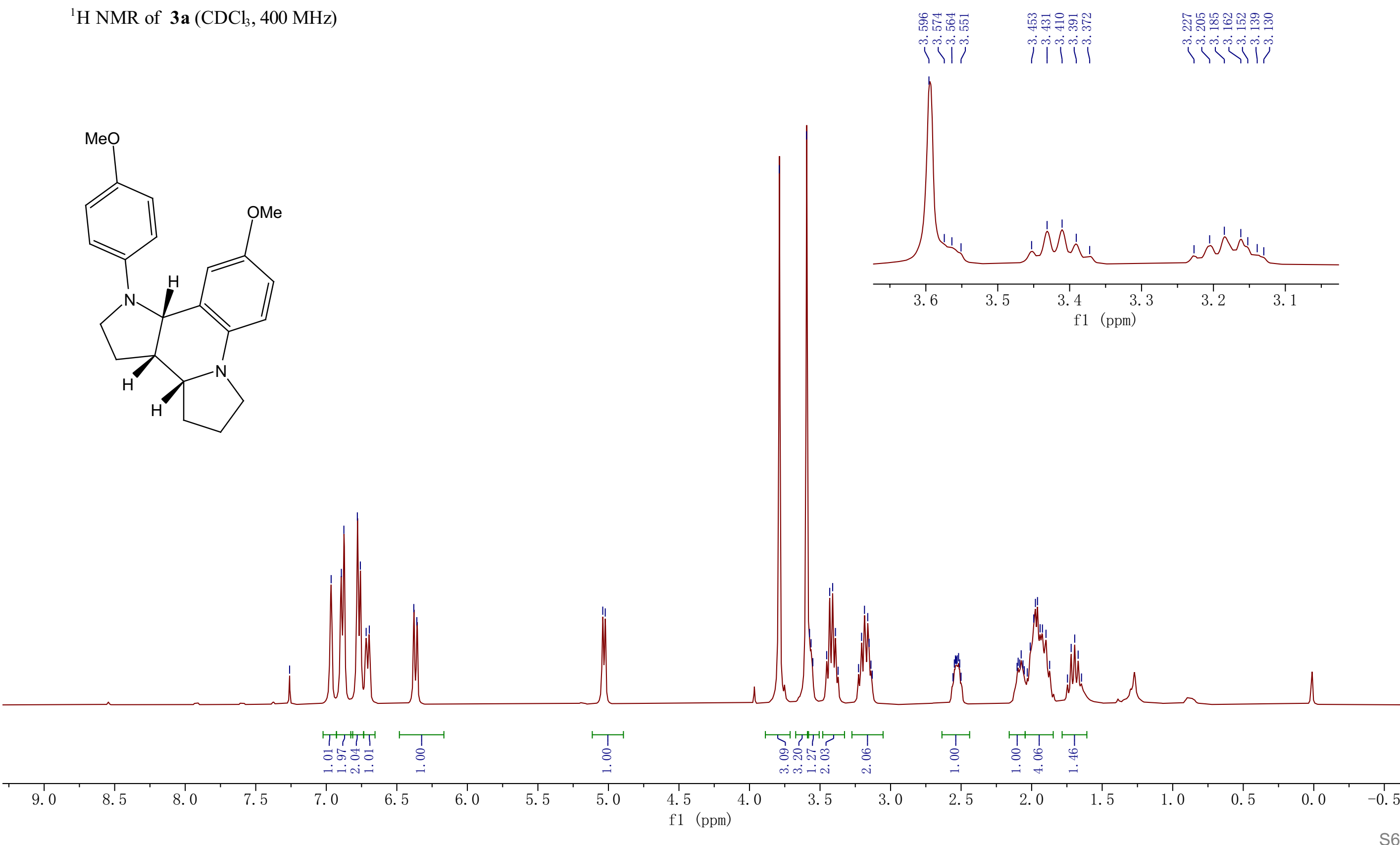
${ }^{13} \mathrm{C}\left\{{ }^{1} \mathrm{H}\right\}$ NMR of $\mathbf{3 a}\left(\mathrm{CDCl}_{3}, 100 \mathrm{MHz}\right)$

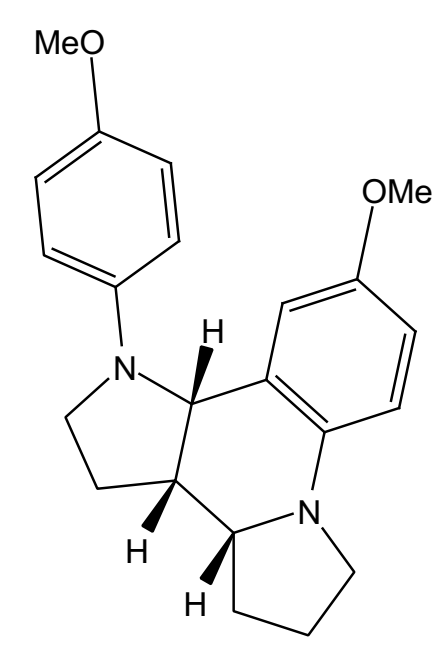

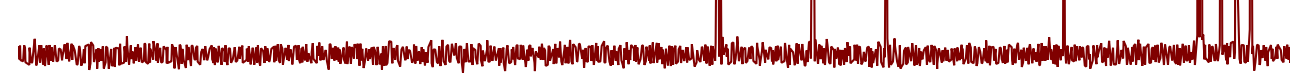




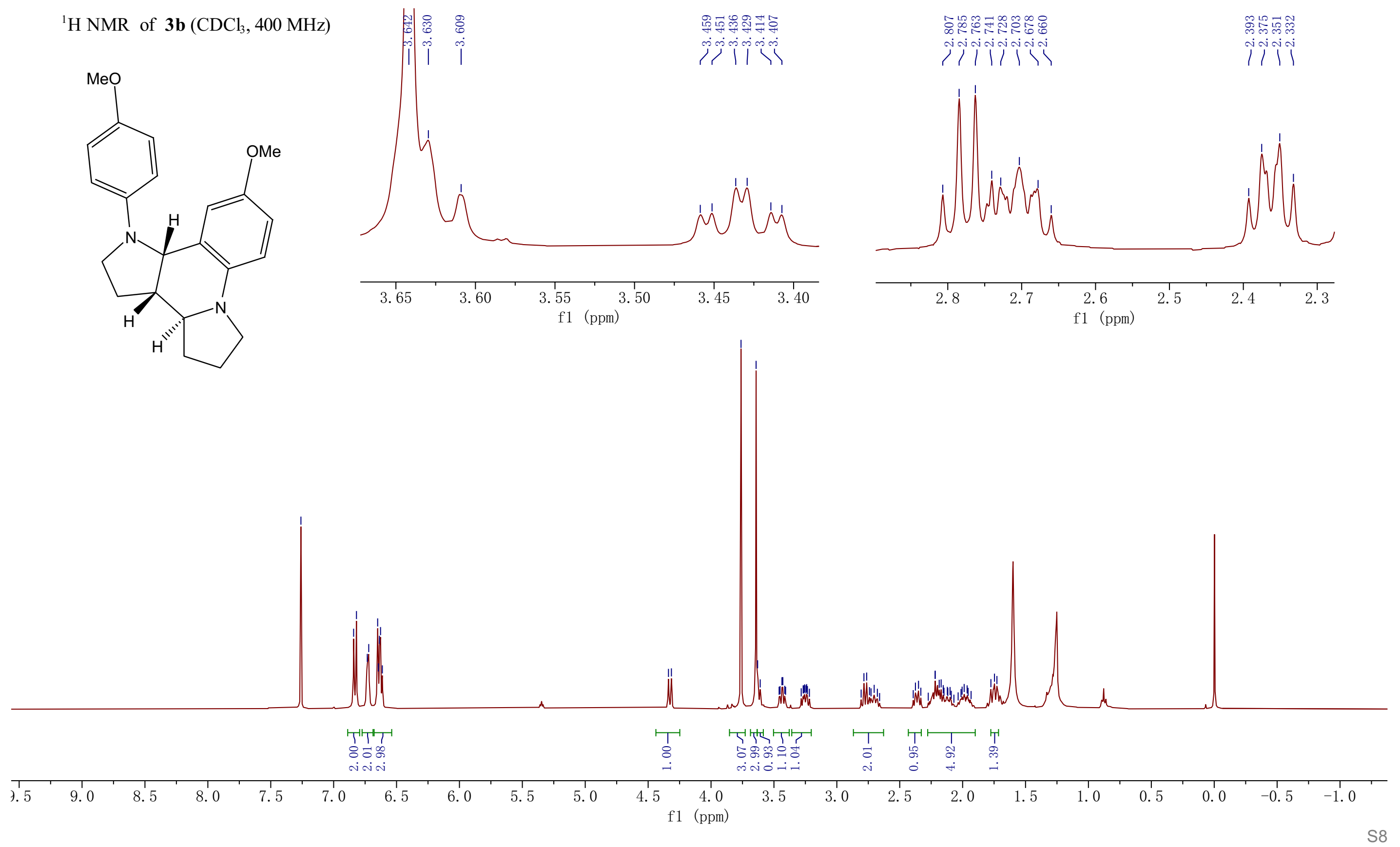




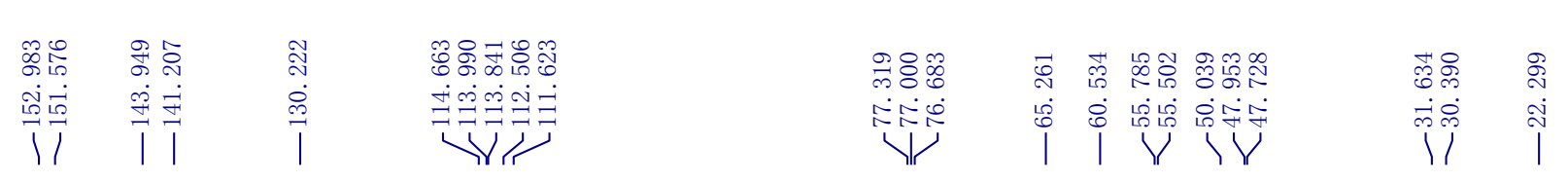

${ }^{13} \mathrm{C}\left\{{ }^{1} \mathrm{H}\right\}$ NMR of $\mathbf{3 b}\left(\mathrm{CDCl}_{3}, 100 \mathrm{MHz}\right)$

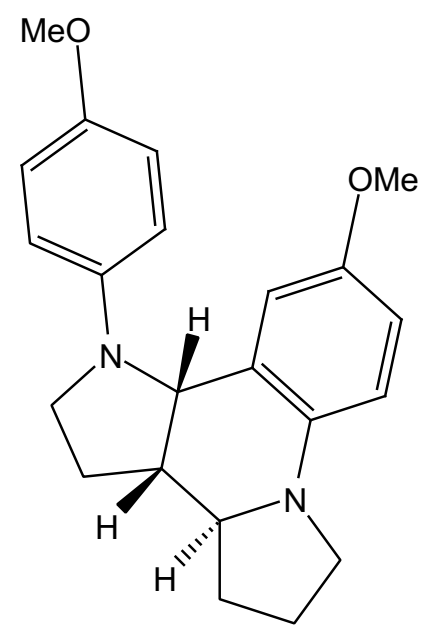


${ }^{1} \mathrm{H}$ NMR of 3a-d3 $\left(\mathrm{CDCl}_{3}, 400 \mathrm{MHz}\right)$
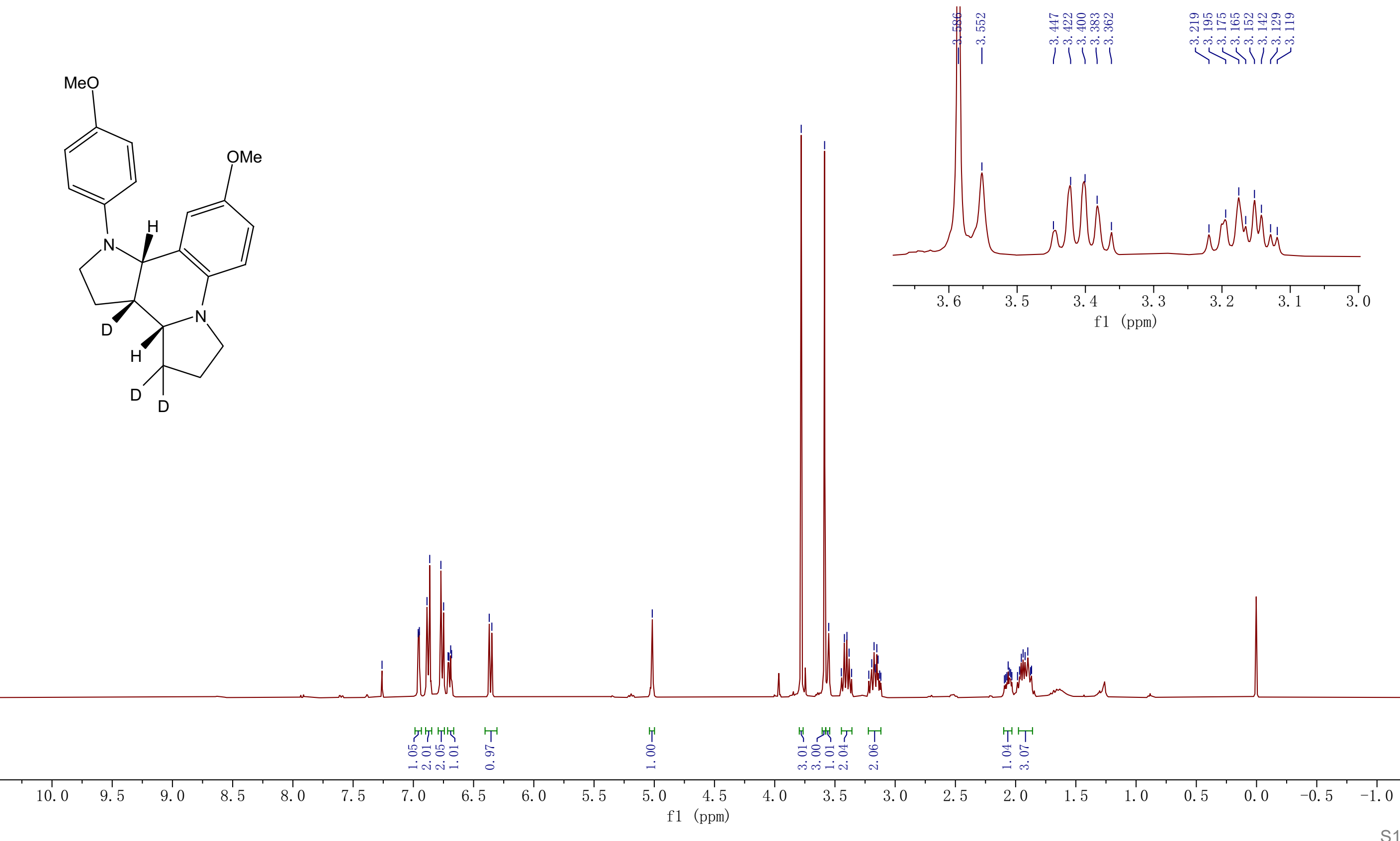
${ }^{1} \mathrm{H}$ NMR of $\mathbf{3 b}$-d3 $\left(\mathrm{CDCl}_{3}, 400 \mathrm{MHz}\right)$<smiles>[2H]C1([2H])CCN2c3ccc(OC)cc3[C@H]3N(c4ccc(OC)cc4)CC[C@@]3([2H])[C@H]21</smiles>
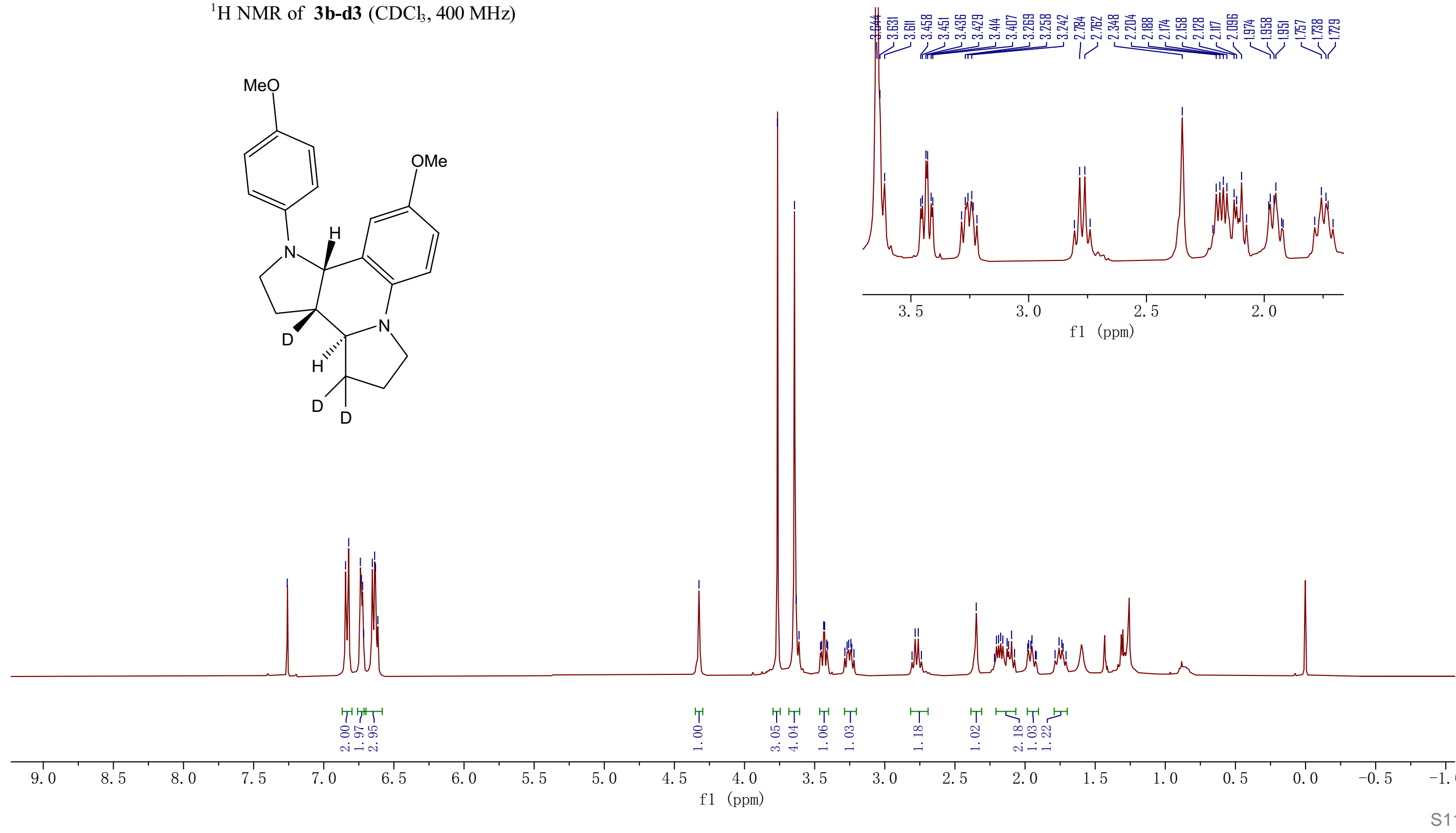
${ }^{1} \mathrm{H}$ NMR of $\mathbf{4 a}\left(\mathrm{CDCl}_{3}, 400 \mathrm{MHz}\right)$
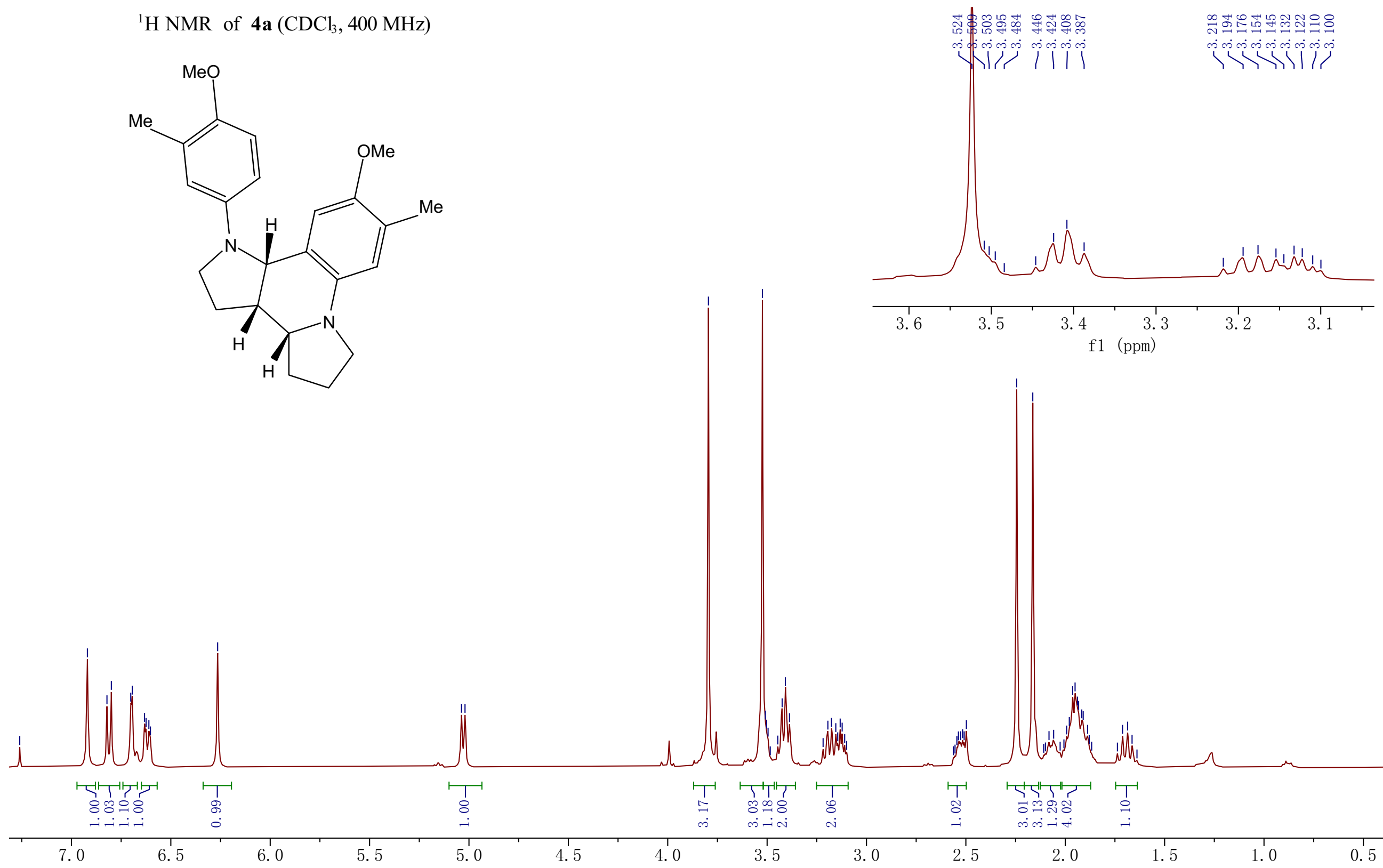

f1 (ppm) 

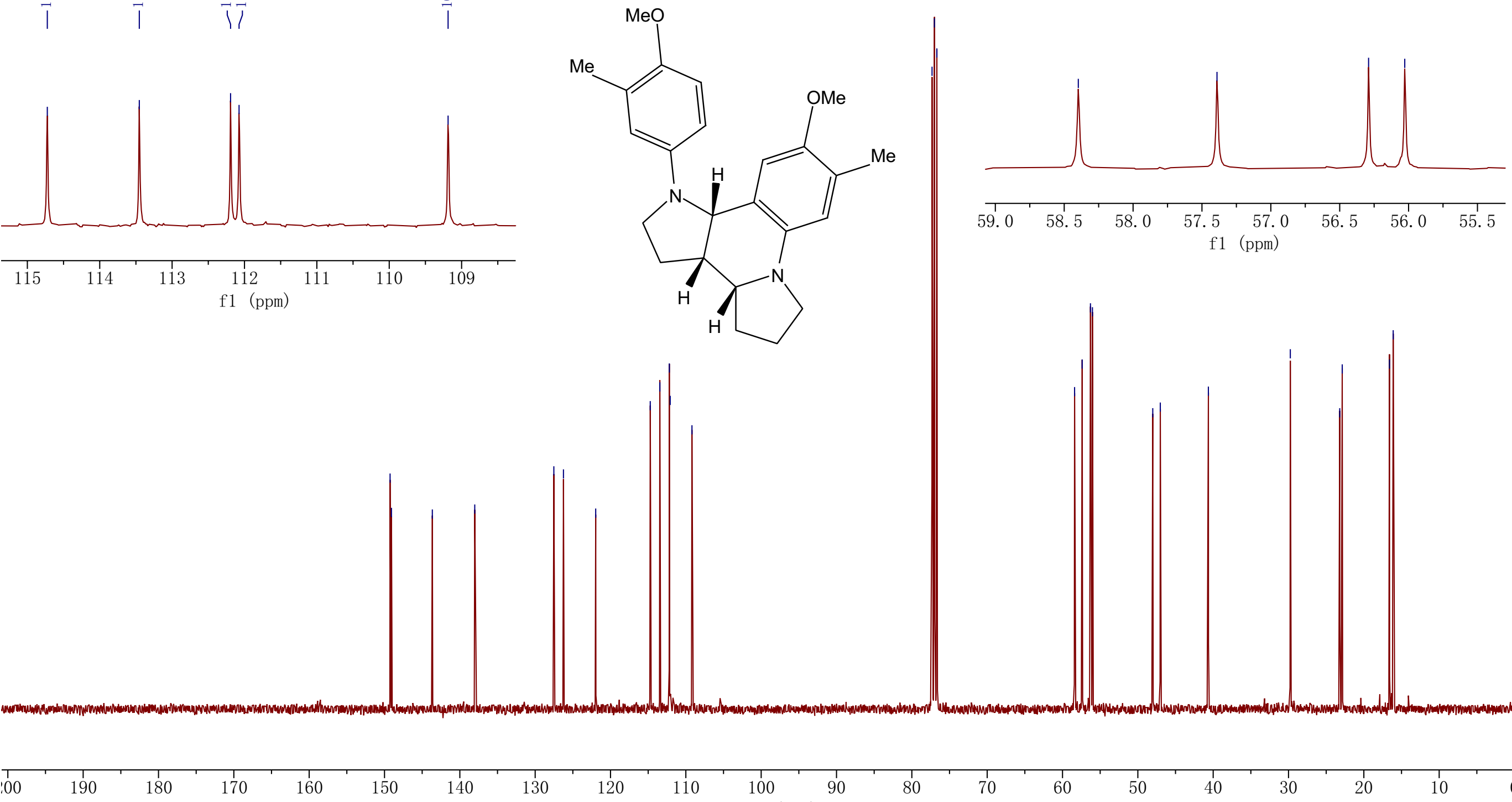

160

150

$140 \quad 130$

120

110

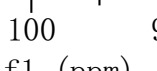

80

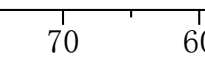

50

40

$30 \quad 20$

$20+10,0$ 


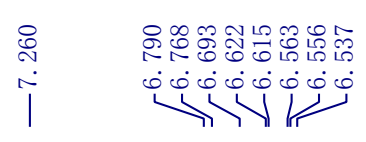

${ }^{1} \mathrm{H} \mathrm{NMR}$ of $\mathbf{4 b}\left(\mathrm{CDCl}_{3}, 400 \mathrm{MHz}\right)$ (<smiles>COc1ccc(N2CC[C@H]3[C@H]2c2cc(OC)c(C)cc2N2CCC[C@H]32)cc1C</smiles>

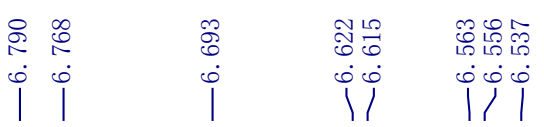

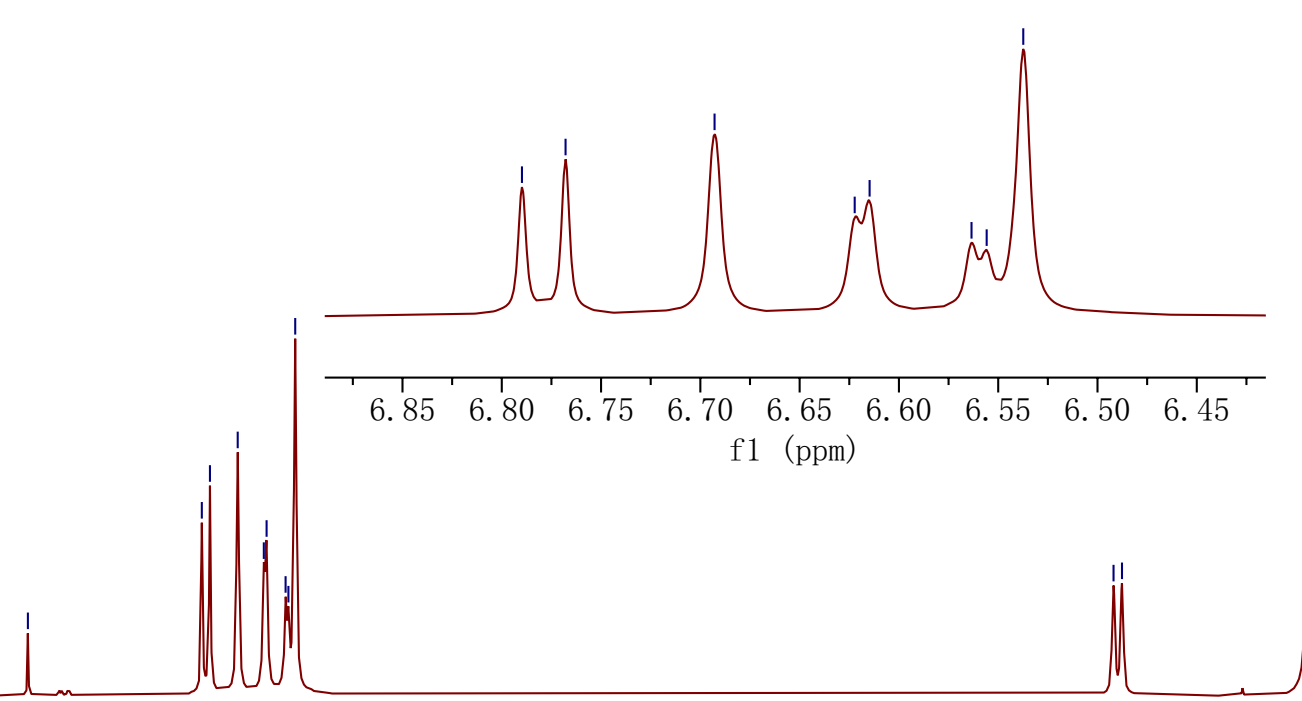

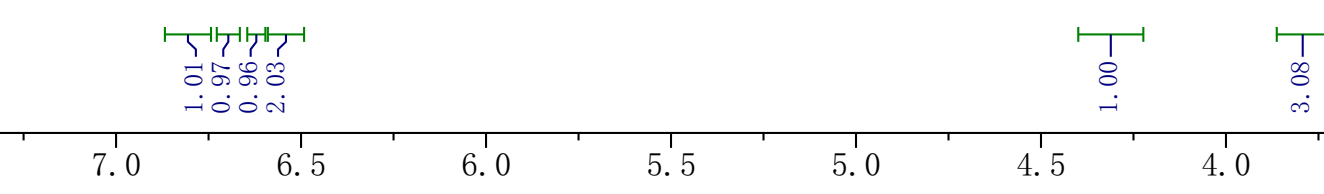

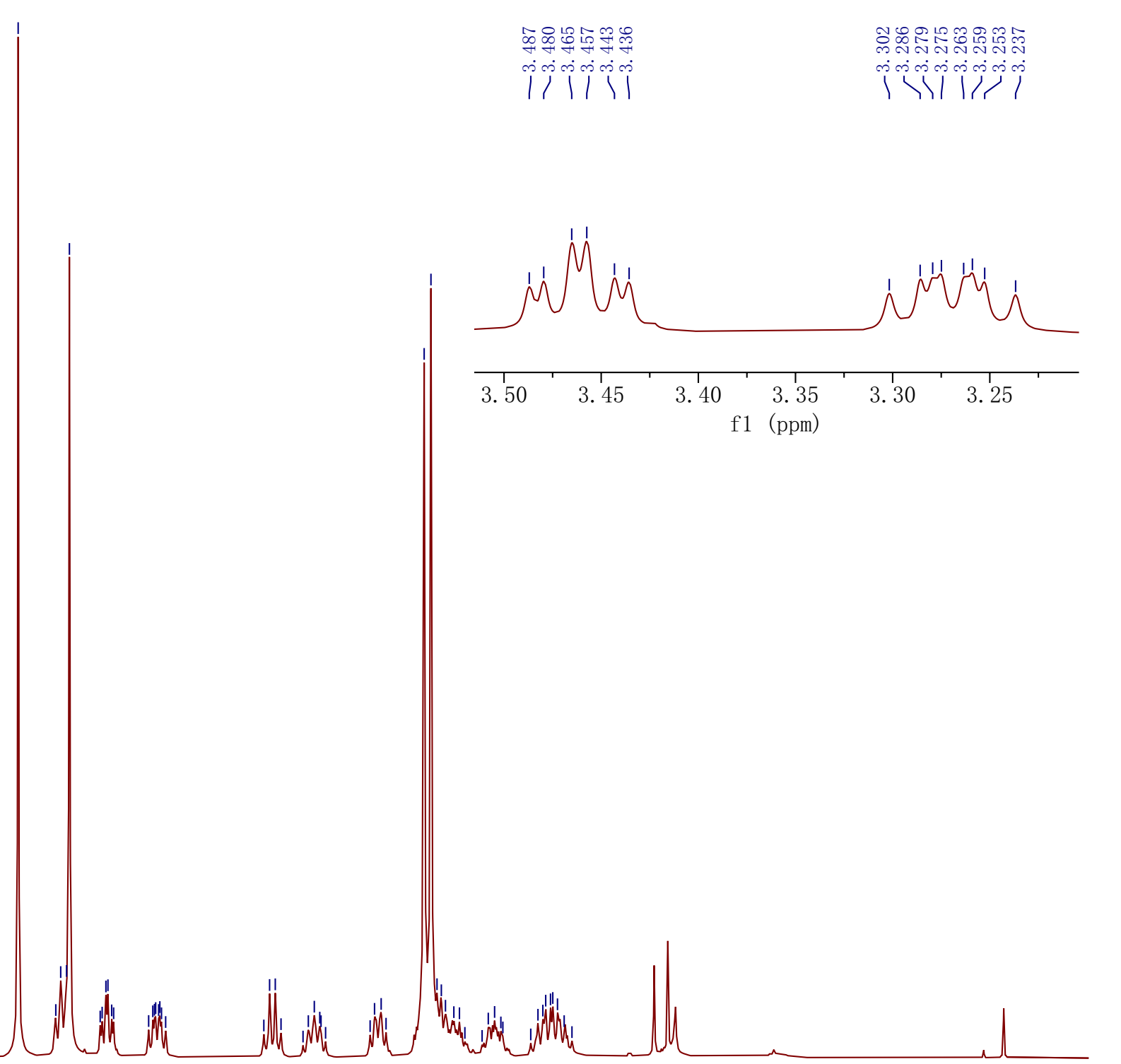

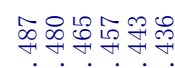

i

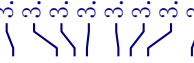

(1)

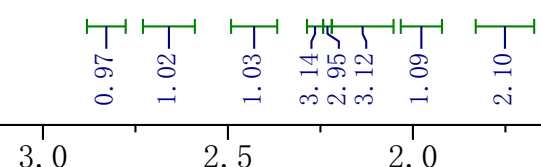

3.5

f1 (ppm) 
${ }^{13} \mathrm{C}\left\{{ }^{1} \mathrm{H}\right\}$ NMR of $\mathbf{4 b}\left(\mathrm{CDCl}_{3}, 100 \mathrm{MHz}\right)$

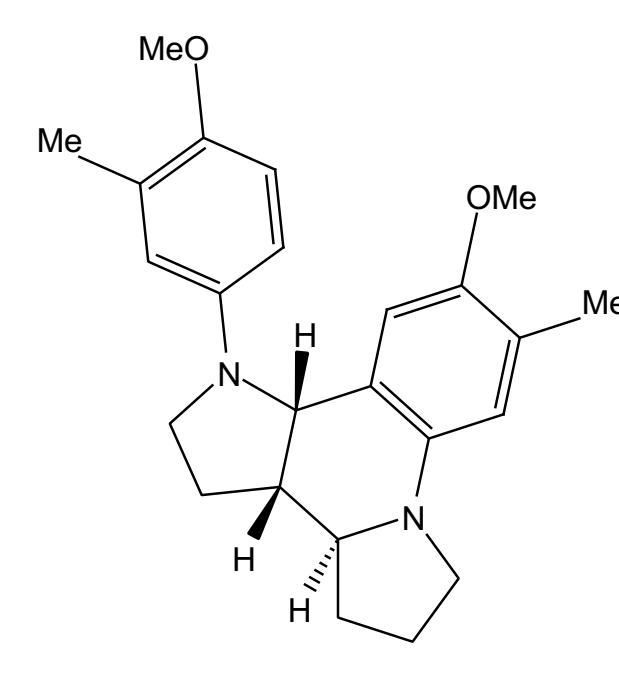

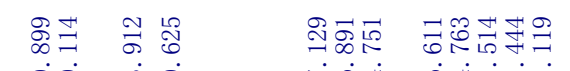

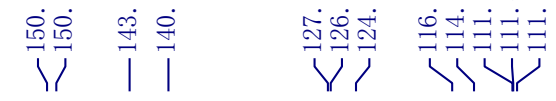
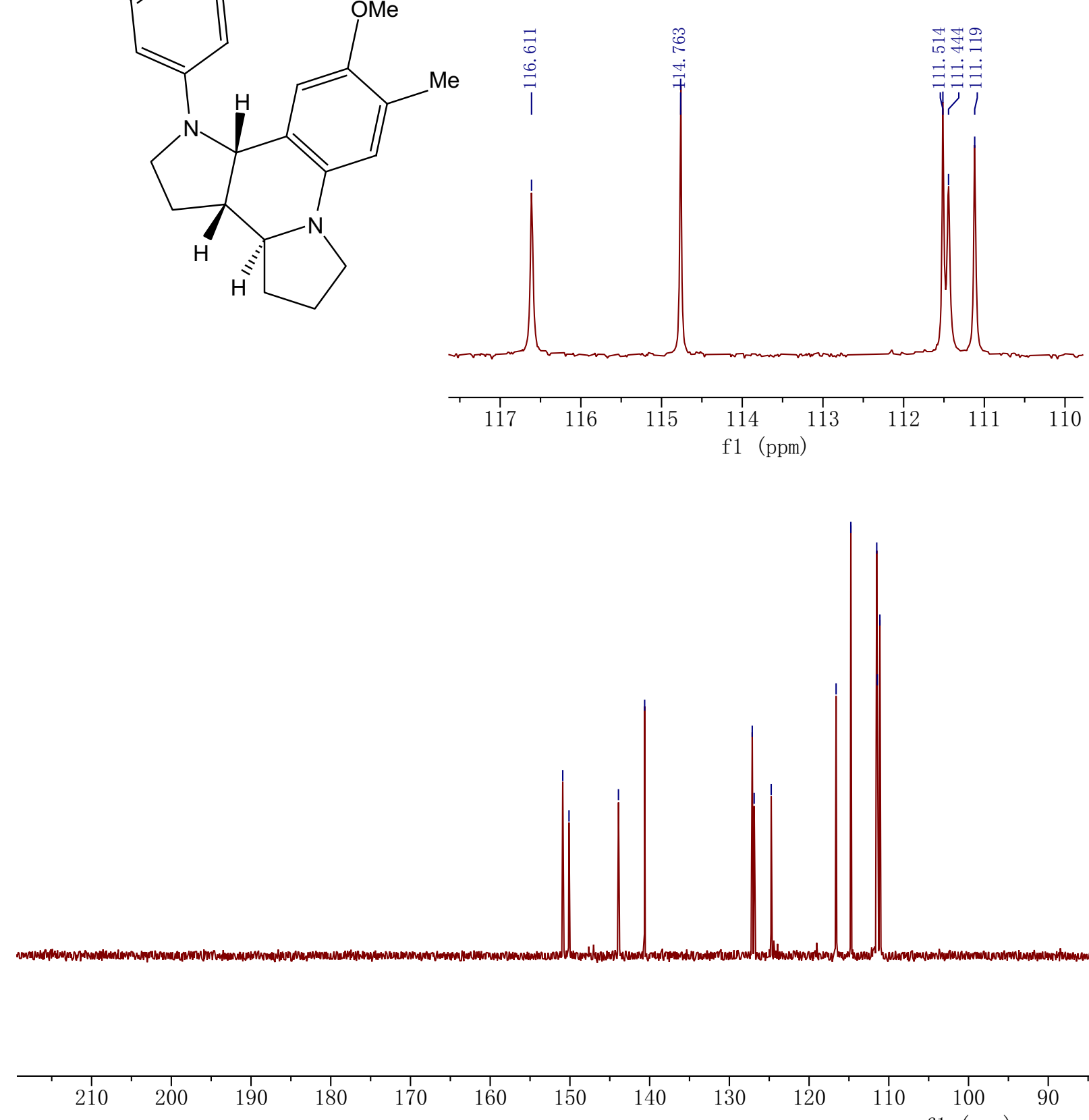
${ }^{1} \mathrm{H}$ NMR of $\mathbf{5 a}\left(\mathrm{CDCl}_{3}, 400 \mathrm{MHz}\right)$
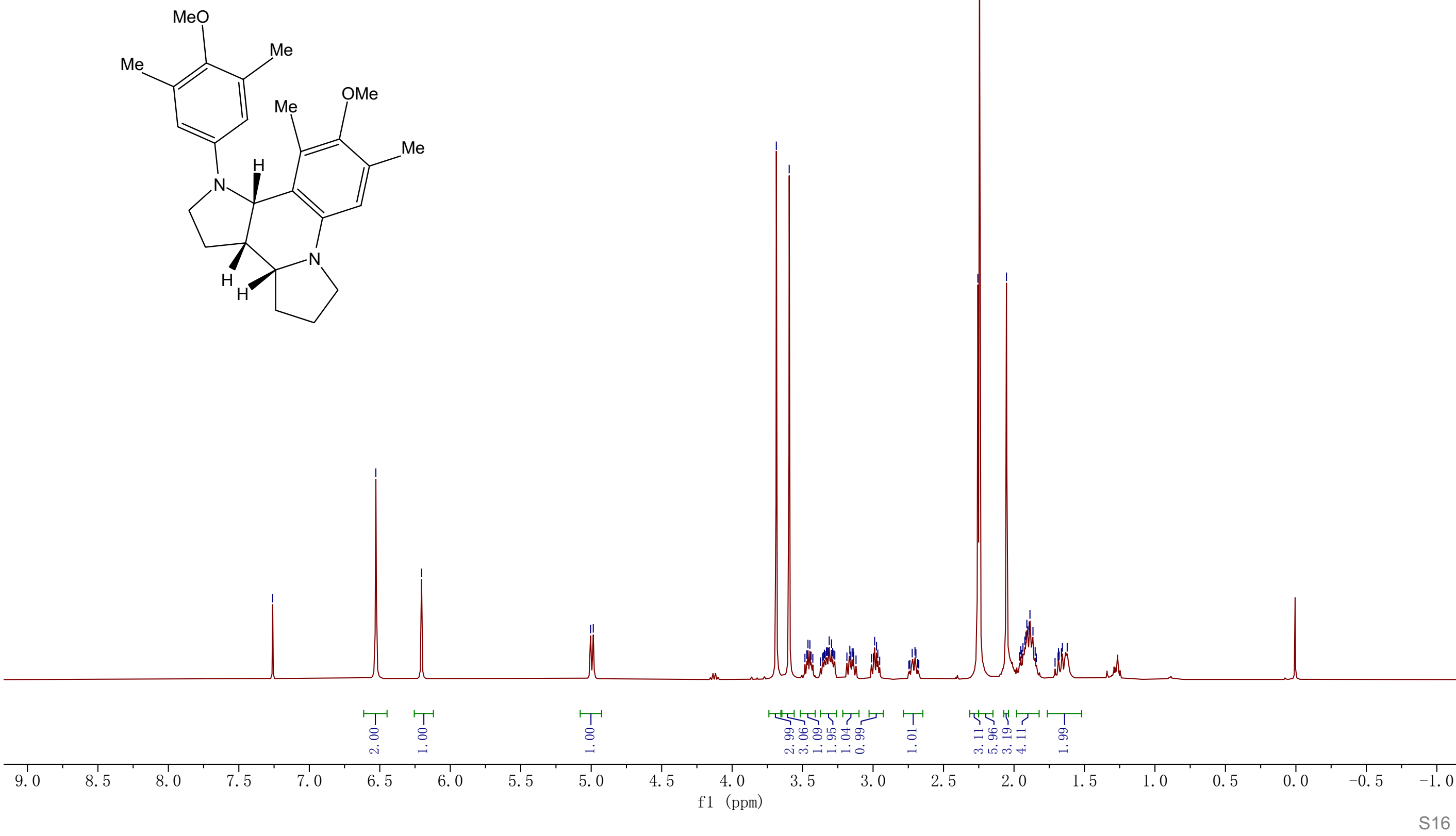
${ }^{13} \mathrm{C}\left\{{ }^{1} \mathrm{H}\right\}$ NMR of $\mathbf{5 a}\left(\mathrm{CDCl}_{3}, 100 \mathrm{MHz}\right)$
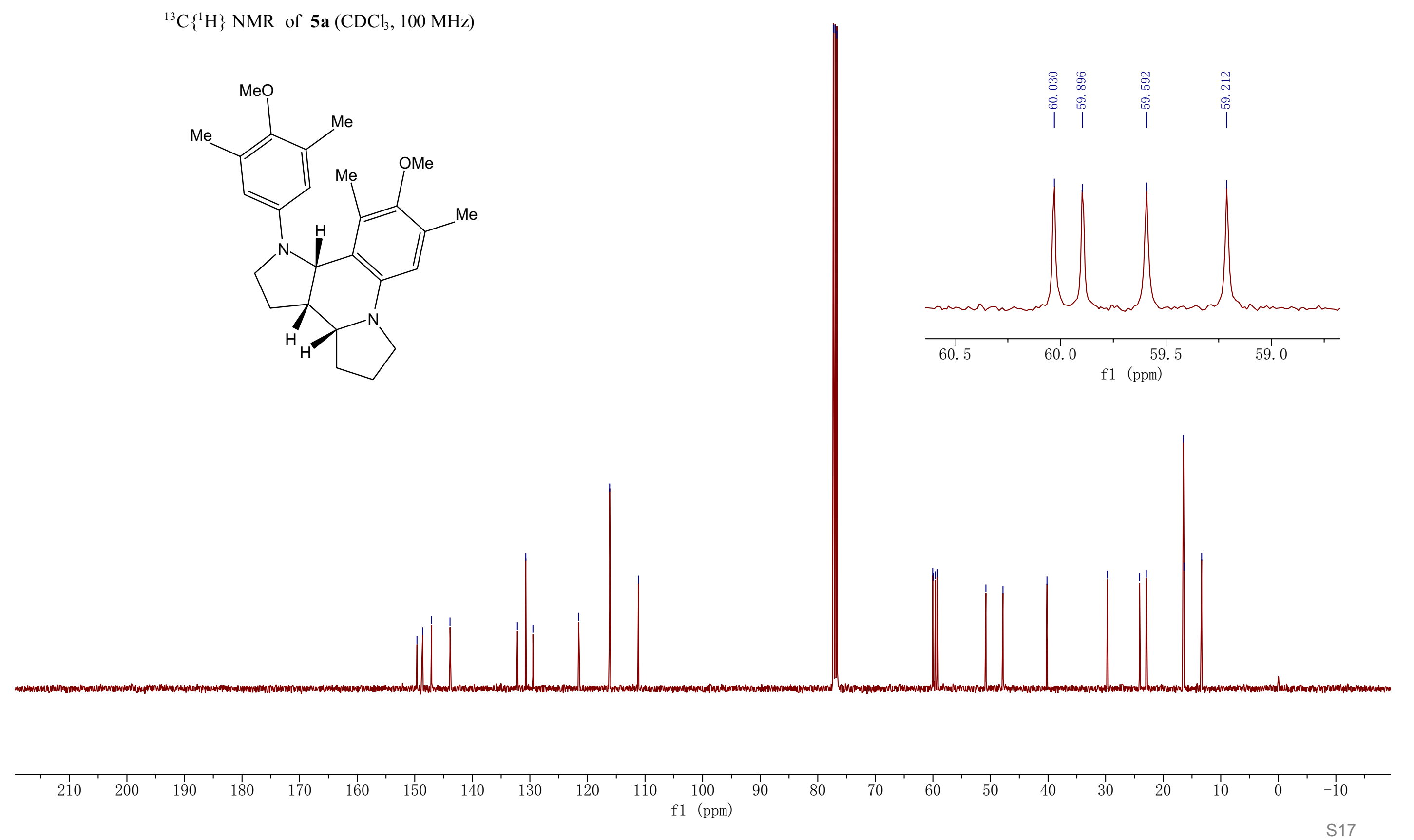
${ }^{1} \mathrm{H} \mathrm{NMR}$ of $\mathbf{5 b}\left(\mathrm{CDCl}_{3}, 400 \mathrm{MHz}\right)$

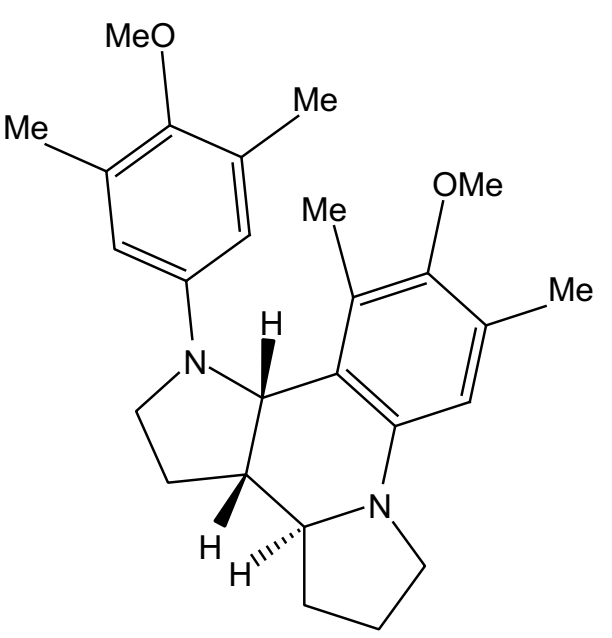

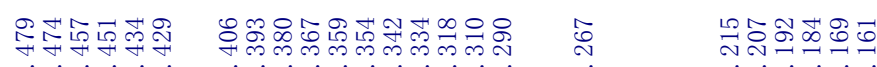

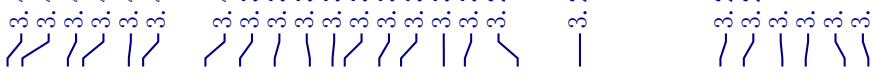

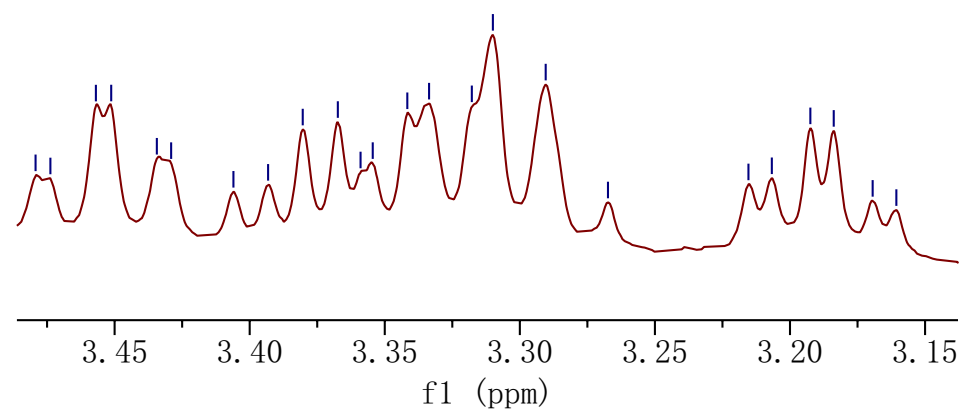

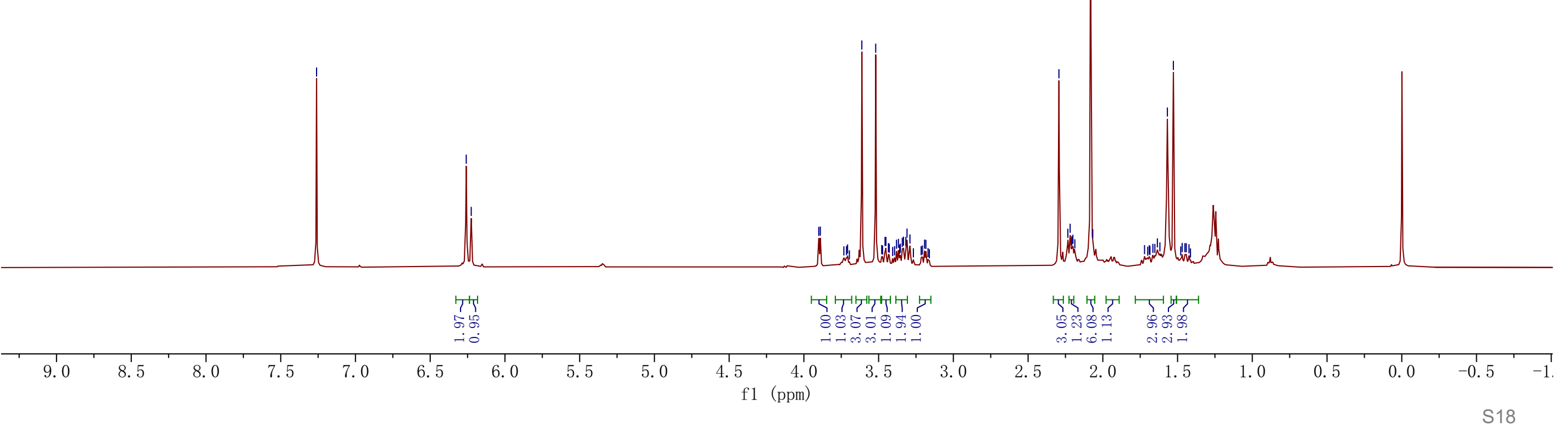




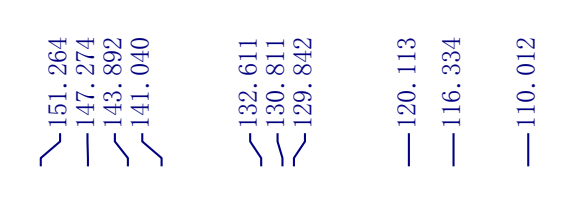

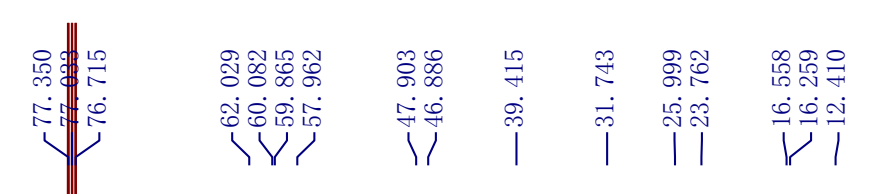

${ }^{13} \mathrm{C}\left\{{ }^{1} \mathrm{H}\right\}$ NMR of $\mathbf{5 b}\left(\mathrm{CDCl}_{3}, 100 \mathrm{MHz}\right)$

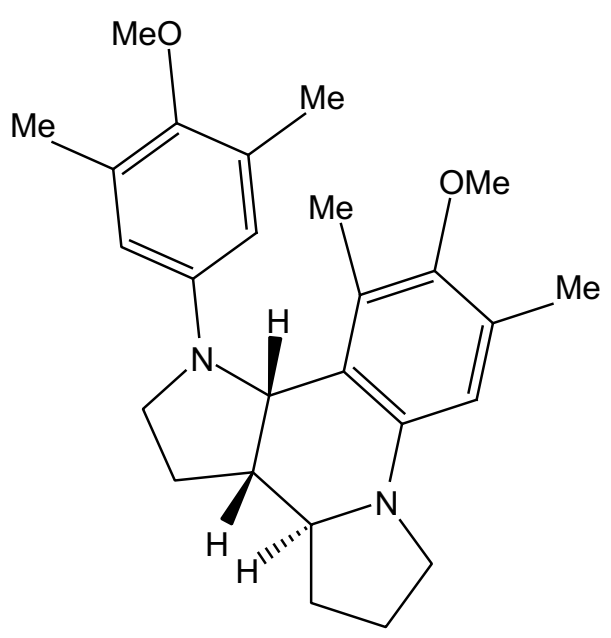


${ }^{1} \mathrm{H} \mathrm{NMR}$ of $\mathbf{6 a}$ and $\mathbf{6 b}\left(\mathrm{CDCl}_{3}, 400 \mathrm{MHz}\right)$

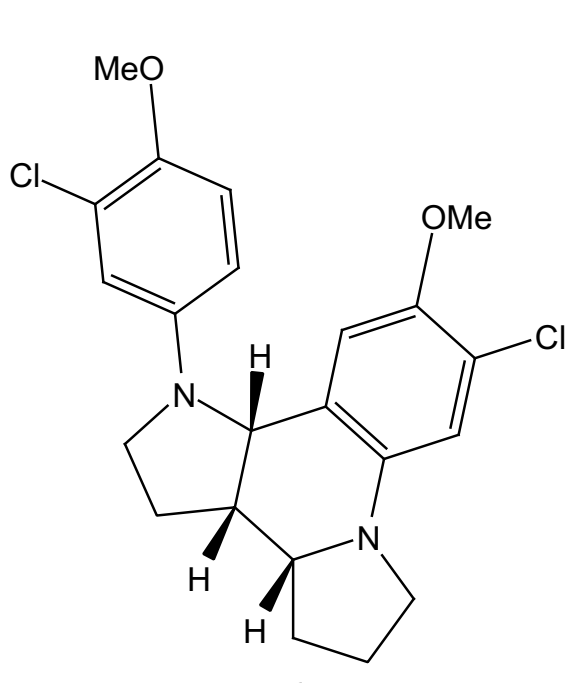

6a

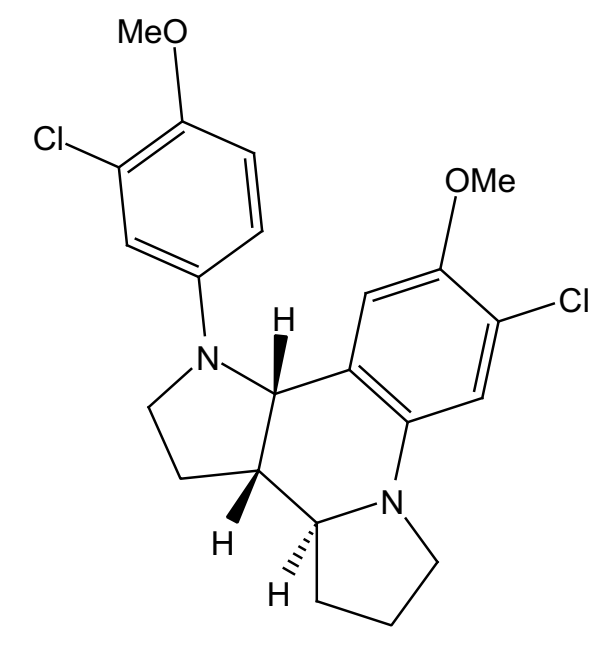

6b

ca. $74 / 26$

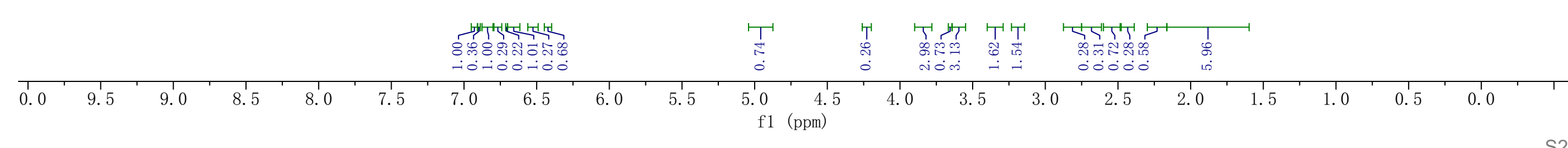




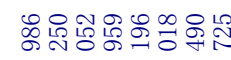

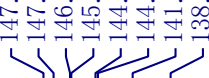
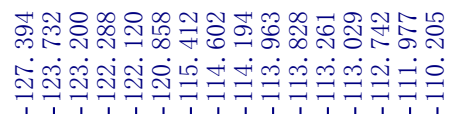

${ }^{13} \mathrm{C}\left\{{ }^{1} \mathrm{H}\right\} \mathrm{NMR}$ of $\mathbf{6 a}$ and $\mathbf{6 b}\left(\mathrm{CDCl}_{3}, 100 \mathrm{MHz}\right)$

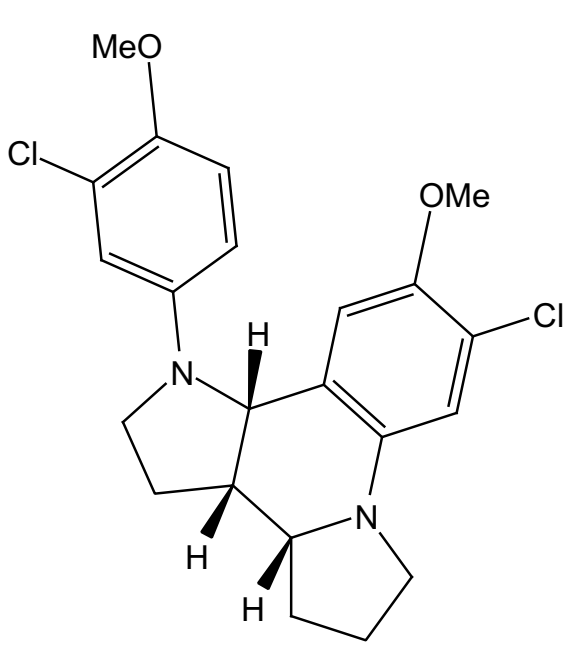

6a

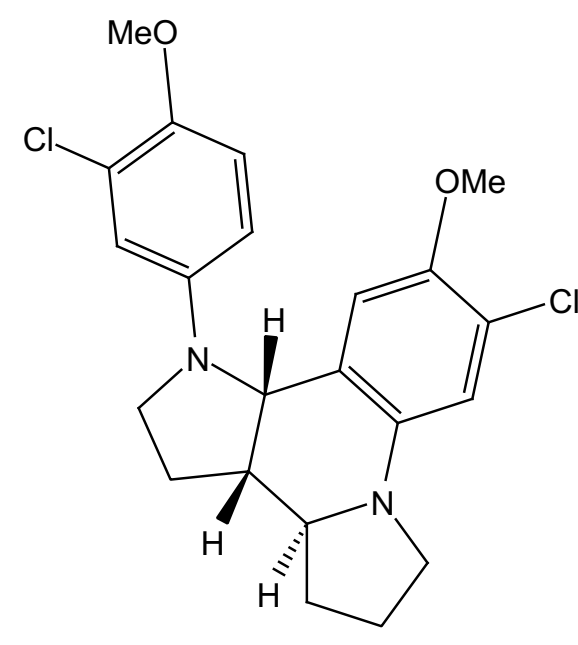

$6 \mathbf{b}$ ca. $74 / 26$
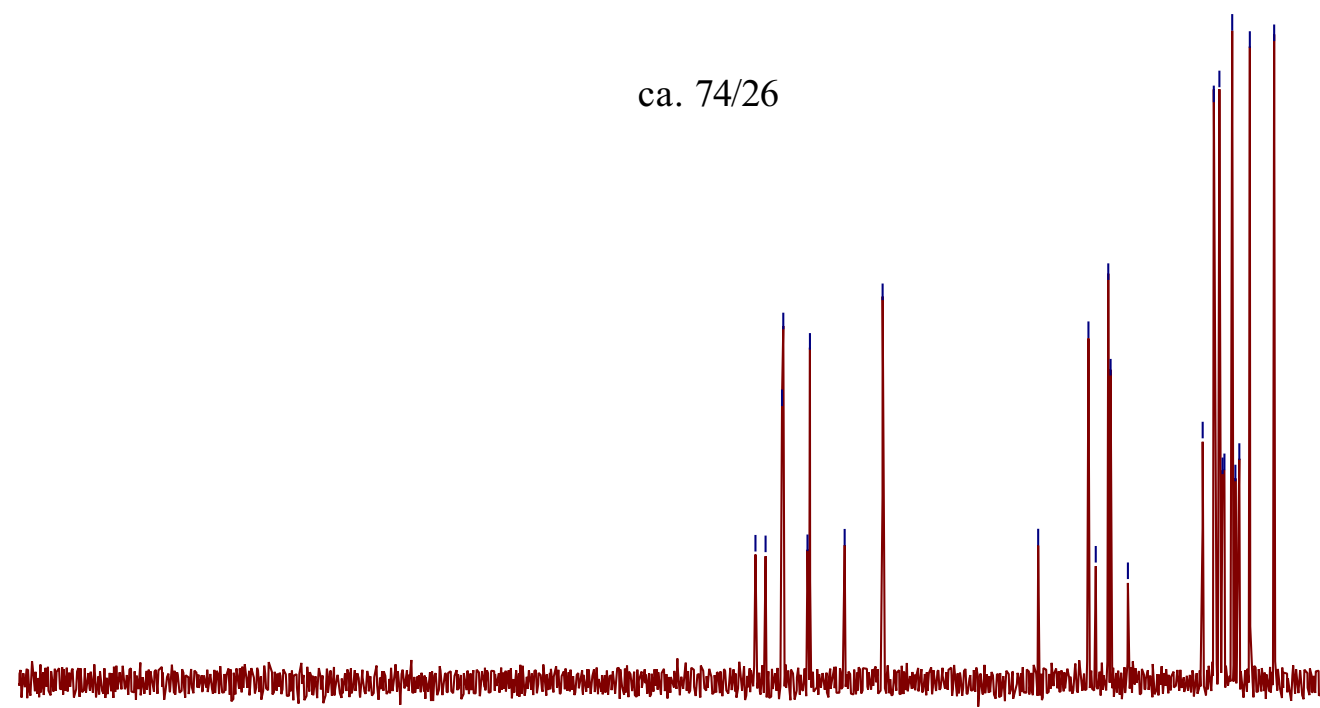
${ }^{1} \mathrm{H} \mathrm{NMR}$ of $7 \mathbf{a}\left(\mathrm{CDCl}_{3}, 400 \mathrm{MHz}\right)$
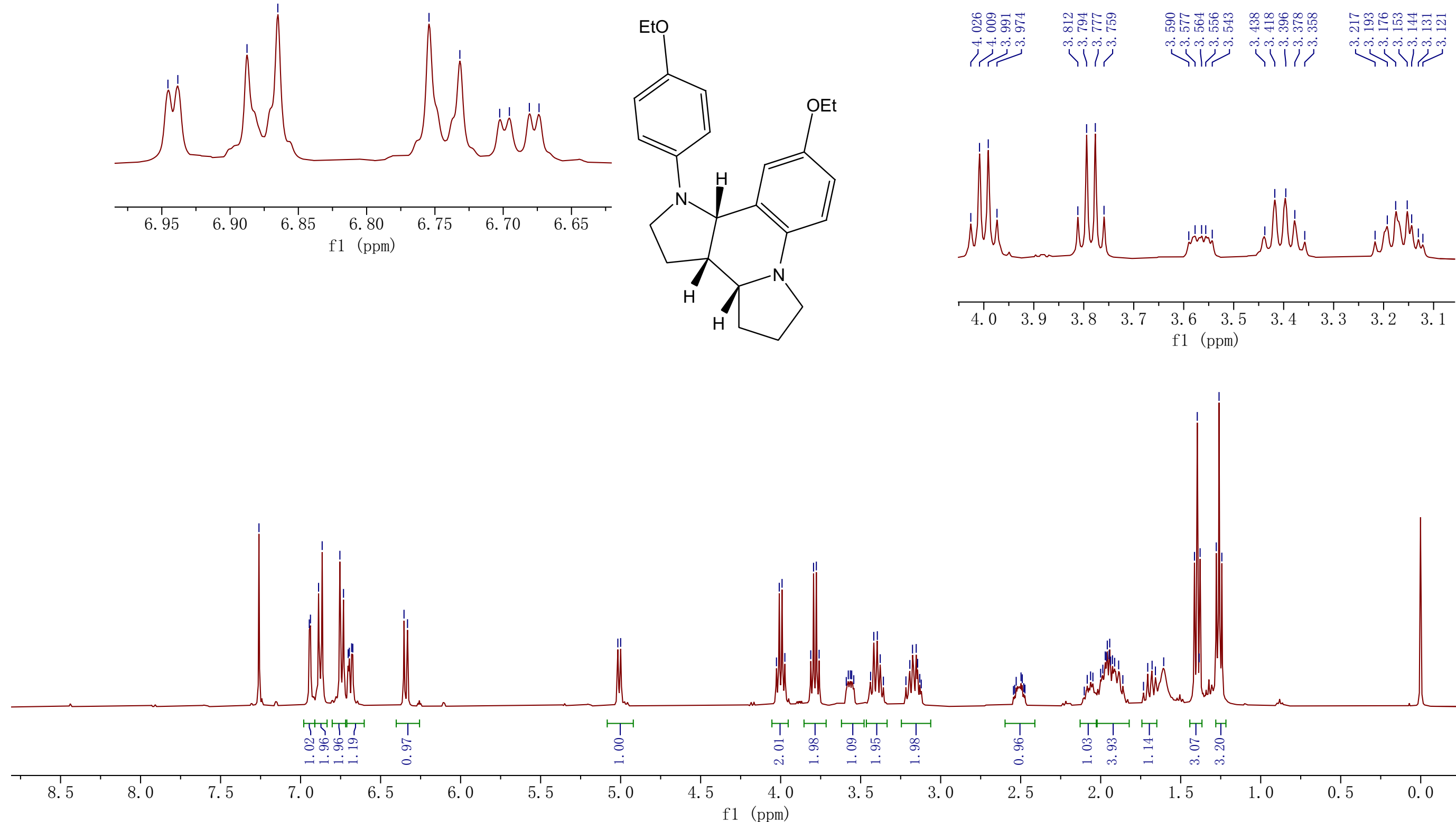

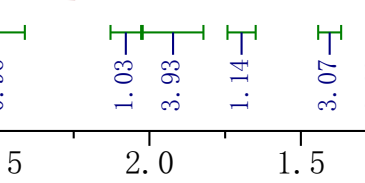

1.0

0. 


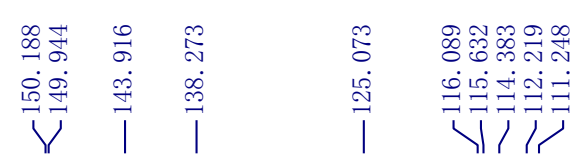

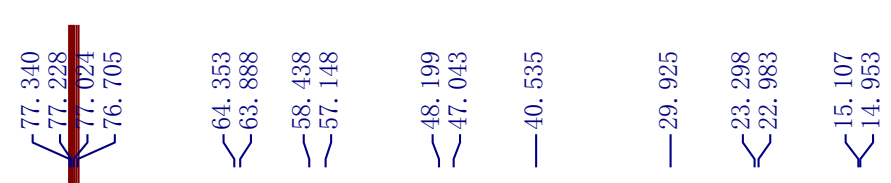

${ }^{13} \mathrm{C}\left\{{ }^{1} \mathrm{H}\right\}$ NMR of $7 \mathbf{a}\left(\mathrm{CDCl}_{3}, 100 \mathrm{MHz}\right)$
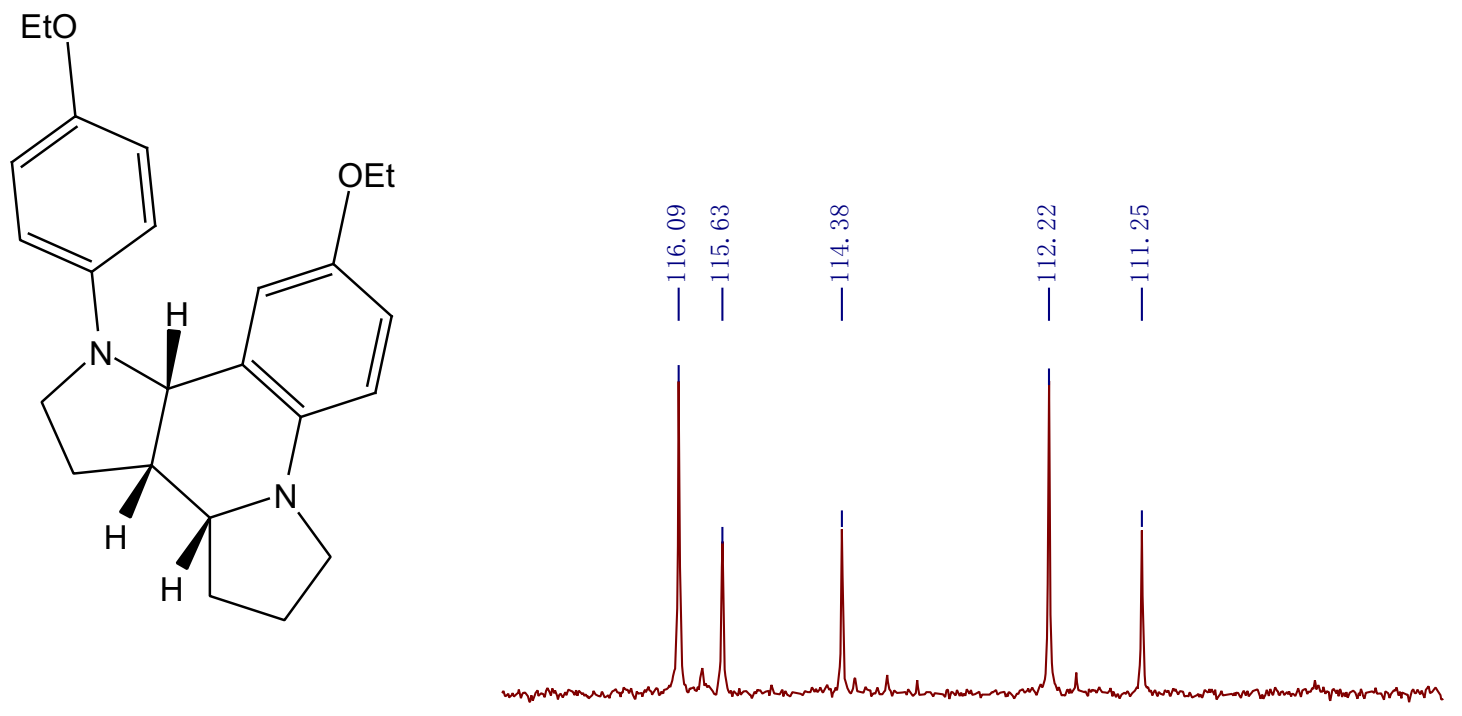

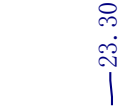

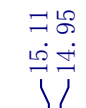
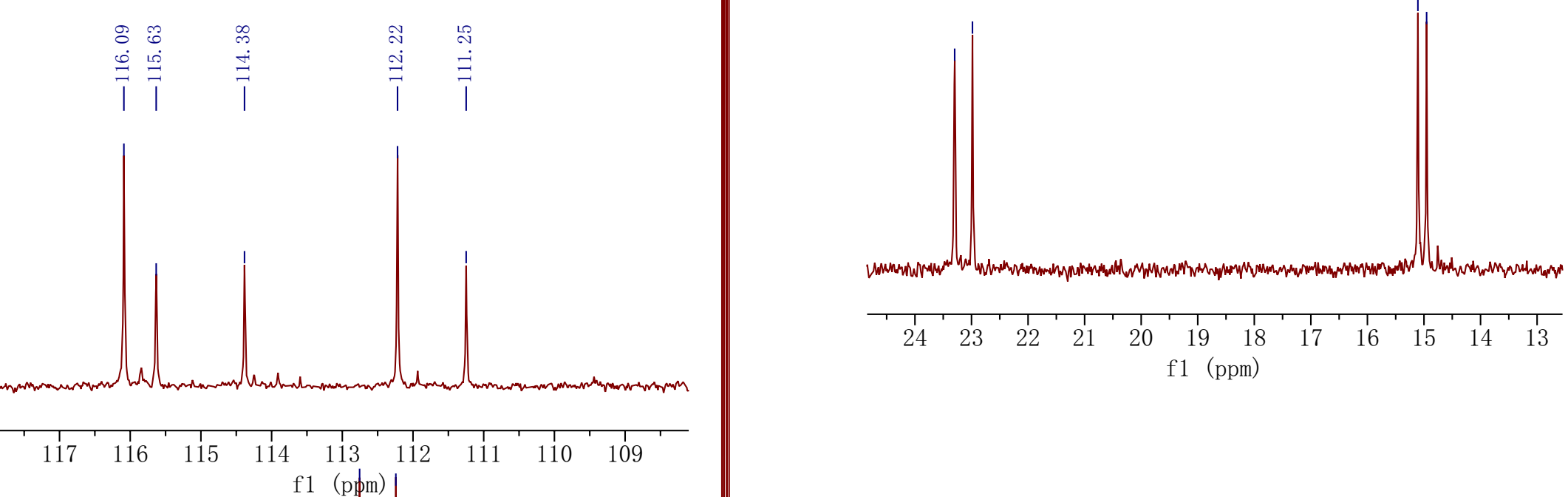

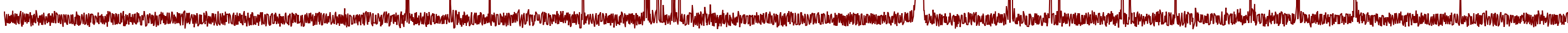

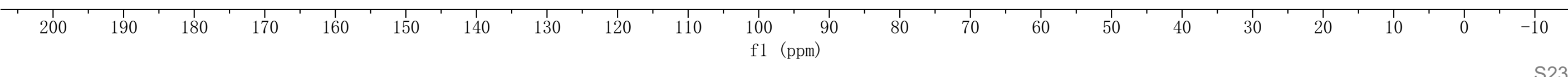


${ }^{1} \mathrm{H} \mathrm{NMR}$ of $\mathbf{7 b}\left(\mathrm{CDCl}_{3}, 400 \mathrm{MHz}\right)$
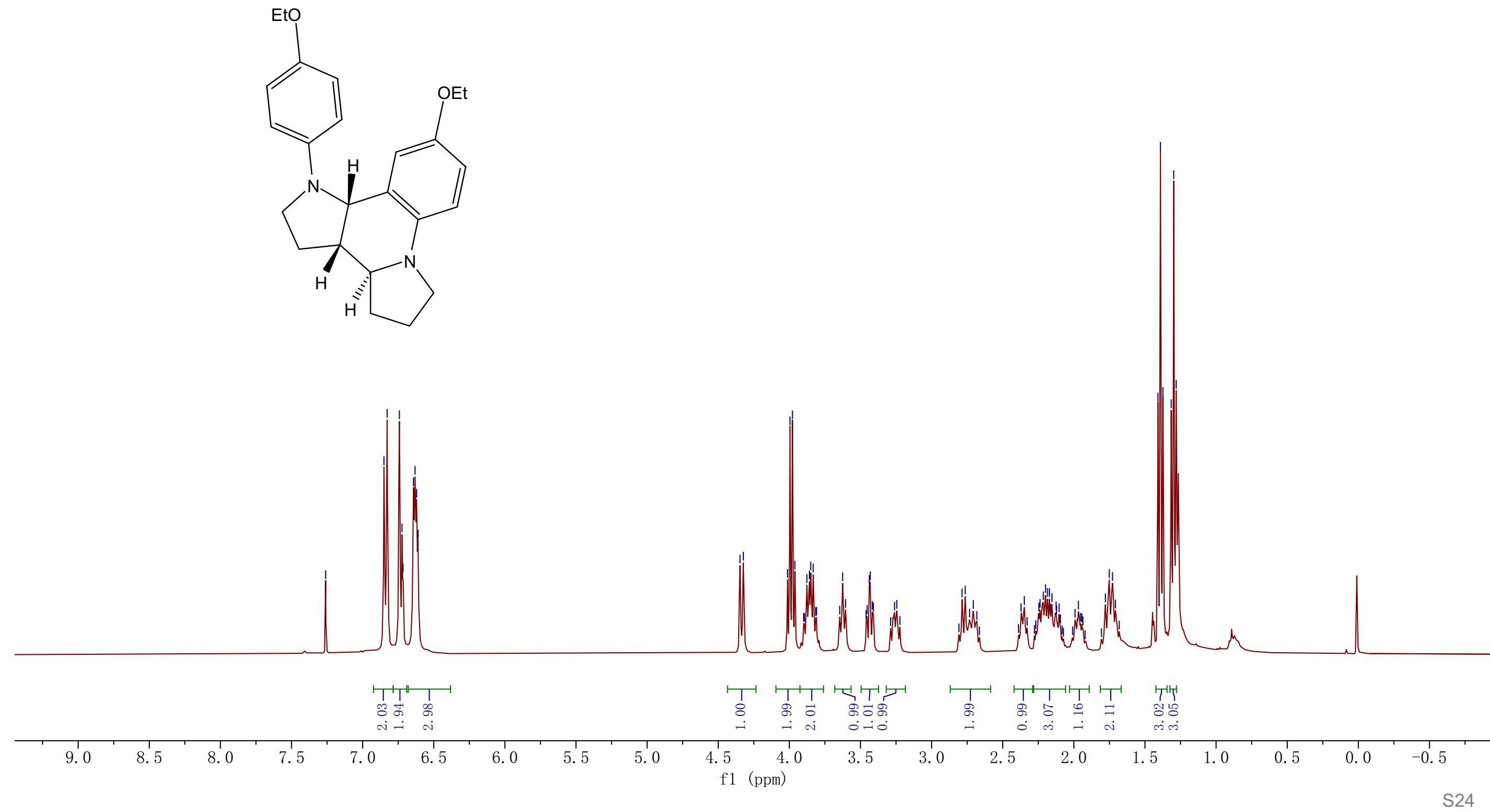
${ }^{13} \mathrm{C}\left\{{ }^{1} \mathrm{H}\right\} \mathrm{NMR}$ of $7 \mathbf{b}\left(\mathrm{CDCl}_{3}, 100 \mathrm{MHz}\right)$ ।

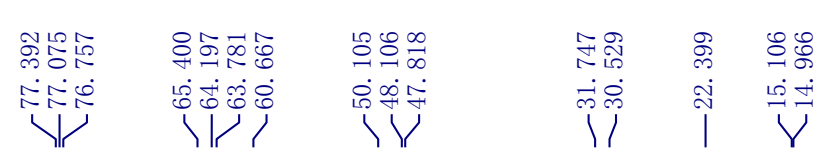
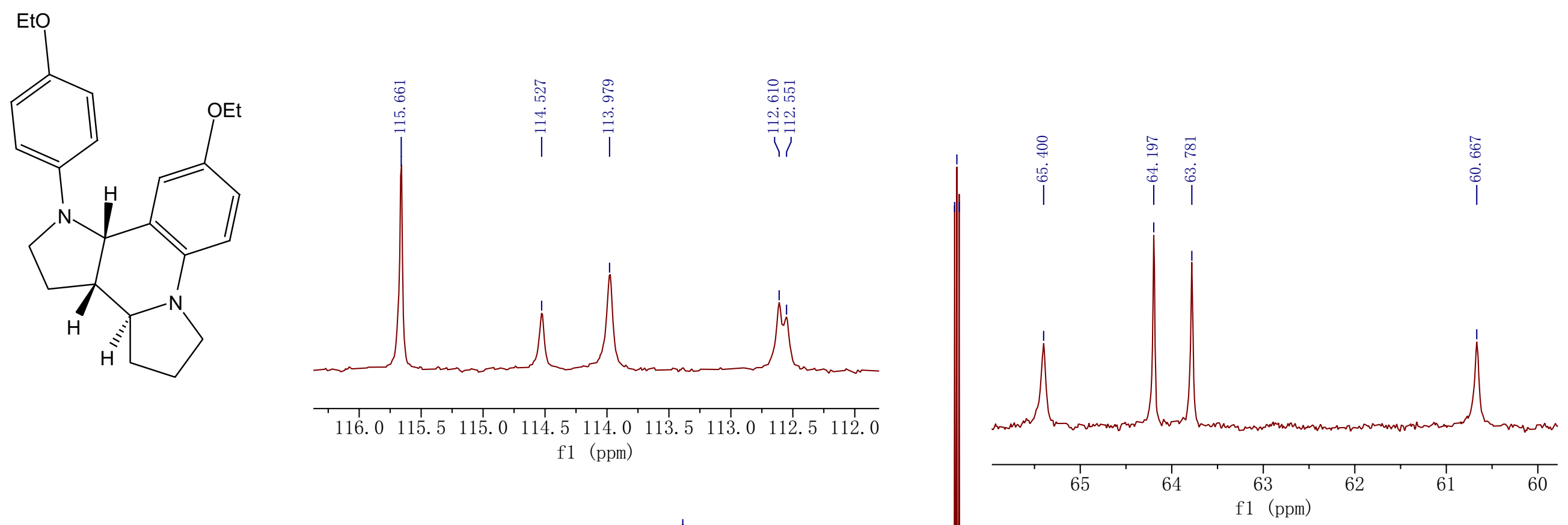
${ }^{1} \mathrm{H}$ NMR of $\mathbf{8 a}$ and $\mathbf{8 b}\left(\mathrm{CDCl}_{3}, 400 \mathrm{MHz}\right)$

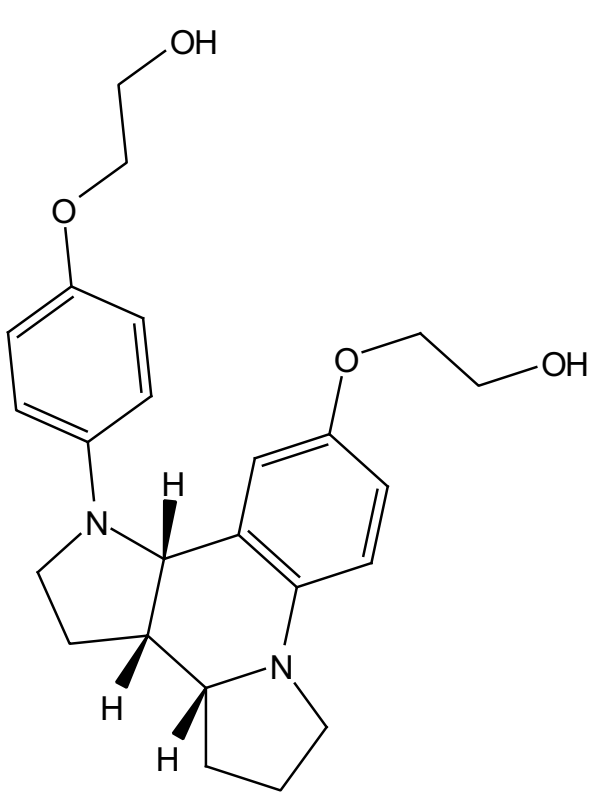

8a

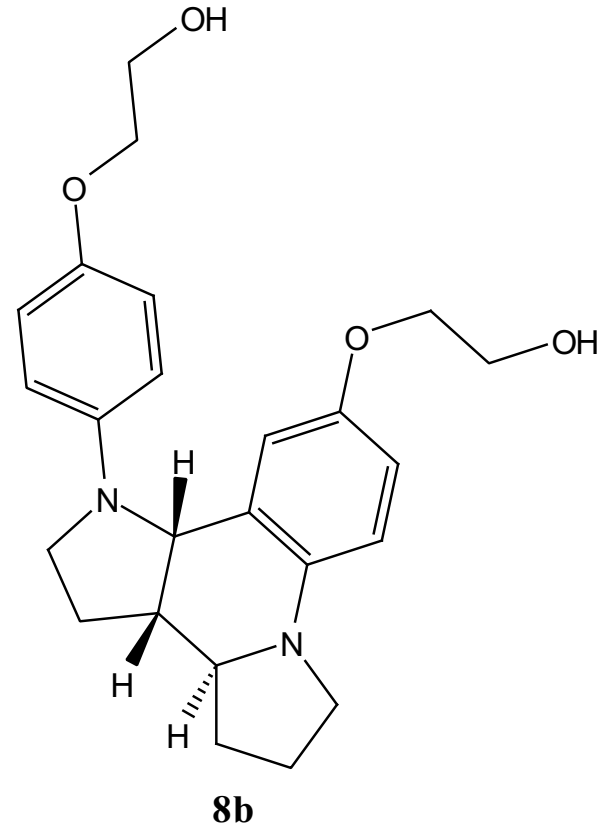

ca. $67 / 33$

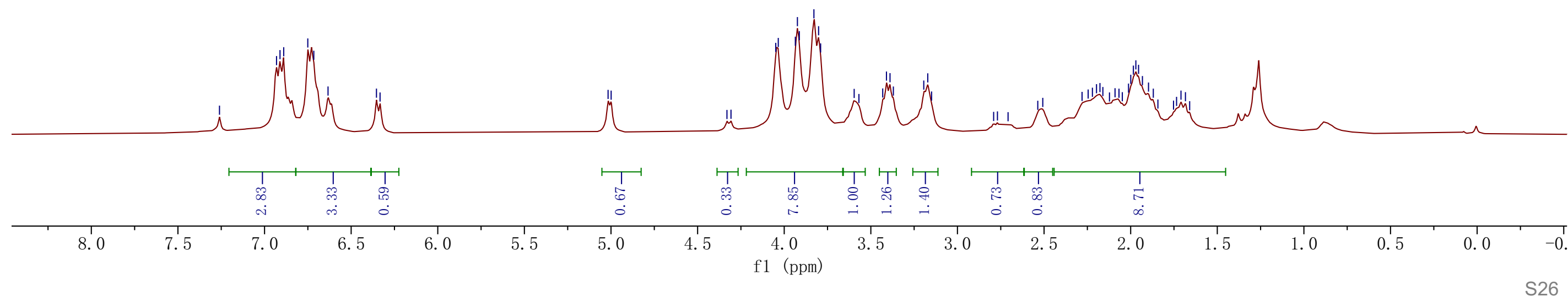


${ }^{13} \mathrm{C}\left\{{ }^{1} \mathrm{H}\right\} \mathrm{NMR}$ of $\mathbf{8 a}$ and $\mathbf{8 b}\left(\mathrm{CDCl}_{3}, 100 \mathrm{MHz}\right)$
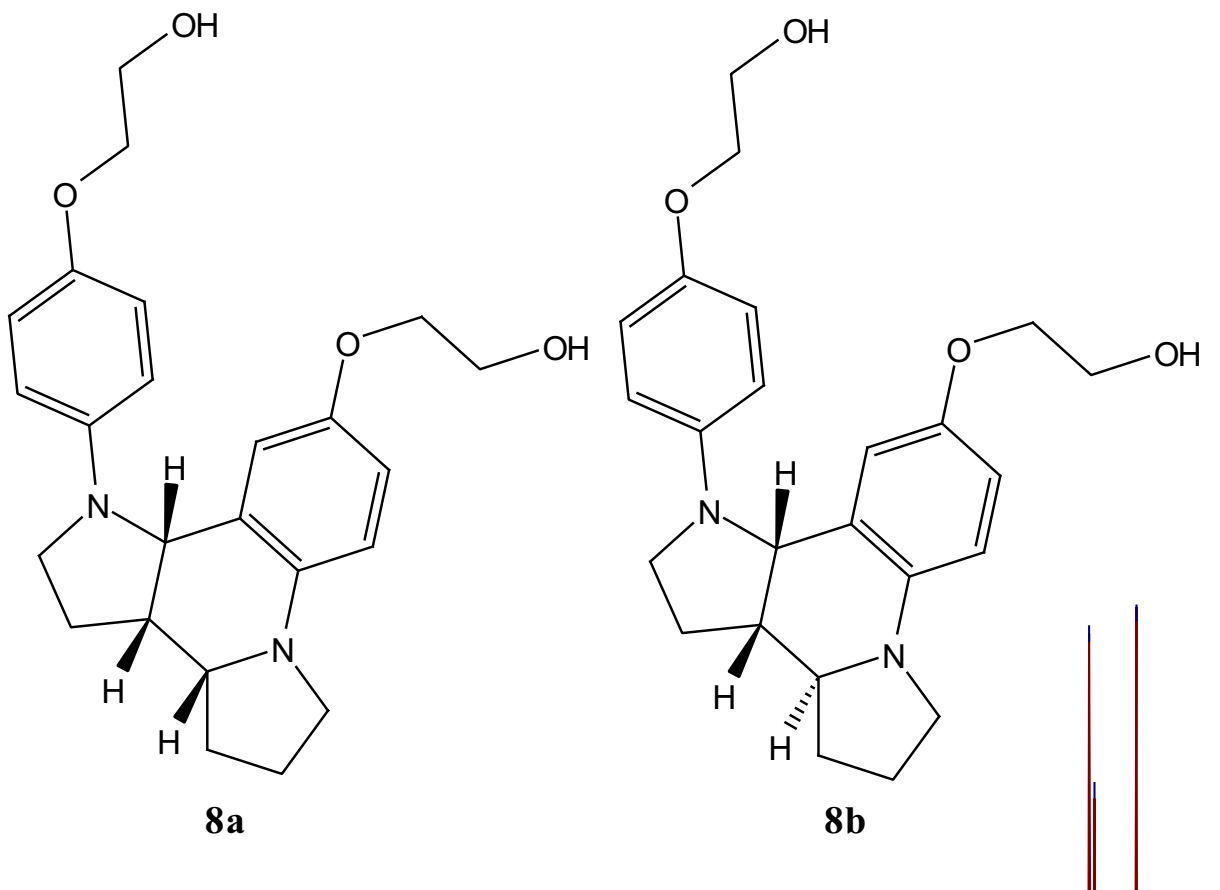

ca. $67 / 33$ 

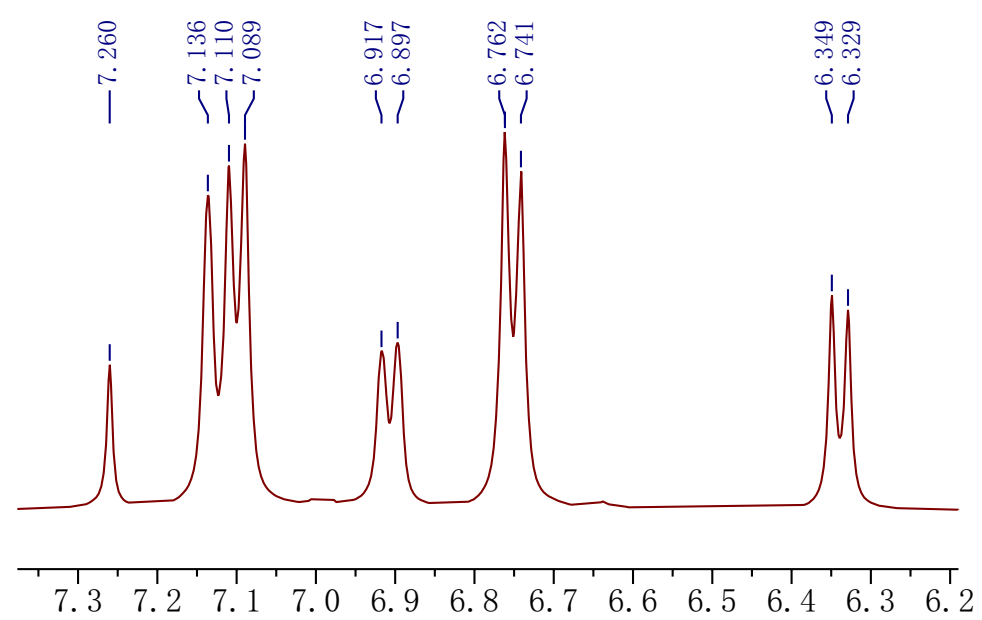

f1 (ppm)

${ }^{1} \mathrm{H} \mathrm{NMR}$ of $\mathbf{9 a}\left(\mathrm{CDCl}_{3}, 400 \mathrm{MHz}\right)$

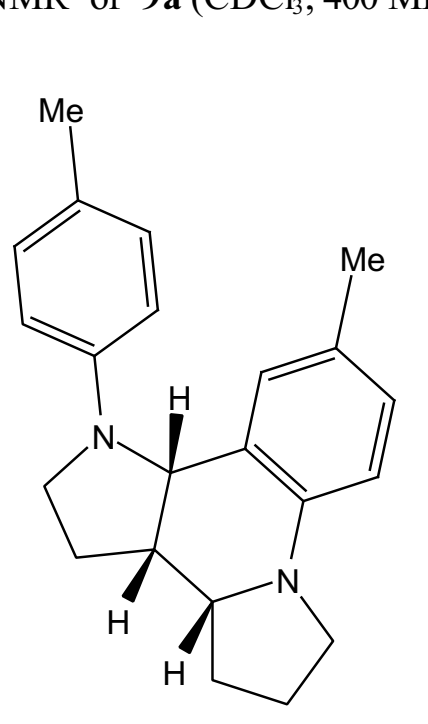

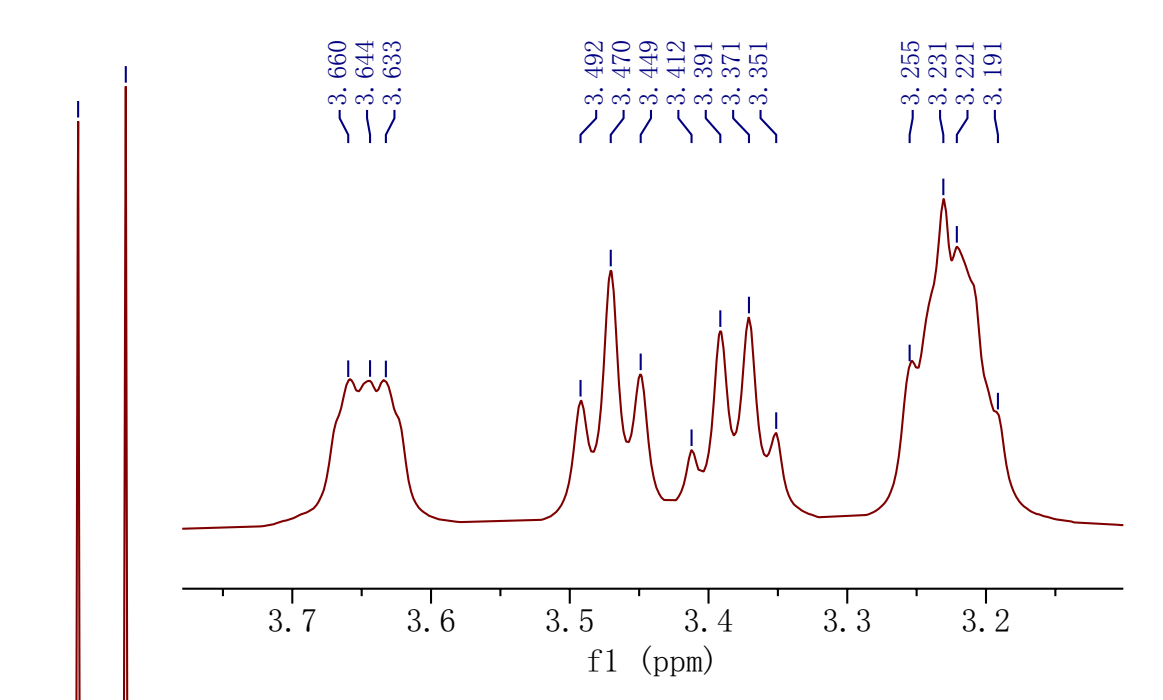
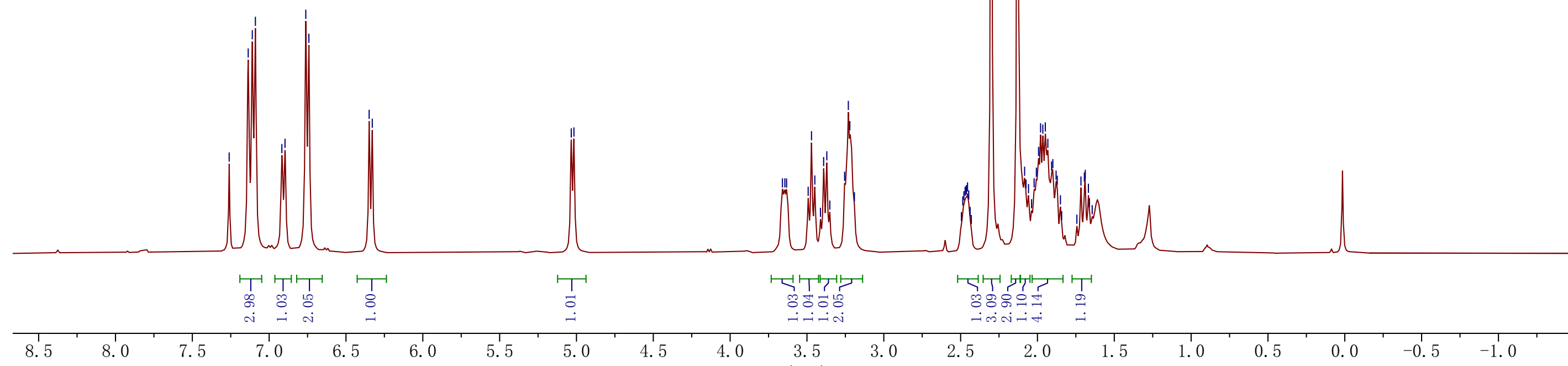

f1 (ppm) 
${ }^{1} \mathrm{H}$ NMR of $9 \mathbf{b}\left(\mathrm{CDCl}_{3}, 400 \mathrm{MHz}\right)$

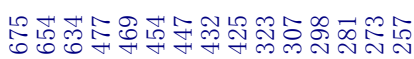

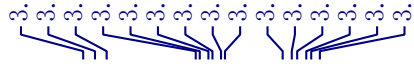
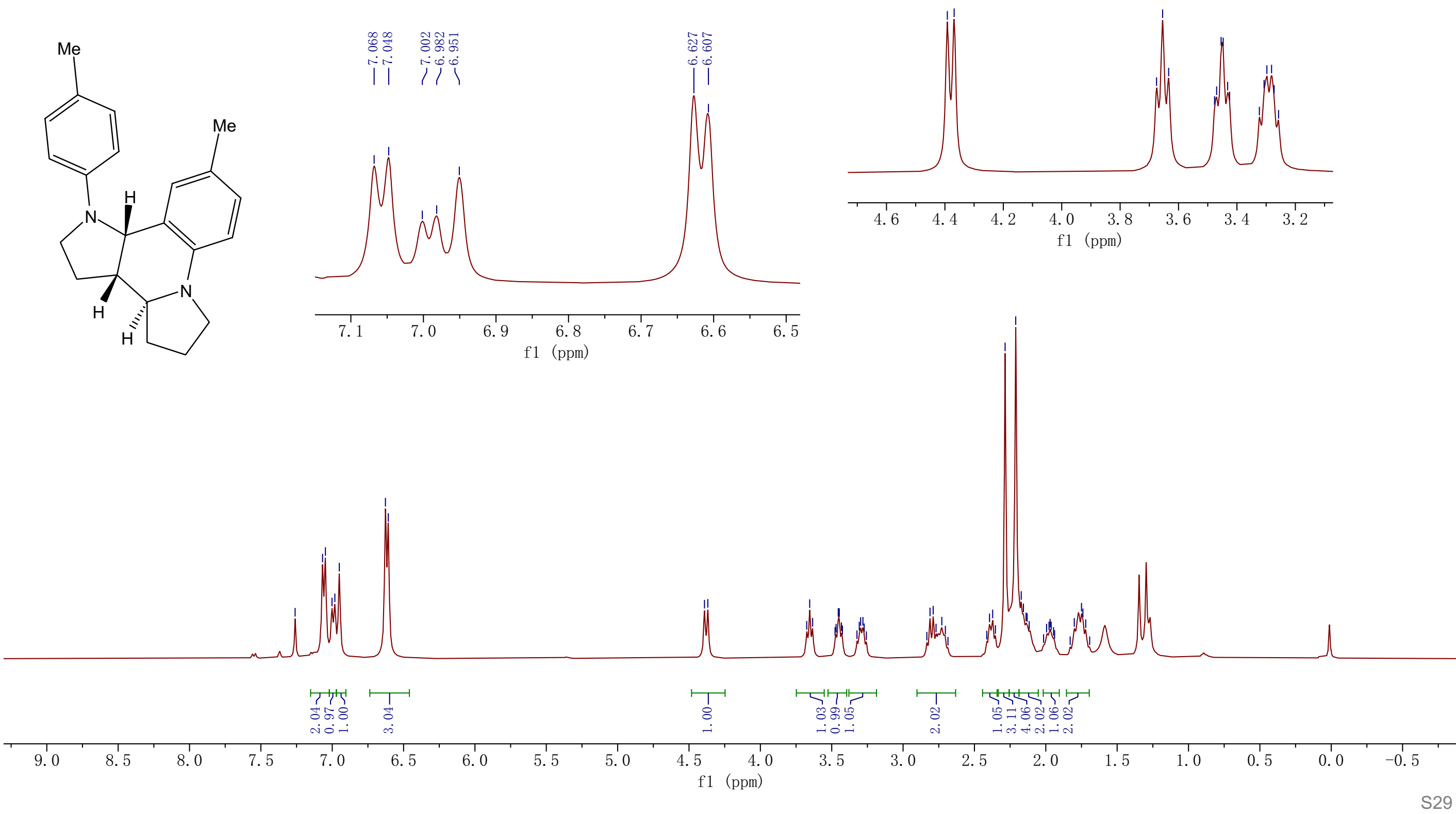


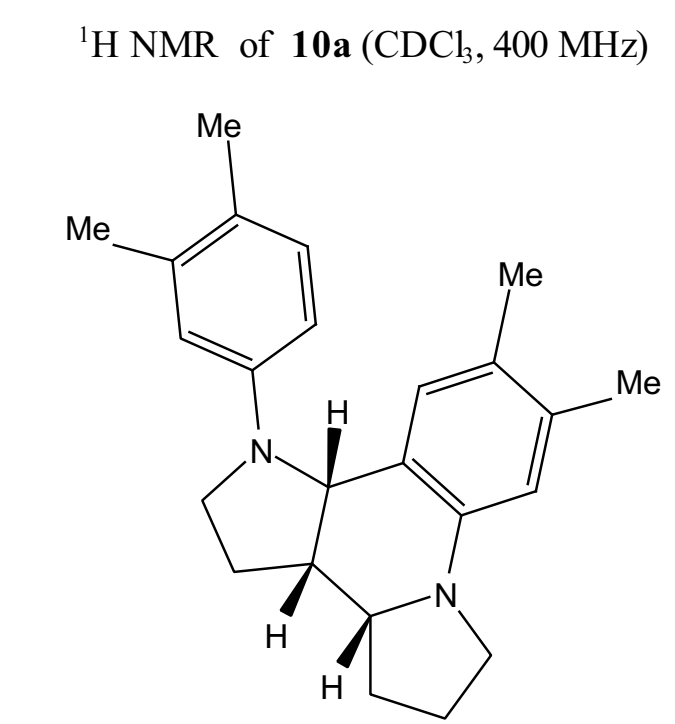

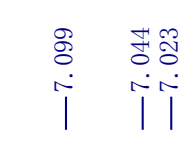

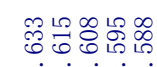

iोil|

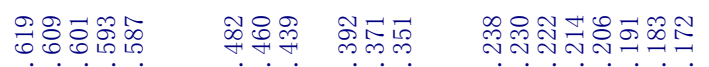

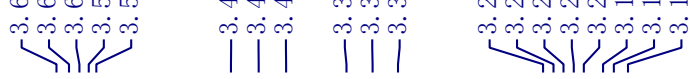

\section{Me}
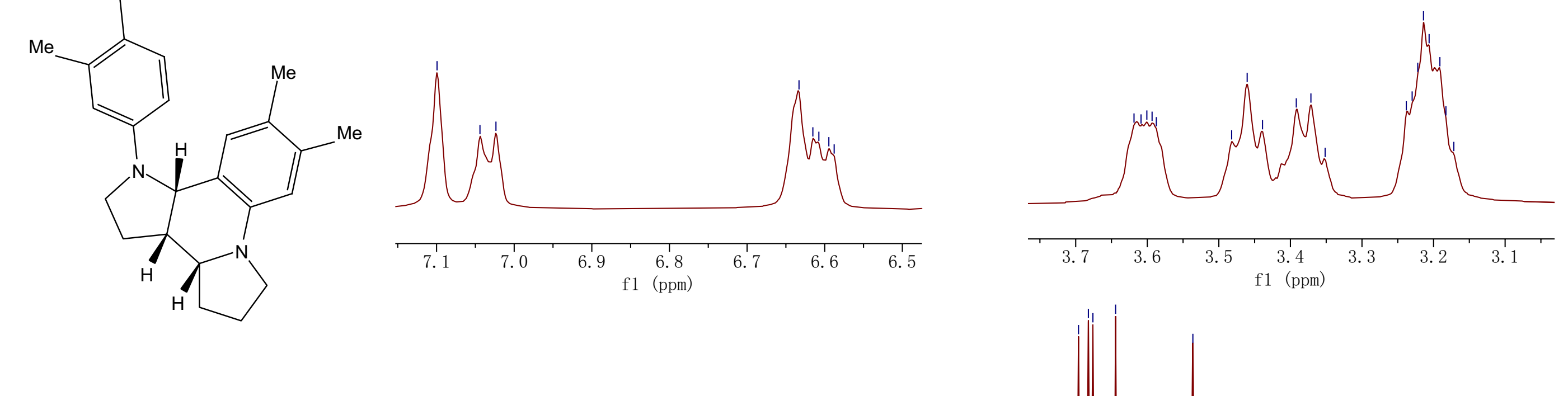


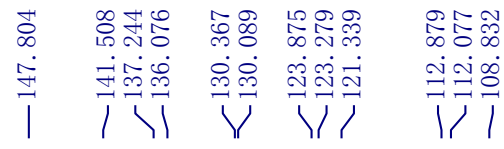

${ }^{13} \mathrm{C}\left\{{ }^{1} \mathrm{H}\right\}$ NMR of $\mathbf{1 0 a}\left(\mathrm{CDCl}_{3}, 100 \mathrm{MHz}\right)$
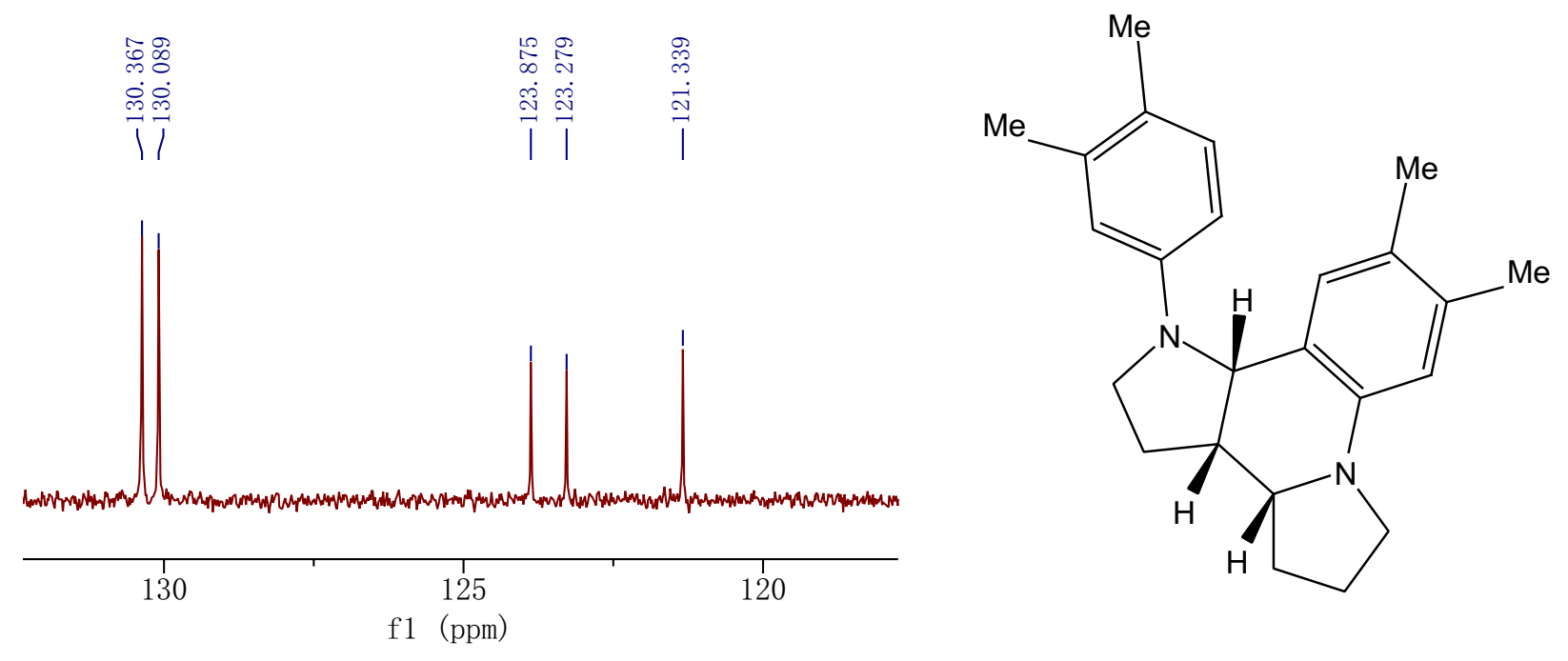
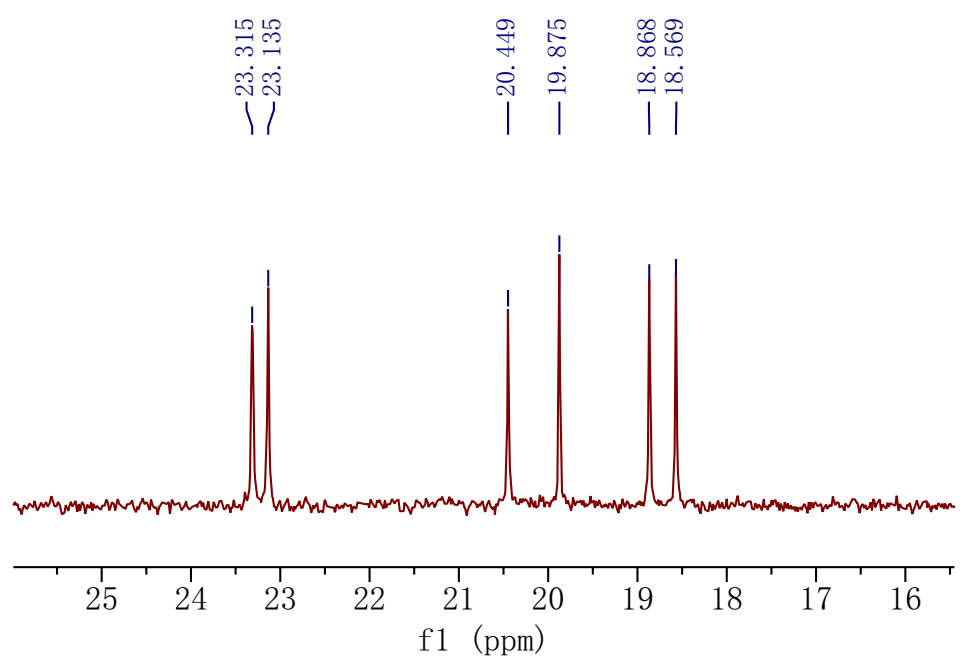


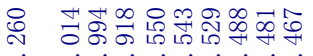 \\ I पi}

${ }^{1} \mathrm{H} \mathrm{NMR}$ of $\mathbf{1 0 b}\left(\mathrm{CDCl}_{3}, 400 \mathrm{MHz}\right)$

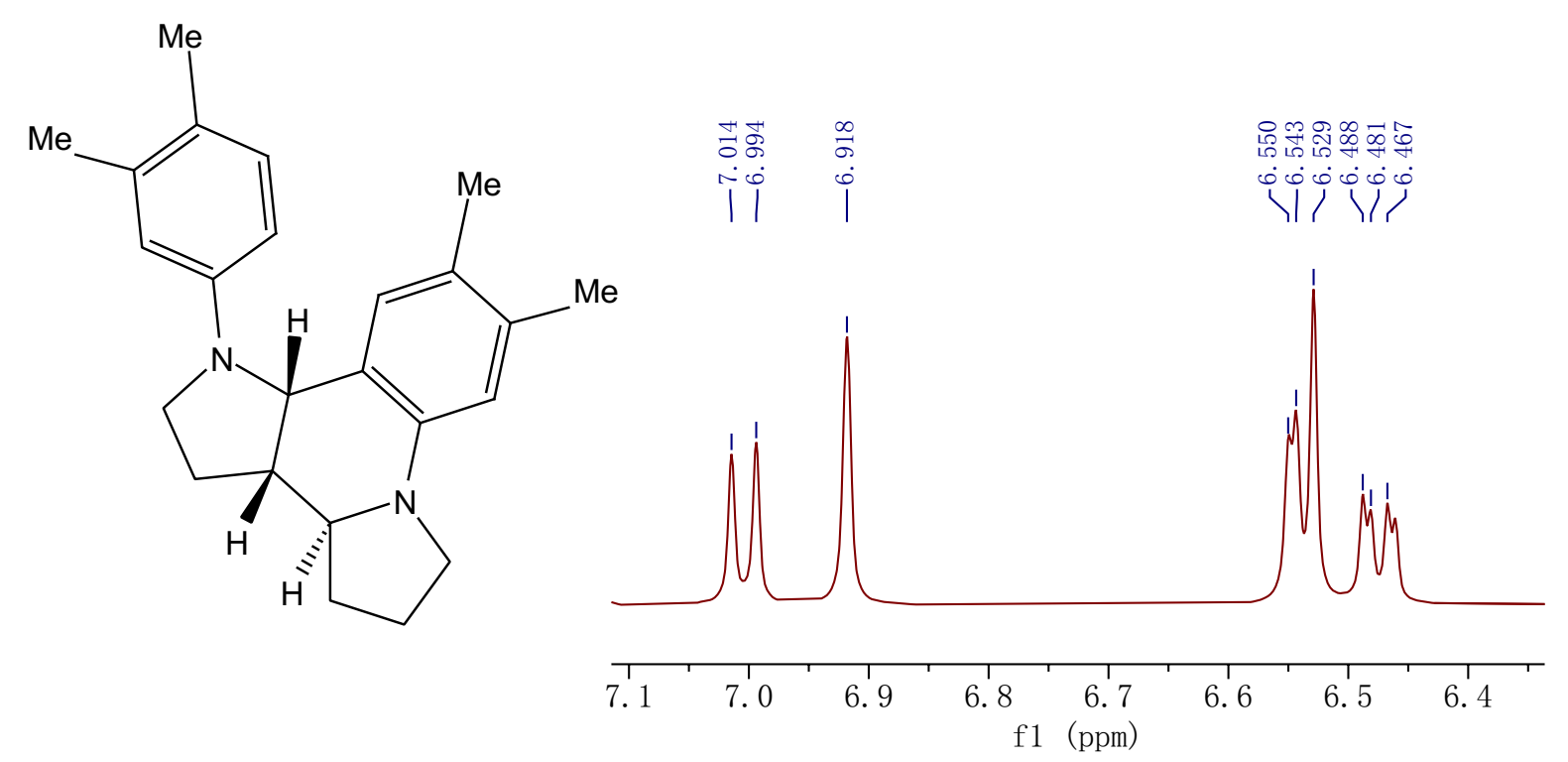

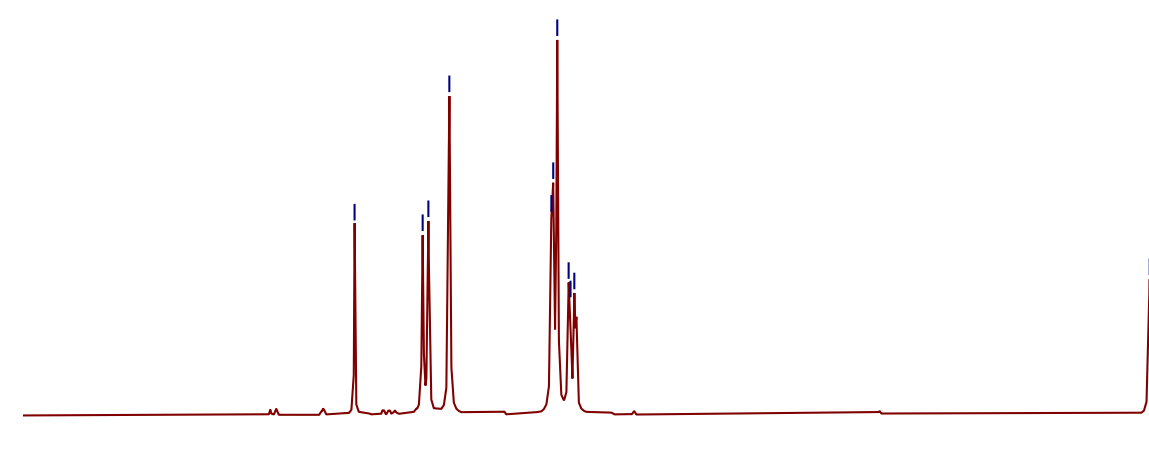

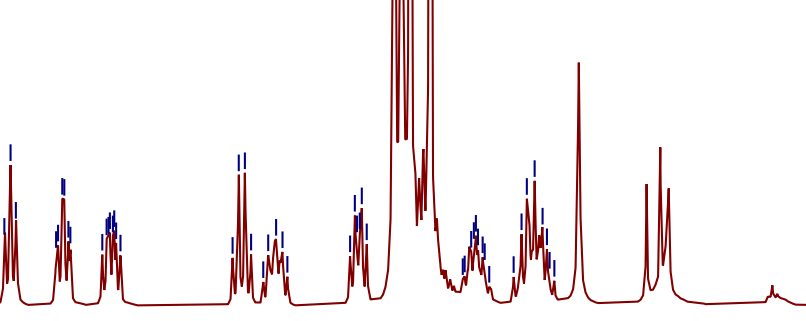

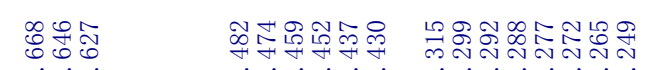

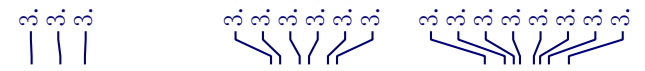

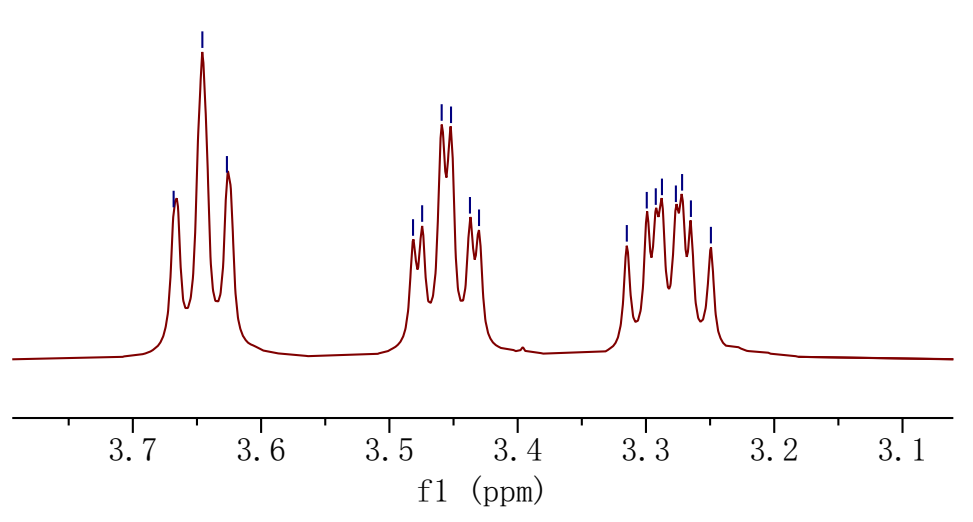

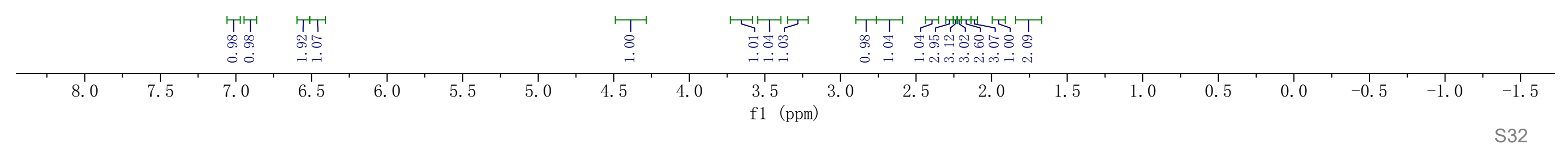


${ }^{3} \mathrm{C}\left\{{ }^{1} \mathrm{H}\right\} \mathrm{NMR}$ of $\mathbf{1 0 b}\left(\mathrm{CDCl}_{3}, 100 \mathrm{MHz}\right)$

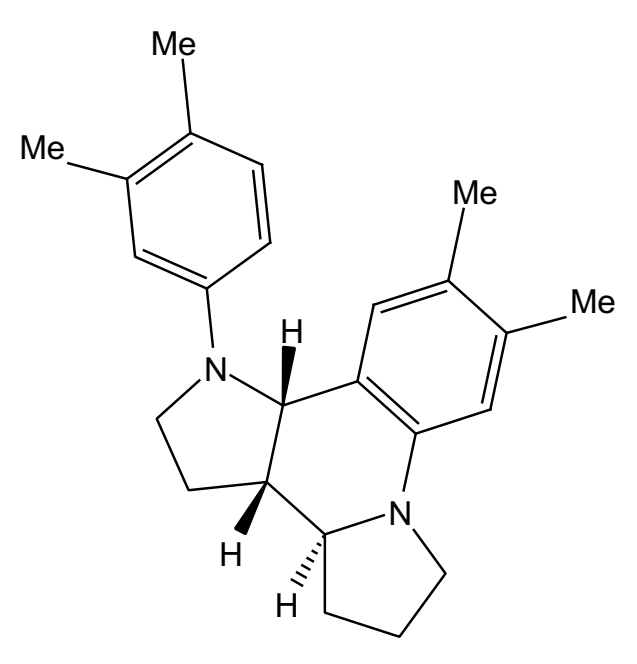

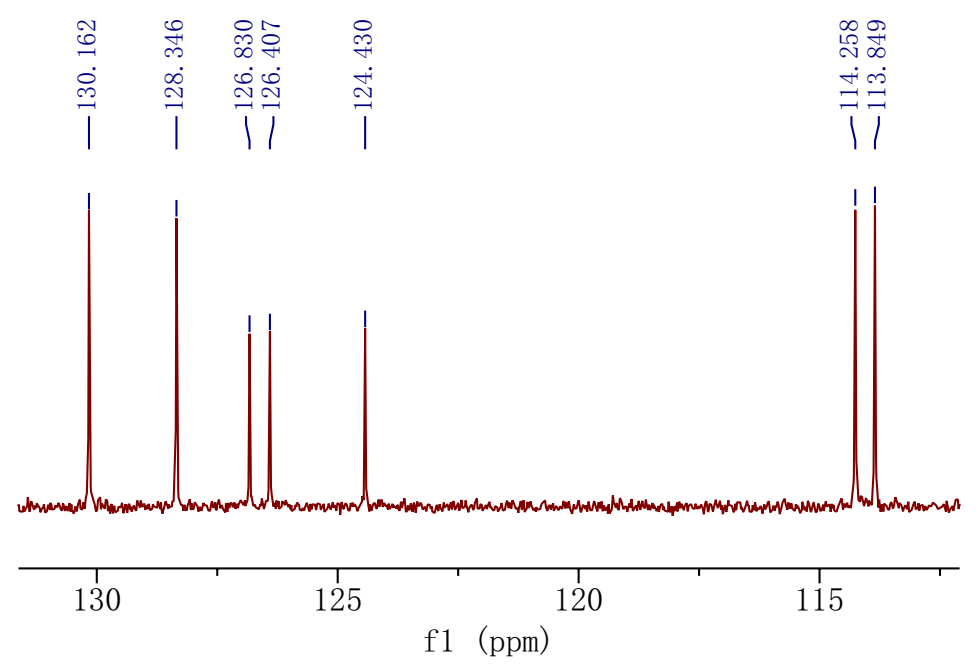

\begin{tabular}{l}
$\infty$ \\
$\substack{m \\
\hdashline}$ \\
ij \\
$\mid$
\end{tabular}

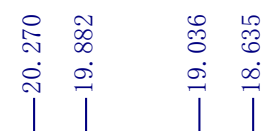
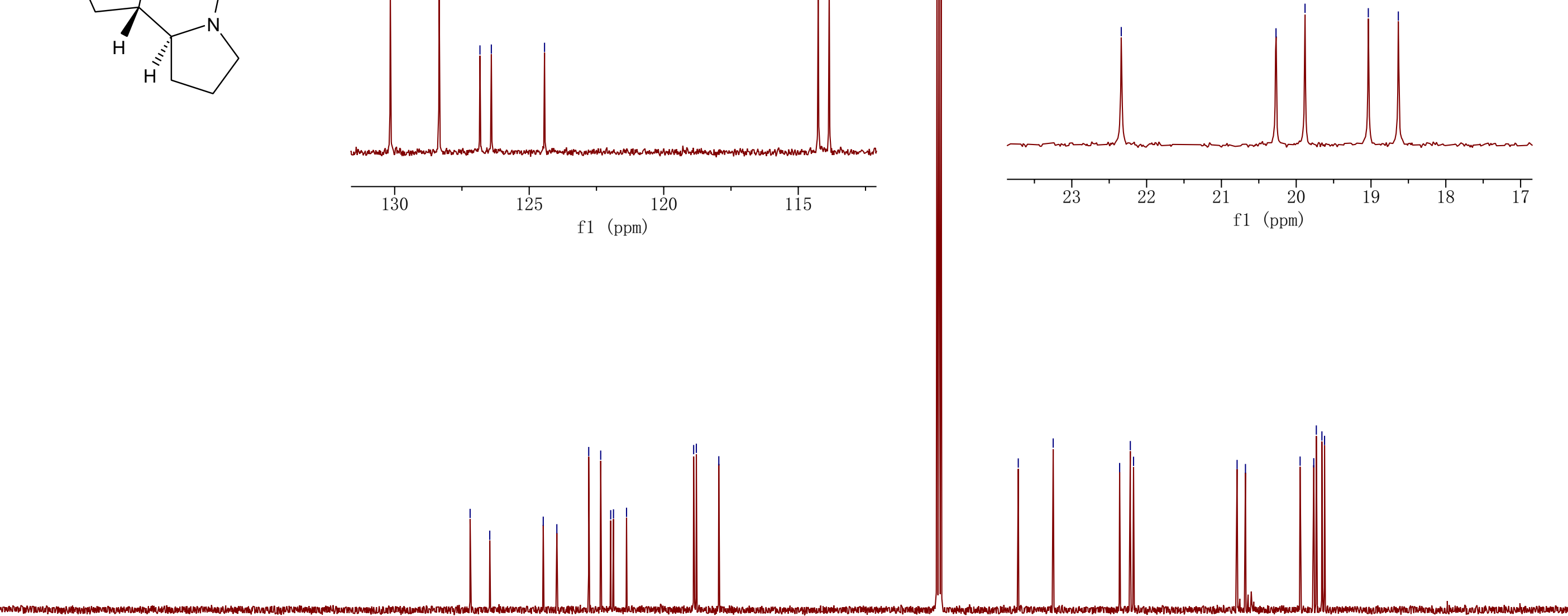
${ }^{1} \mathrm{H}$ NMR of 11a $\left(\mathrm{CDCl}_{3}, 400 \mathrm{MHz}\right)$<smiles></smiles>

\begin{tabular}{|c|c|c|c|c|c|c|c|c|c|c|c|c|c|c|c|c|c|c|c|c|}
\hline & & & & & 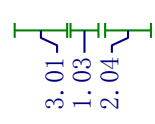 & $\begin{array}{l}\mathfrak{T}_{1}^{1} \\
0 \\
-1\end{array}$ & & & 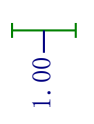 & & 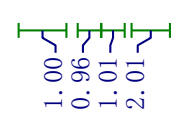 & & 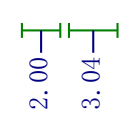 & $\begin{array}{lll}1 & 1 \\
T & 1 & 1 \\
0 & 8 & 7 \\
- & + & 7\end{array}$ & & $\begin{array}{ll}T 1 & T \\
\infty & \infty \\
0 & \infty \\
\dot{\infty} & \dot{\alpha}\end{array}$ & & & & \\
\hline 9.5 & 9.0 & 8.5 & 8. 0 & 7.5 & 7.0 & 6.5 & 6.0 & 5.5 & 5.0 & $\begin{array}{rr}4.5 & 4.0 \\
\text { f1 } & (\mathrm{ppm})\end{array}$ & 3.5 & 3.0 & 2.5 & 2.0 & 1.5 & 1.0 & 0.5 & 0.0 & -0.5 & -1.0 \\
\hline
\end{tabular}


${ }^{13} \mathrm{C}\left\{{ }^{1} \mathrm{H}\right\}$ NMR of $11 \mathrm{a}\left(\mathrm{CDCl}_{3}, 100 \mathrm{MHz}\right)$

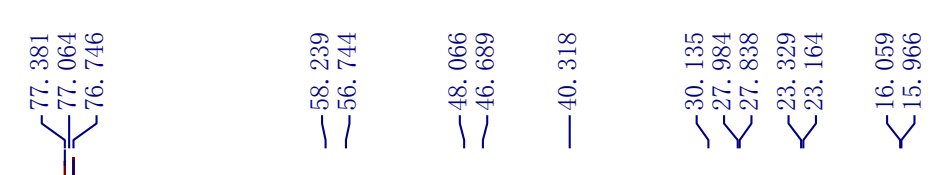
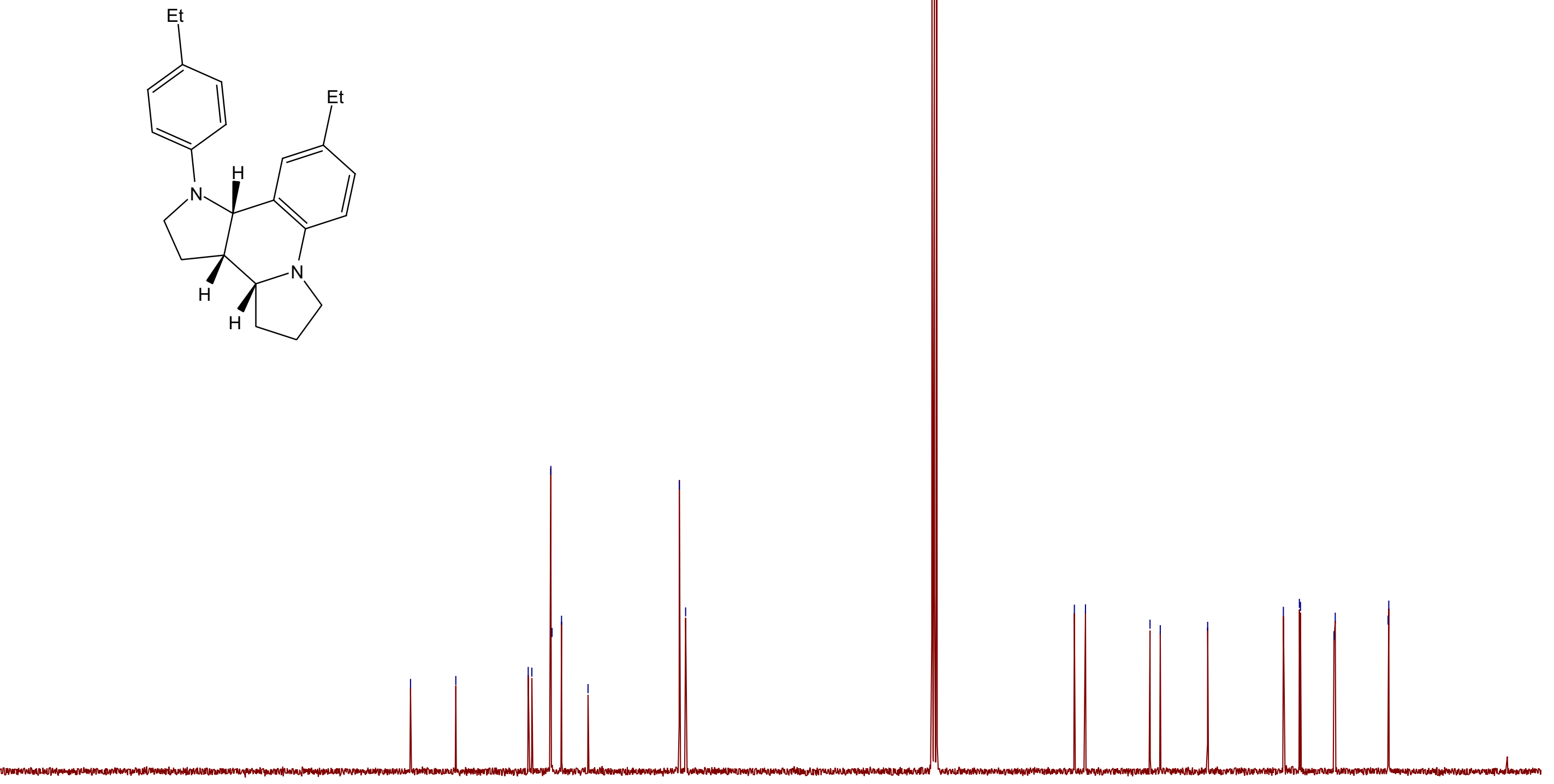
${ }^{1} \mathrm{H}$ NMR of $\mathbf{1 1 b}\left(\mathrm{CDCl}_{3}, 400 \mathrm{MHz}\right)$
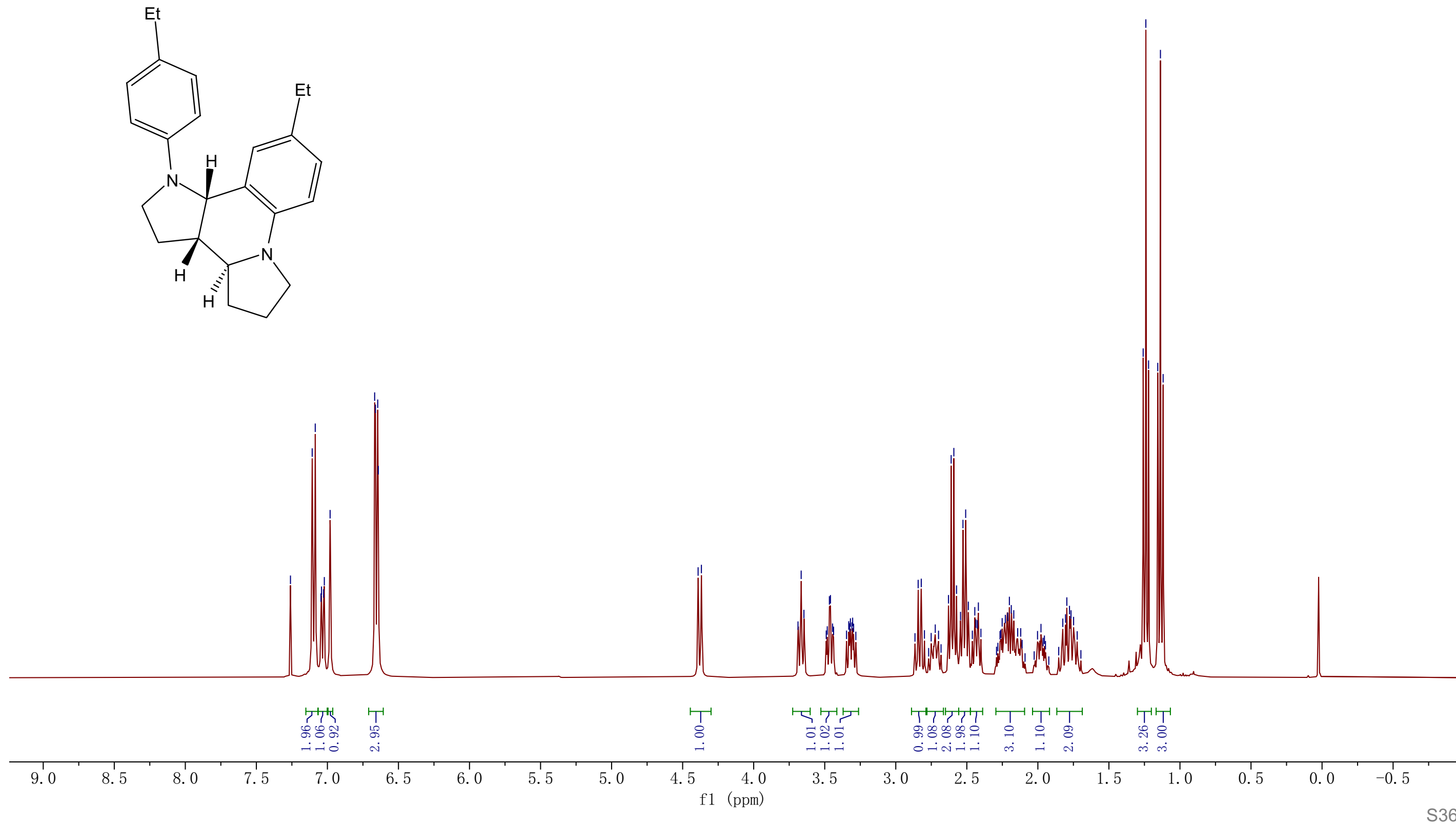
${ }^{13} \mathrm{C}\left\{{ }^{1} \mathrm{H}\right\}$ NMR of $\mathbf{1 1 b}\left(\mathrm{CDCl}_{3}, 100 \mathrm{MHz}\right)$

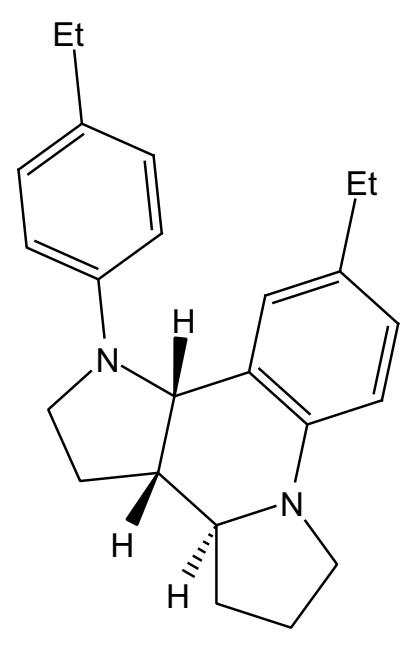

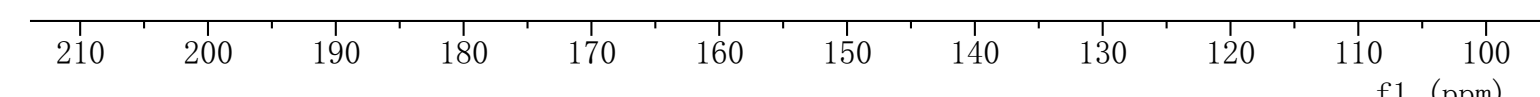


${ }^{1} \mathrm{H}$ NMR of 12a $\left(\mathrm{CDCl}_{3}, 400 \mathrm{MHz}\right)$
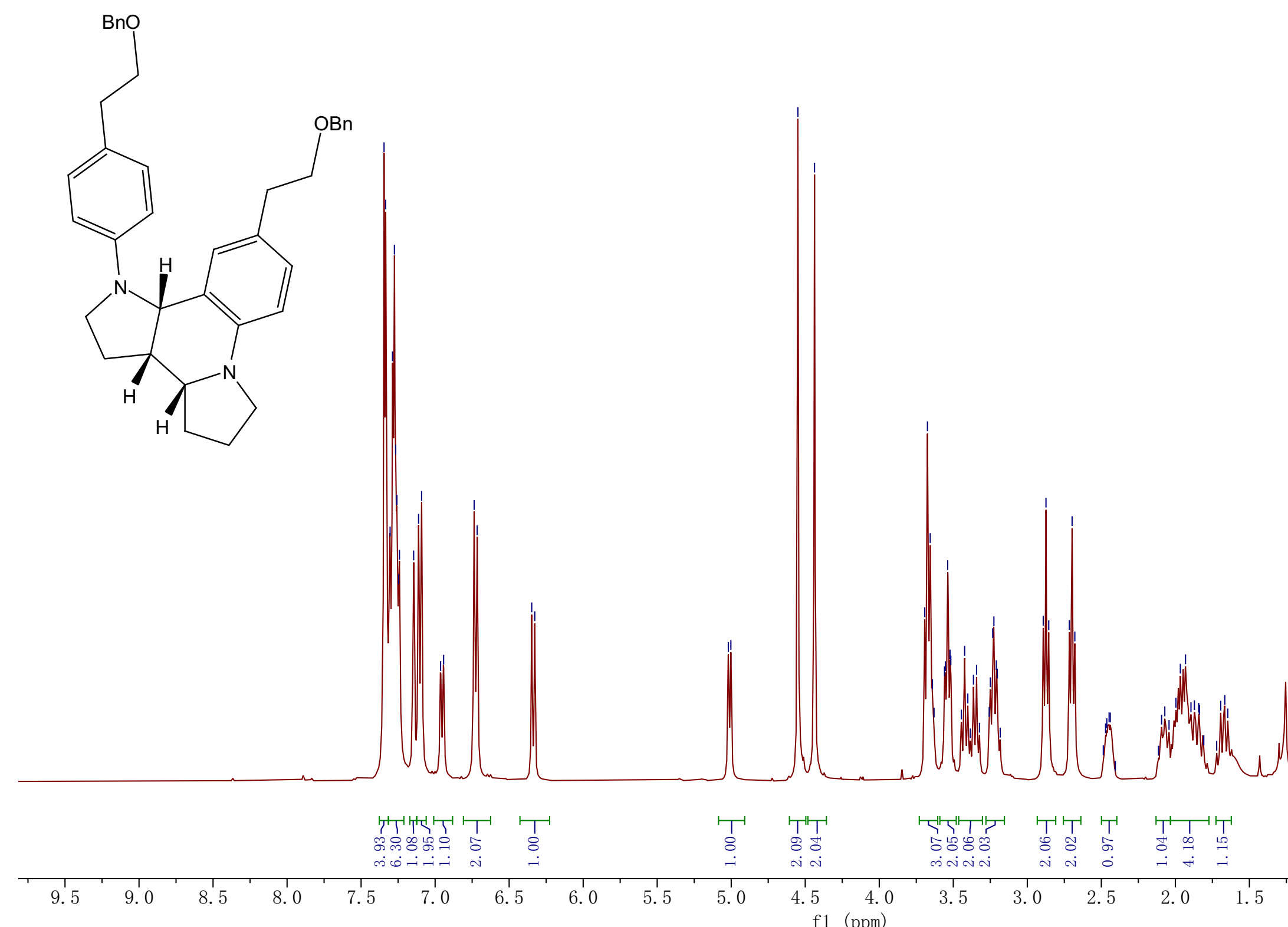

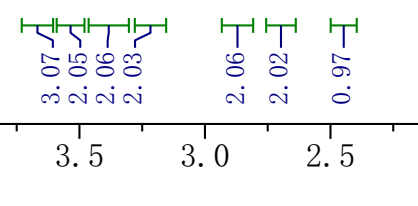

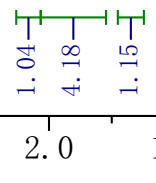

1.5

1.0

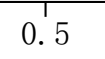

$0.0-0.5$ 
${ }^{13} \mathrm{C}\left\{{ }^{1} \mathrm{H}\right\}$ NMR of $\mathbf{1 2 a}\left(\mathrm{CDCl}_{3}, 100 \mathrm{MHz}\right)$
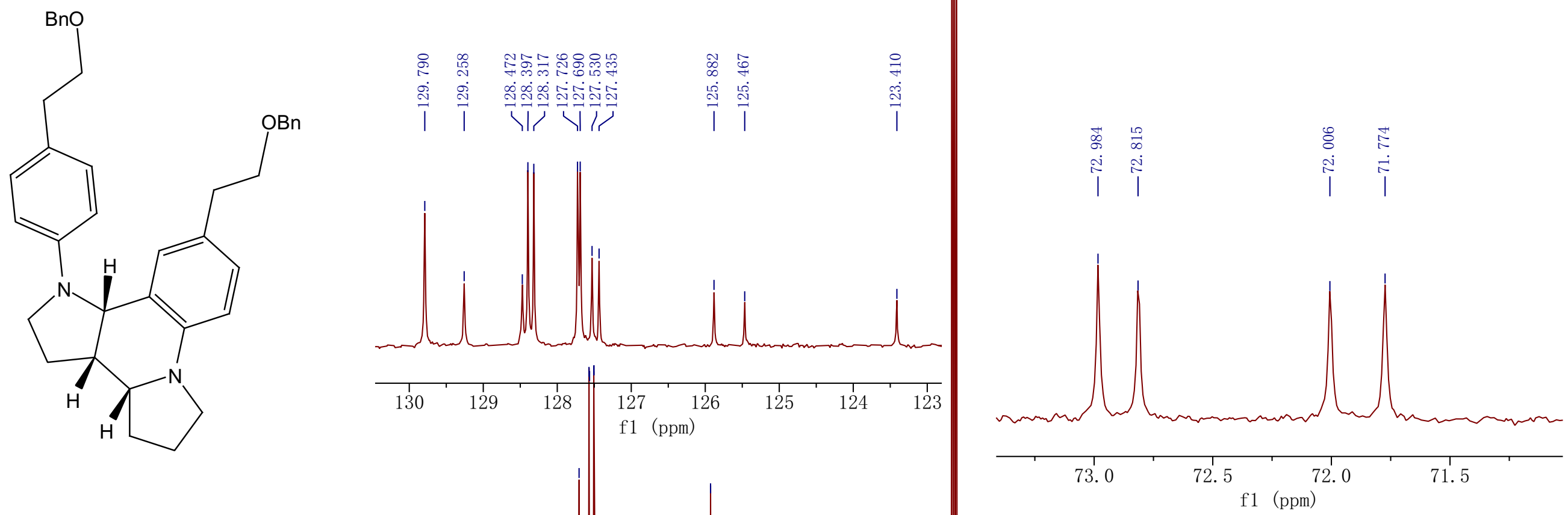
${ }^{1} \mathrm{H} \mathrm{NMR}$ of $\mathbf{1 2 b}\left(\mathrm{CDCl}_{3}, 400 \mathrm{MHz}\right)$
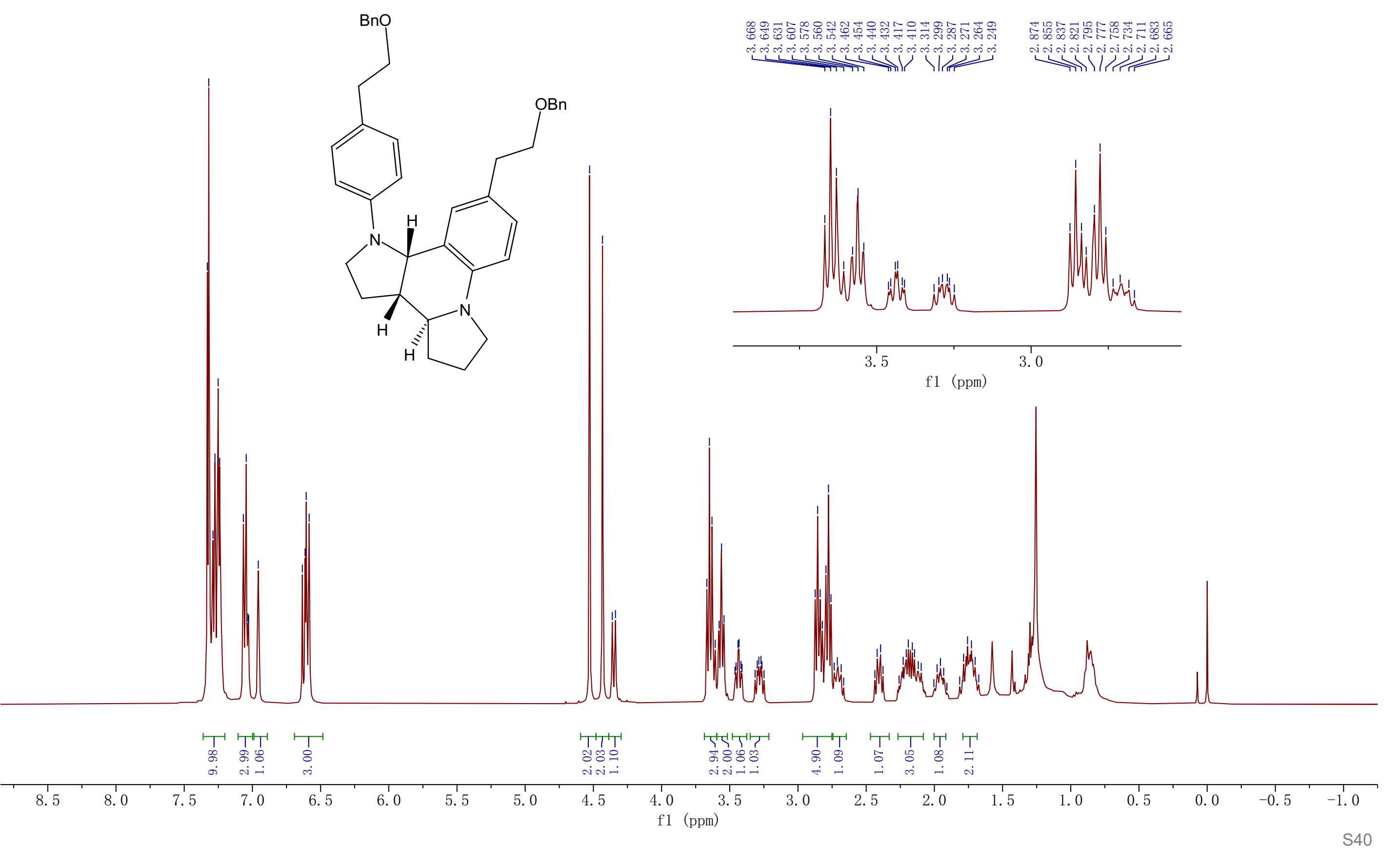


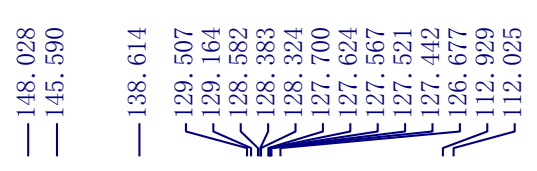

${ }^{13} \mathrm{C}\left\{{ }^{1} \mathrm{H}\right\}$ NMR of $\mathbf{1 2 b}\left(\mathrm{CDCl}_{3}, 100 \mathrm{MHz}\right)$
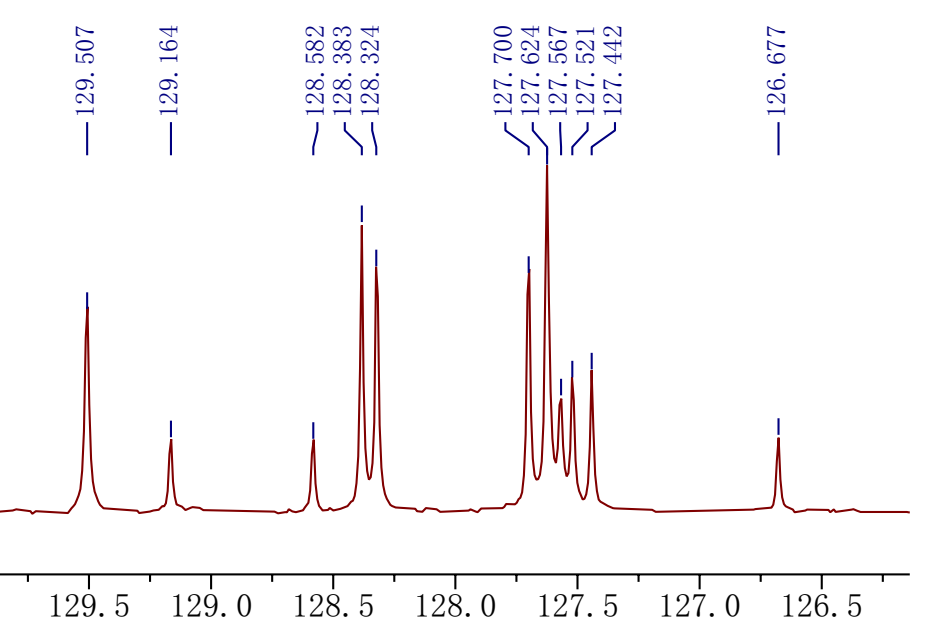
f1 (ppm)

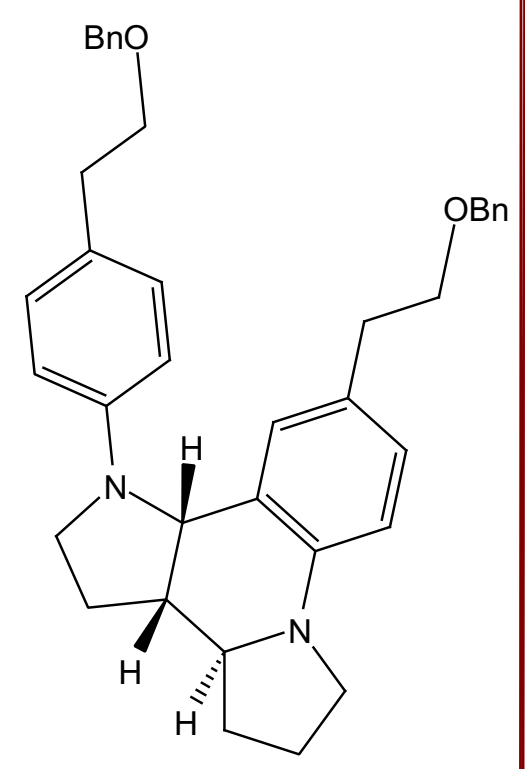

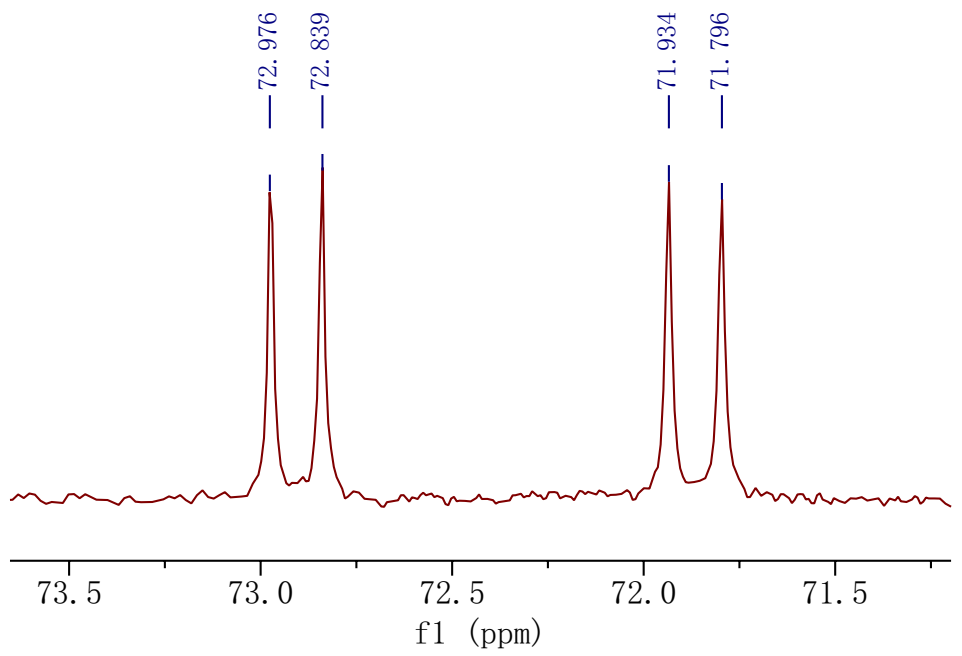

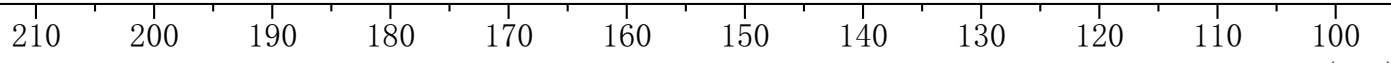

f1 (ppm) 
${ }^{1} \mathrm{H} \mathrm{NMR}$ of 13a and $\mathbf{1 3 b}\left(\mathrm{CDCl}_{3}, 400 \mathrm{MHz}\right)$

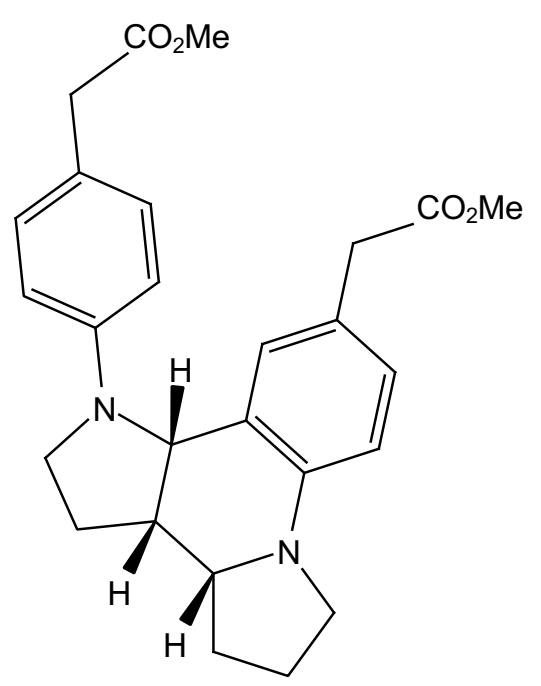

13a

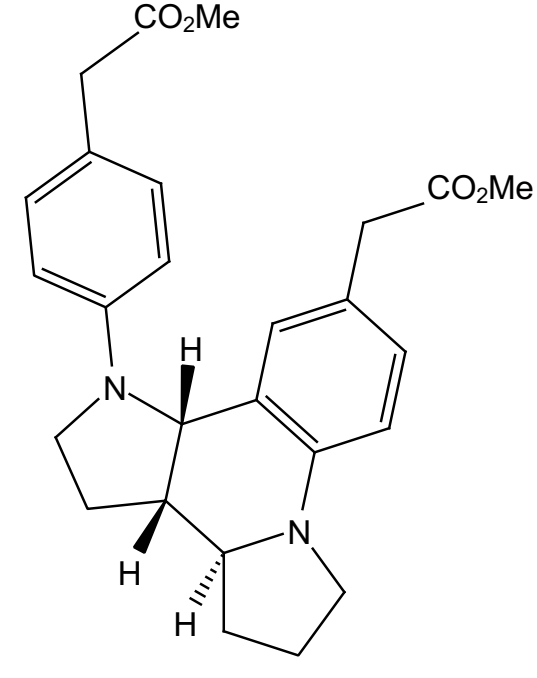

$13 b$

ca. $67 / 33$
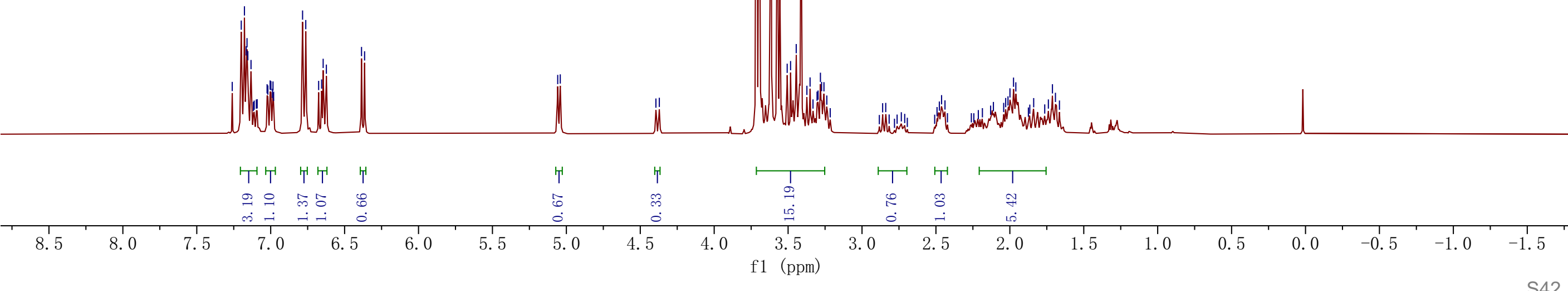
${ }^{13} \mathrm{C}\left\{{ }^{1} \mathrm{H}\right\} \mathrm{NMR}$ of 13a and $\mathbf{1 3 b}\left(\mathrm{CDCl}_{3}, 100 \mathrm{MHz}\right)$
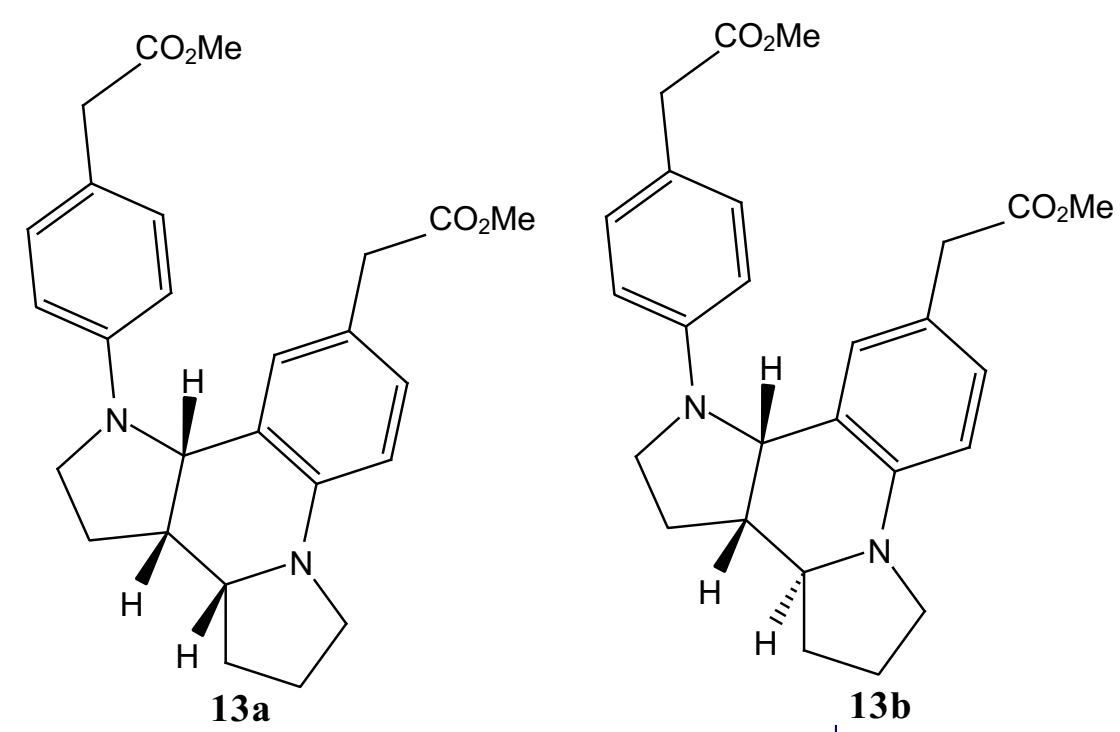

ca. $67 / 33$

13b

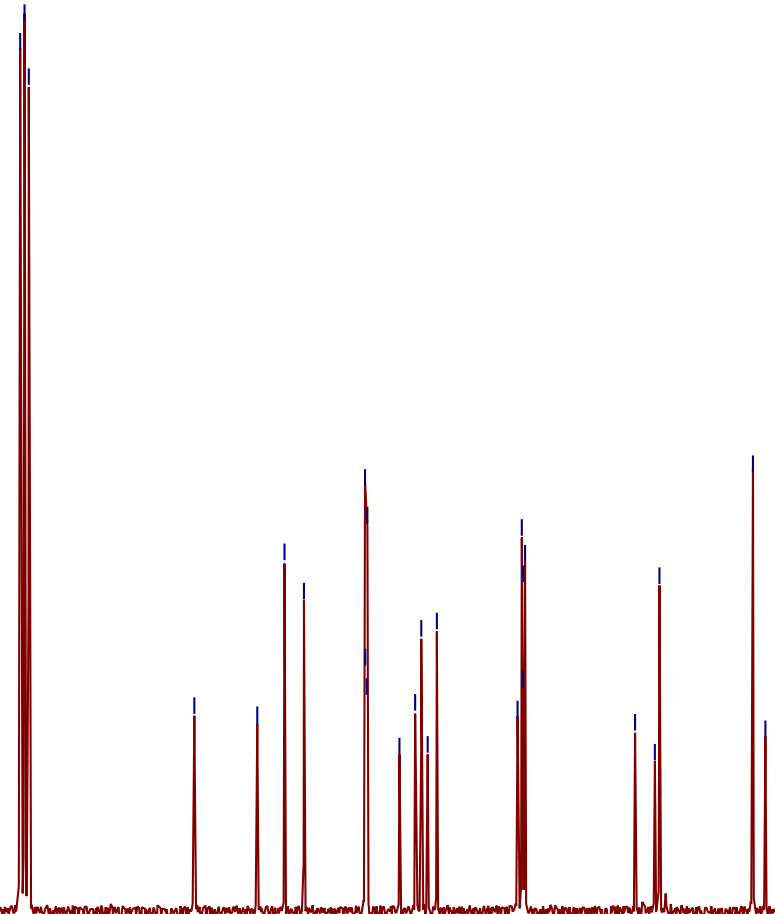




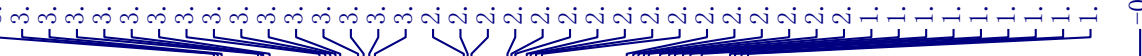

${ }^{1} \mathrm{H} \mathrm{NMR}$ of $14 \mathbf{a}\left(\mathrm{CDCl}_{3}, 400 \mathrm{MHz}\right)$
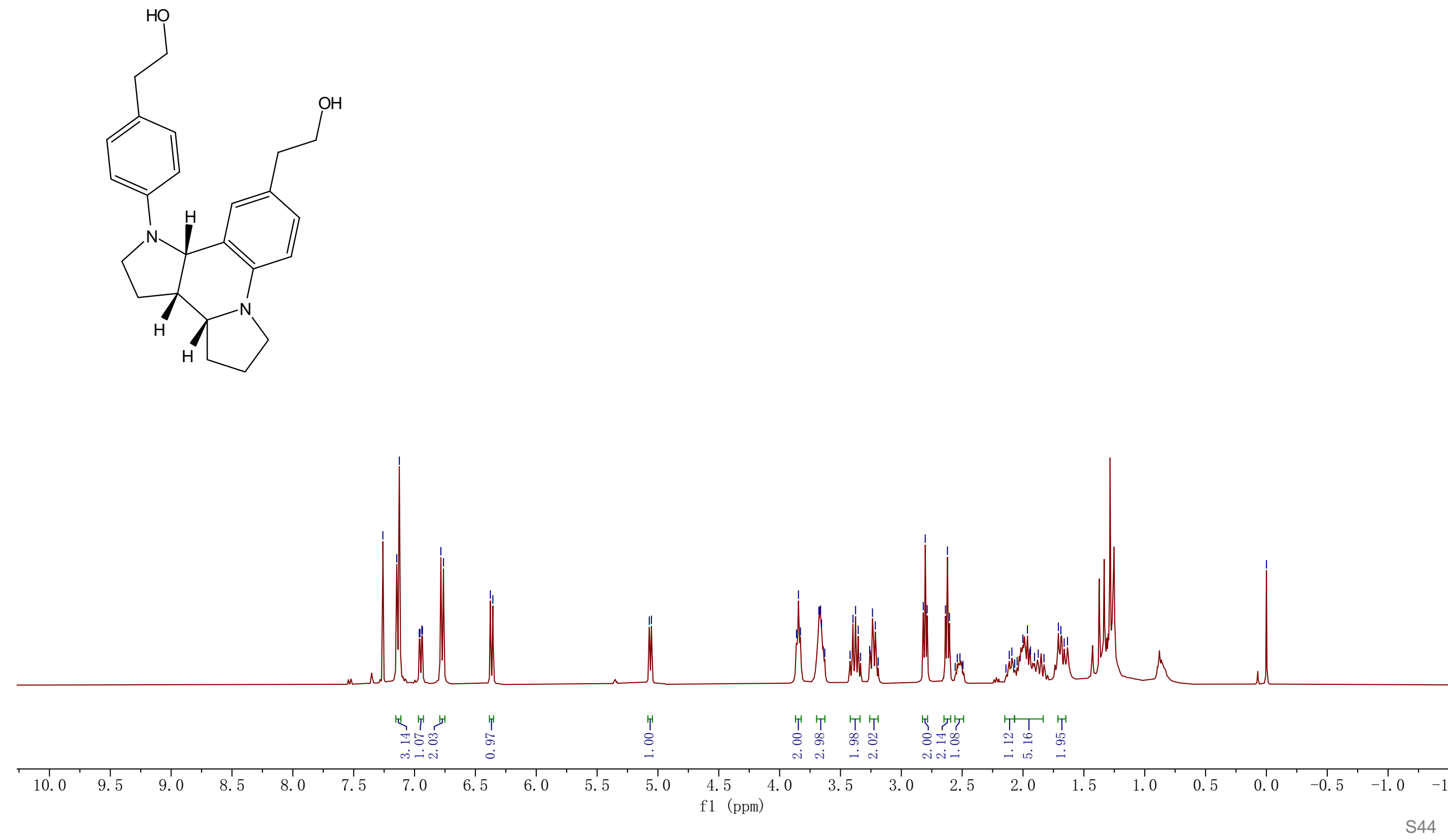
${ }^{1} \mathrm{H} \mathrm{NMR}$ of $14 \mathbf{b}\left(\mathrm{CDCl}_{3}, 400 \mathrm{MHz}\right)$
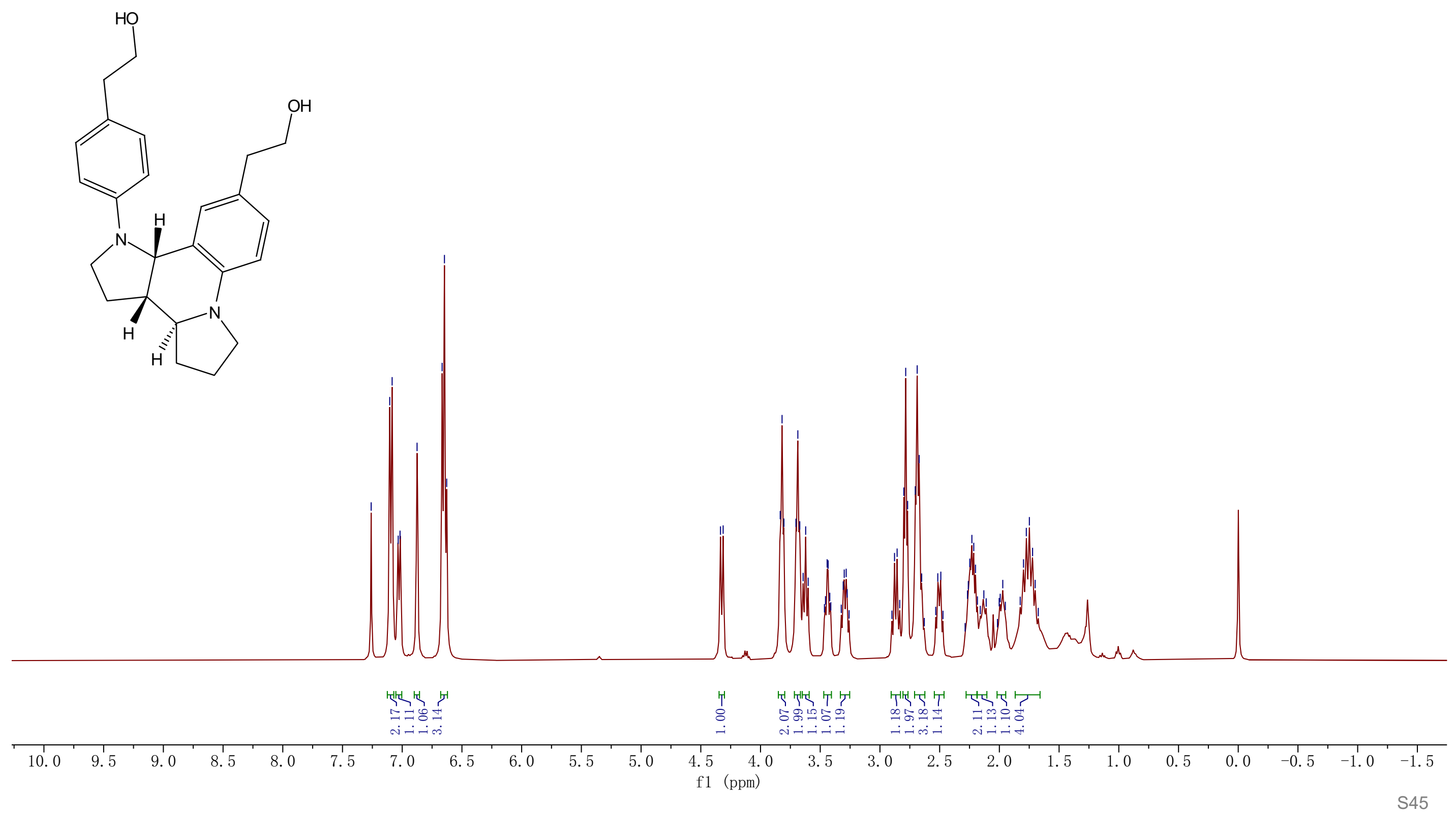
${ }^{1} \mathrm{H} \mathrm{NMR}$ of $15\left(\mathrm{CDCl}_{3}, 400 \mathrm{MHz}\right)$
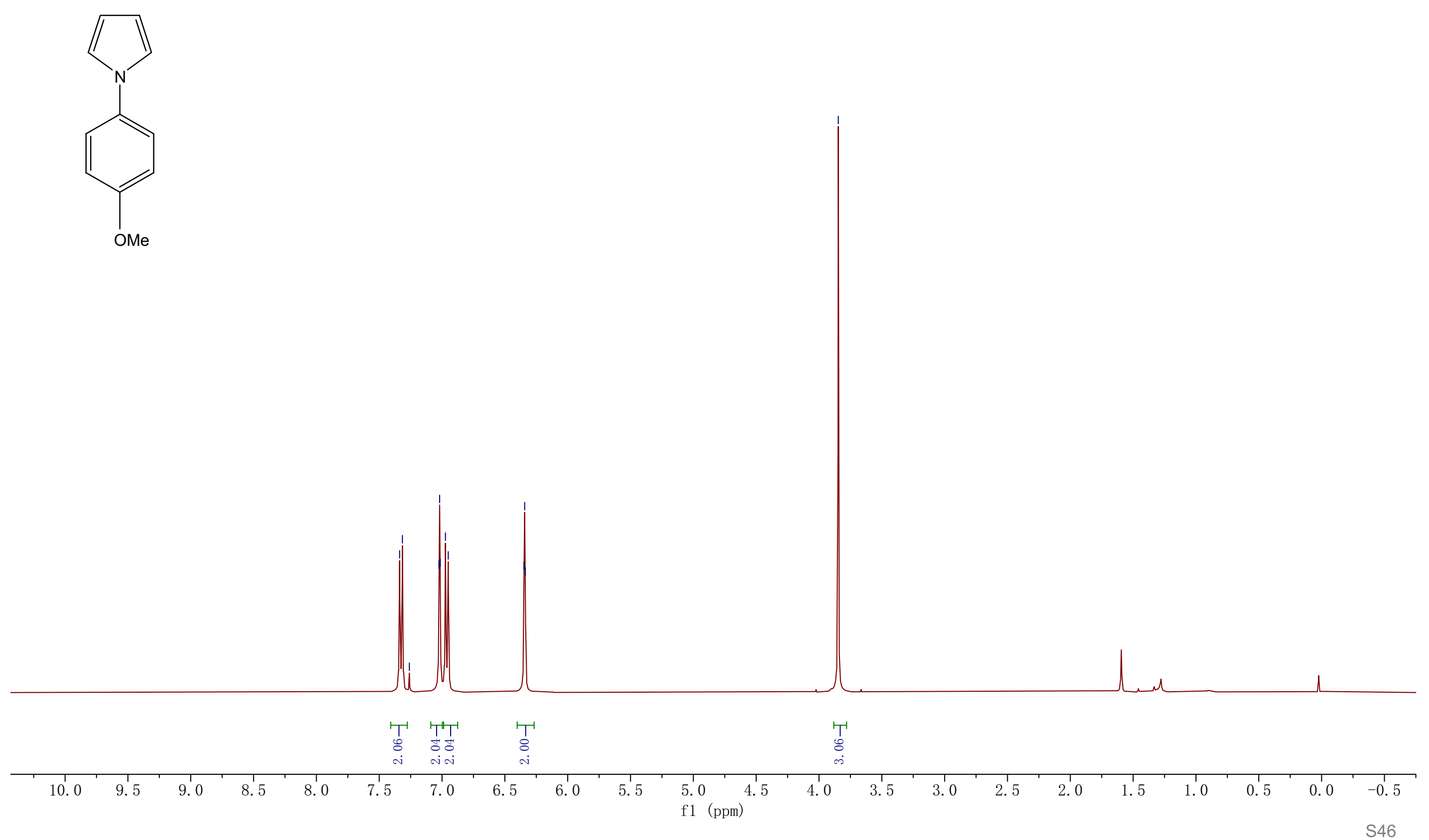
${ }^{1} \mathrm{H} \mathrm{NMR}$ of $\mathbf{1 6}\left(\mathrm{CDCl}_{3}, 400 \mathrm{MHz}\right)$
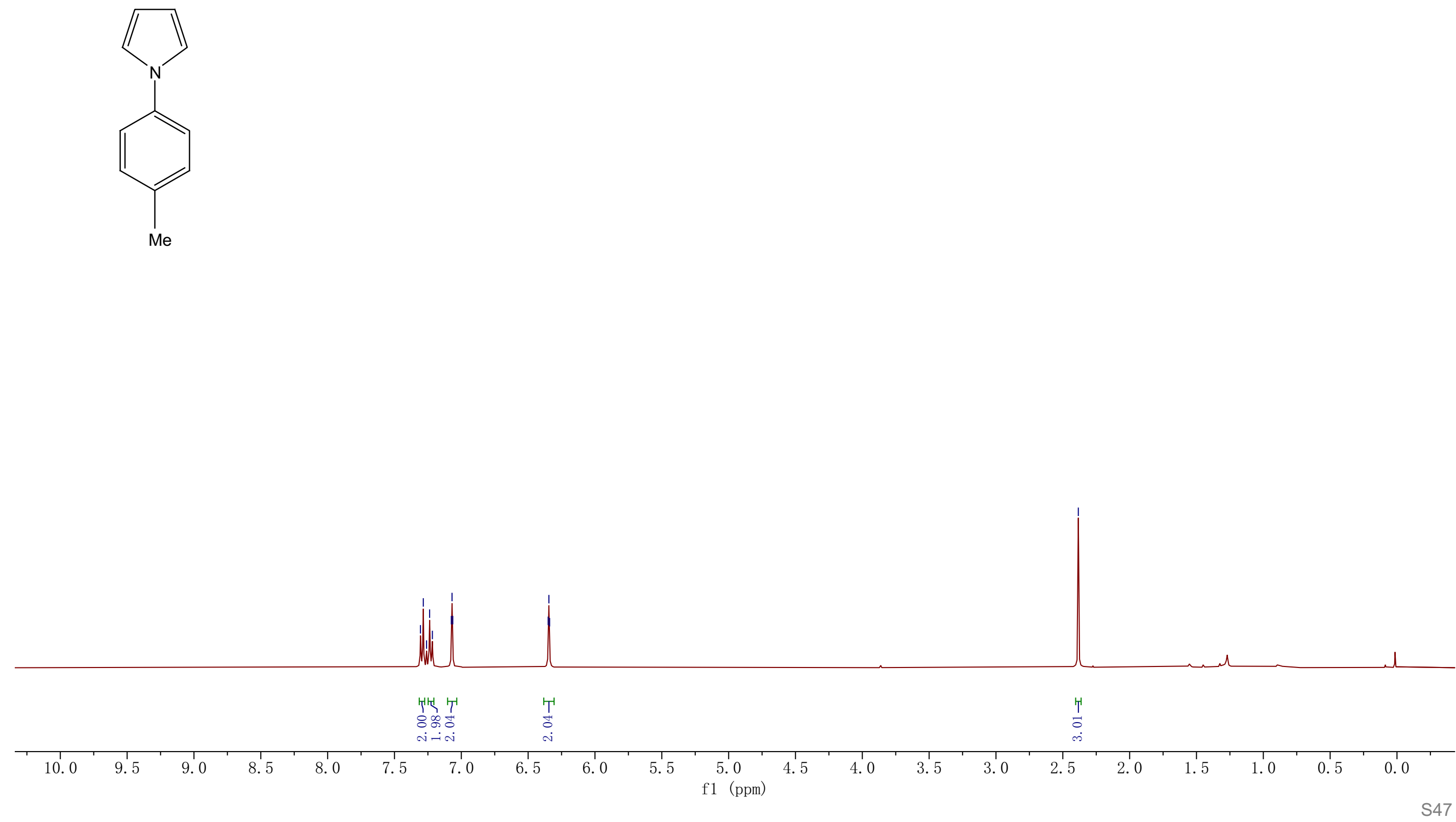
${ }^{1} \mathrm{H}$ NMR of $19\left(\mathrm{CDCl}_{3}, 400 \mathrm{MHz}\right)$
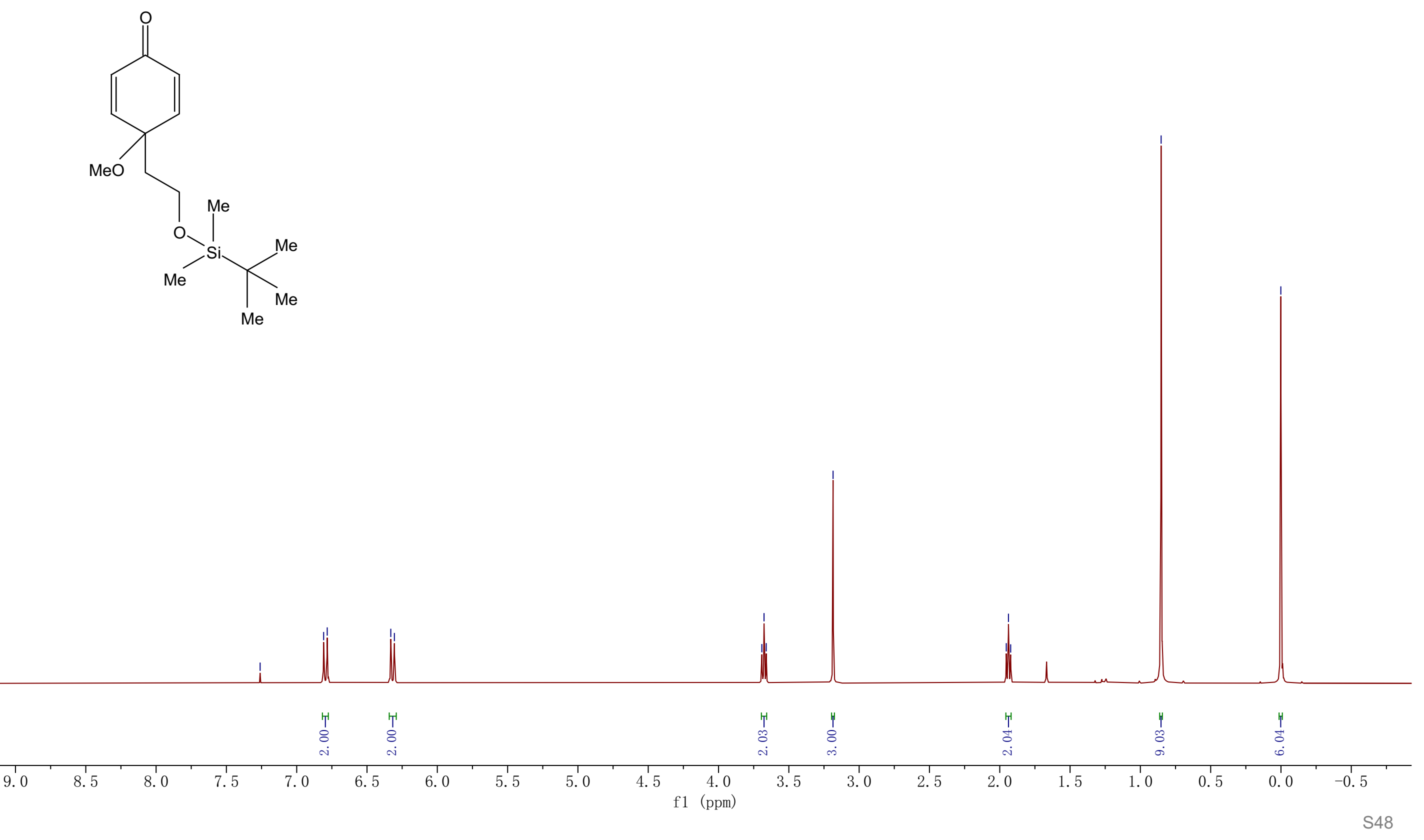
${ }^{13} \mathrm{C}\left\{{ }^{1} \mathrm{H}\right\}$ NMR of $19\left(\mathrm{CDCl}_{3}, 100 \mathrm{MHz}\right)$

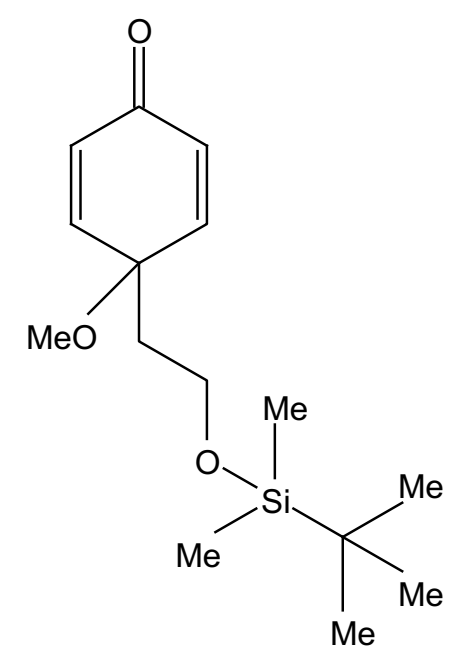

$$
200
$$
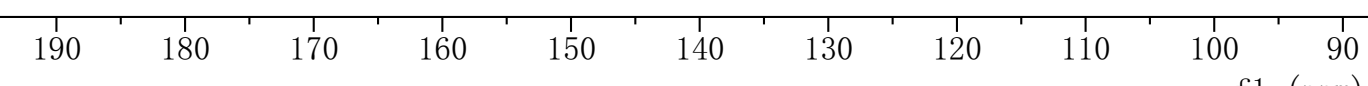

80

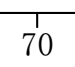

60 
${ }^{1} \mathrm{H} \mathrm{NMR}$ of $20 a\left(\mathrm{CDCl}_{3}, 400 \mathrm{MHz}\right)$
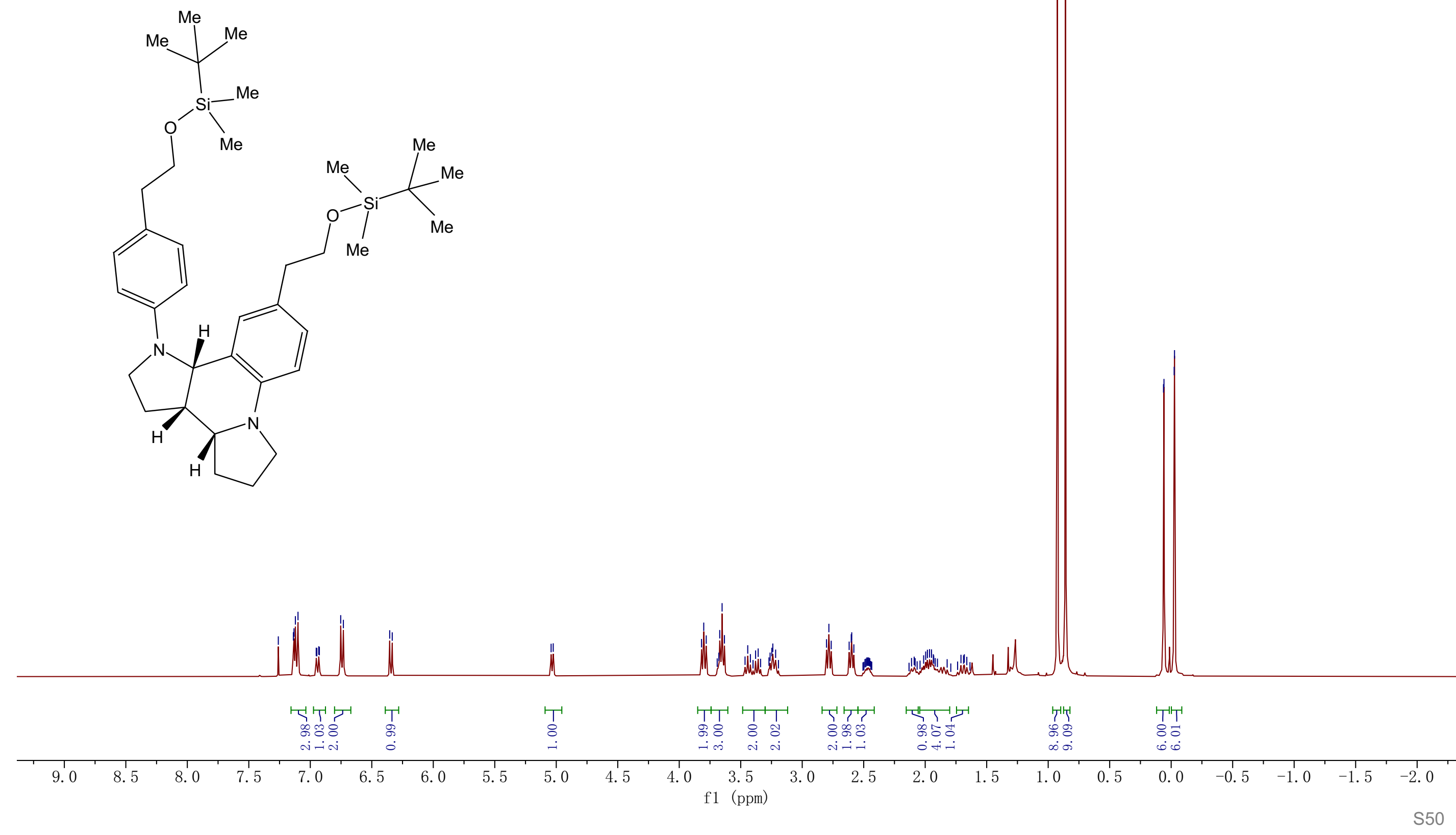
${ }^{13} \mathrm{C}\left\{{ }^{1} \mathrm{H}\right\}$ NMR of $\mathbf{2 0 a}\left(\mathrm{CDCl}_{3}, 100 \mathrm{MHz}\right)$
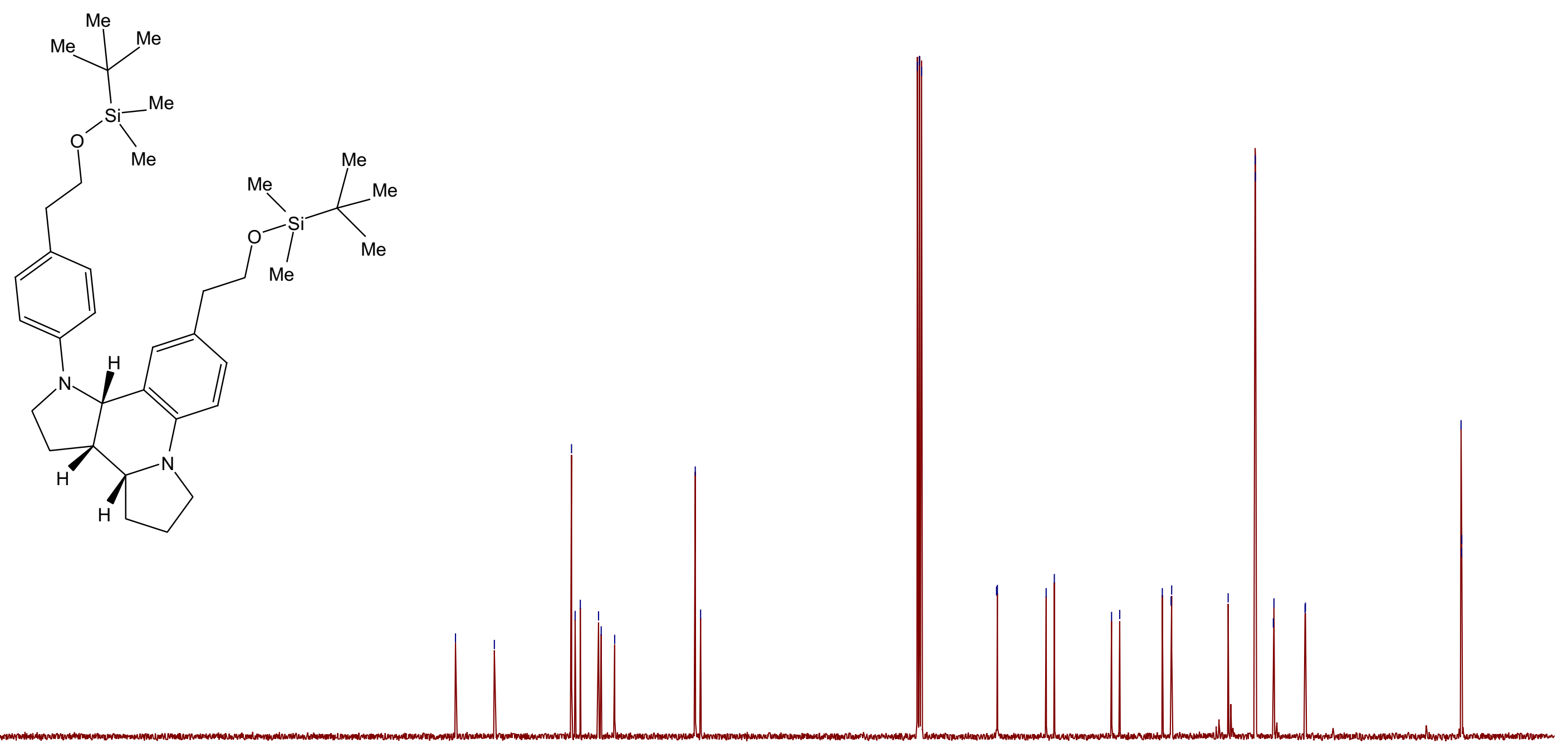
${ }^{1} \mathrm{H}$ NMR of $\mathbf{2 0 b}\left(\mathrm{CDCl}_{3}, 400 \mathrm{MHz}\right)$
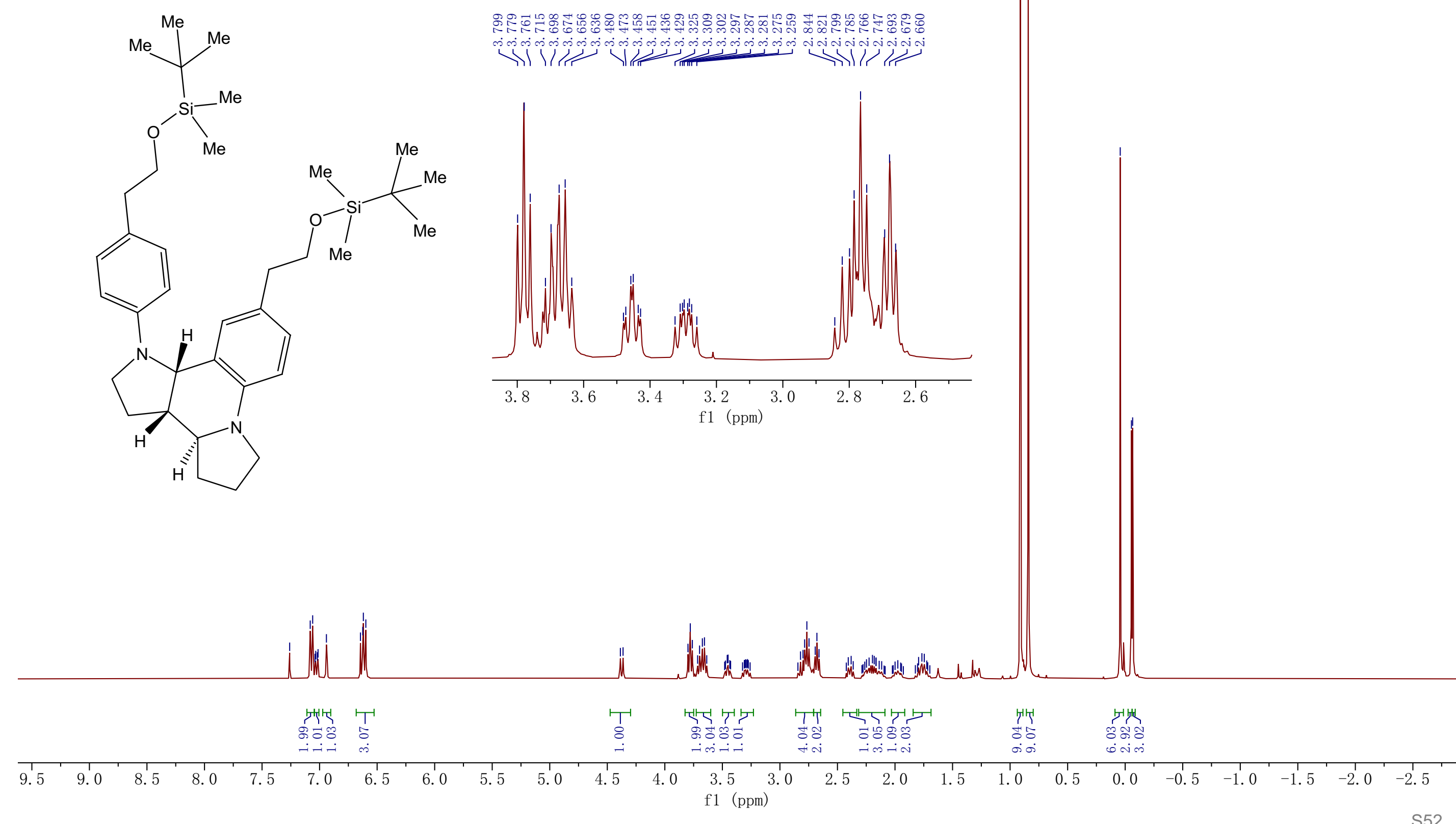
${ }^{13} \mathrm{C}\left\{{ }^{1} \mathrm{H}\right\}$ NMR of $\mathbf{2 0 b}\left(\mathrm{CDCl}_{3}, 100 \mathrm{MHz}\right)$
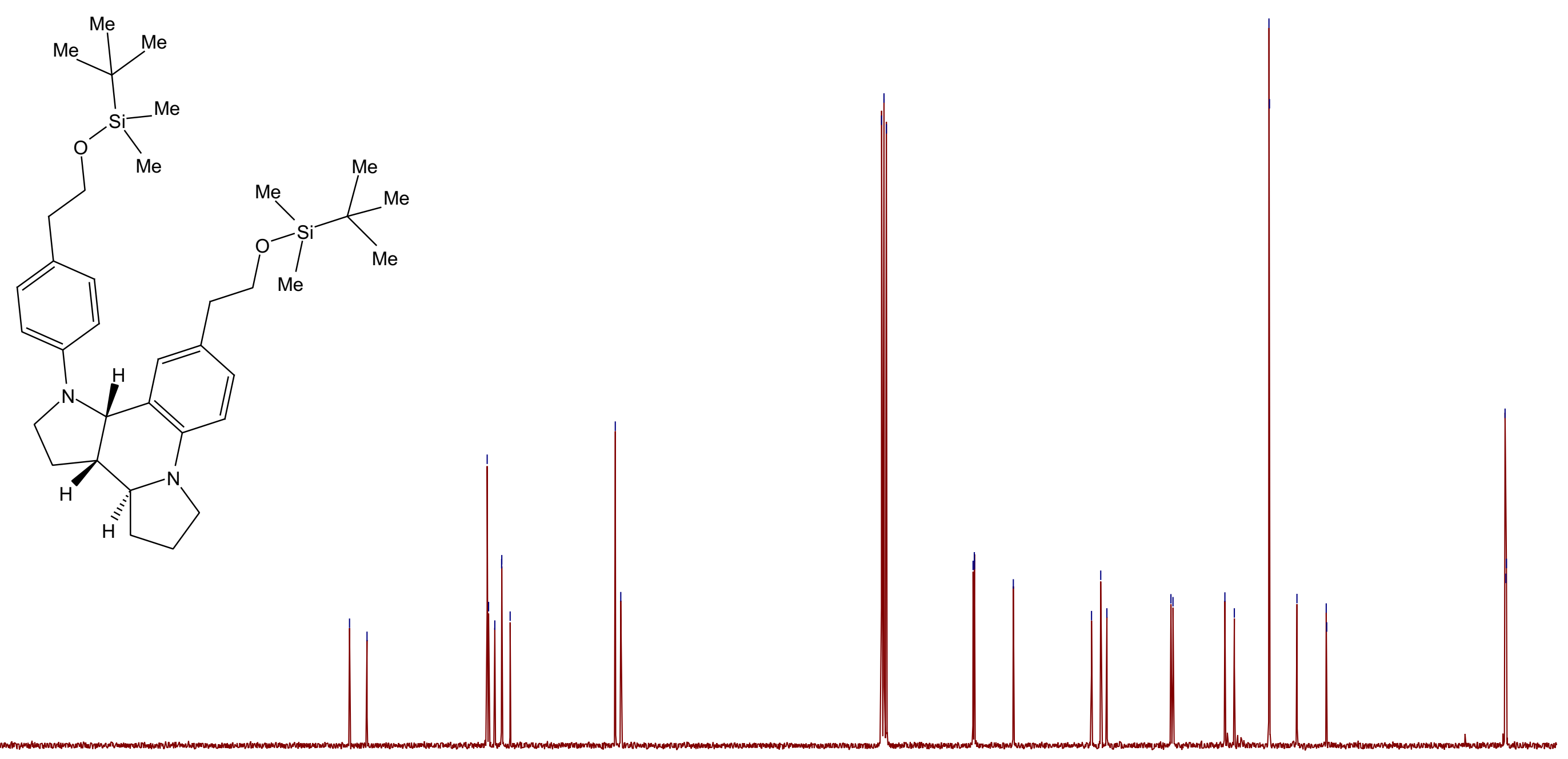
${ }^{1} \mathrm{H}$ NMR of $\mathbf{1 j}\left(\mathrm{CDCl}_{3}, 400 \mathrm{MHz}\right)$
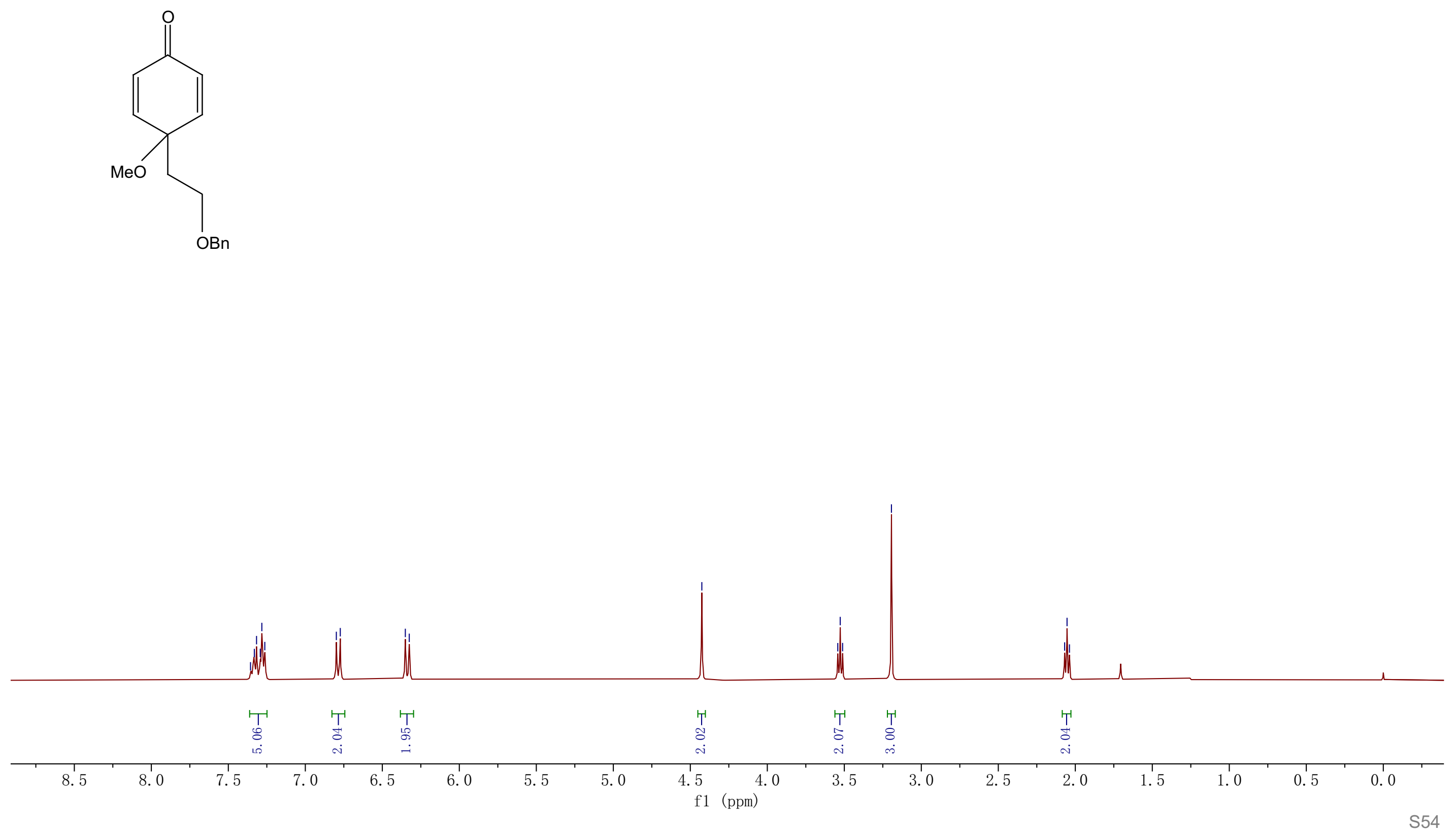
${ }^{13} \mathrm{C}\left\{{ }^{1} \mathrm{H}\right\}$ NMR of $\mathbf{1 j}\left(\mathrm{CDCl}_{3}, 100 \mathrm{MHz}\right)$
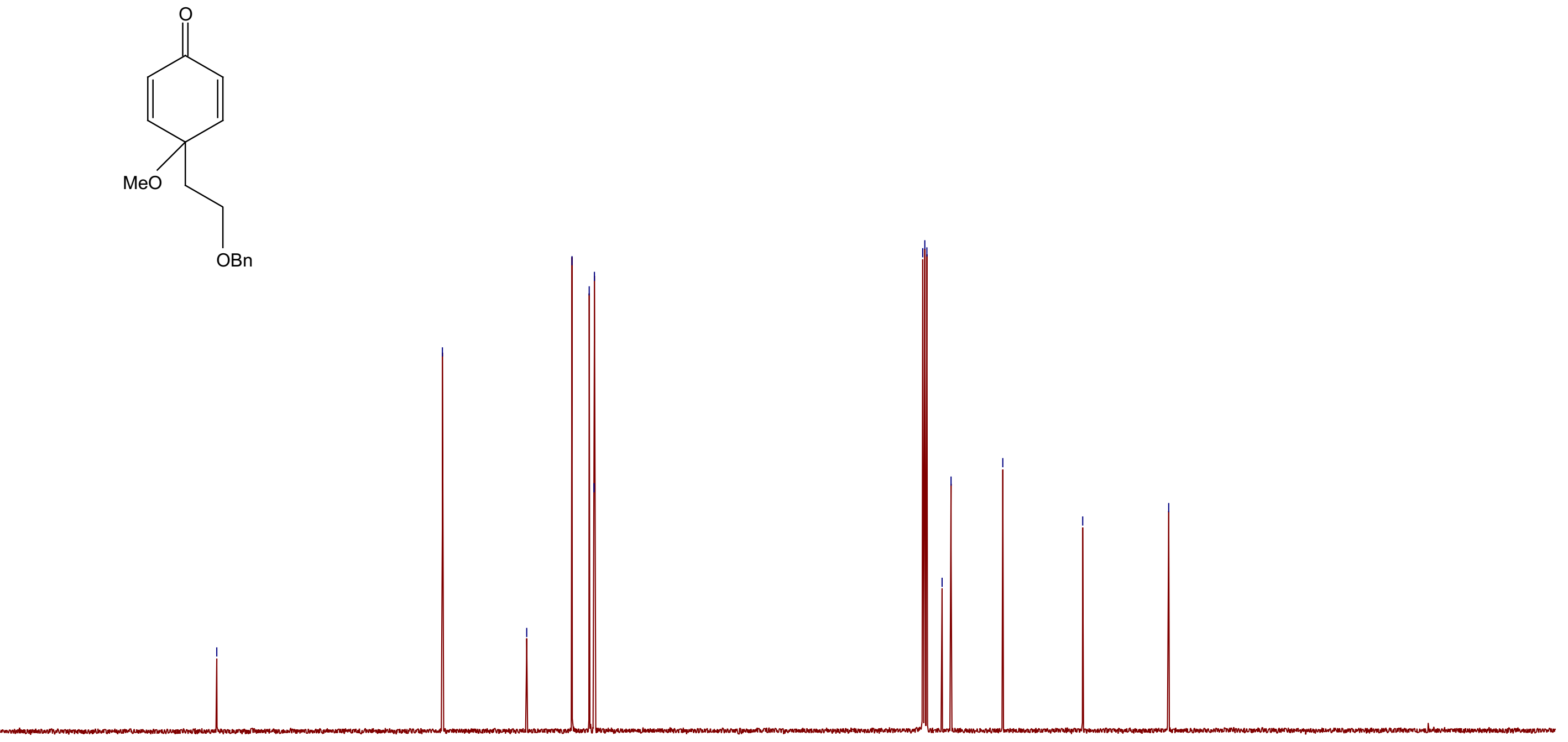
${ }^{1} \mathrm{H}$ NMR of $\mathbf{1 k}\left(\mathrm{CDCl}_{3}, 400 \mathrm{MHz}\right)$
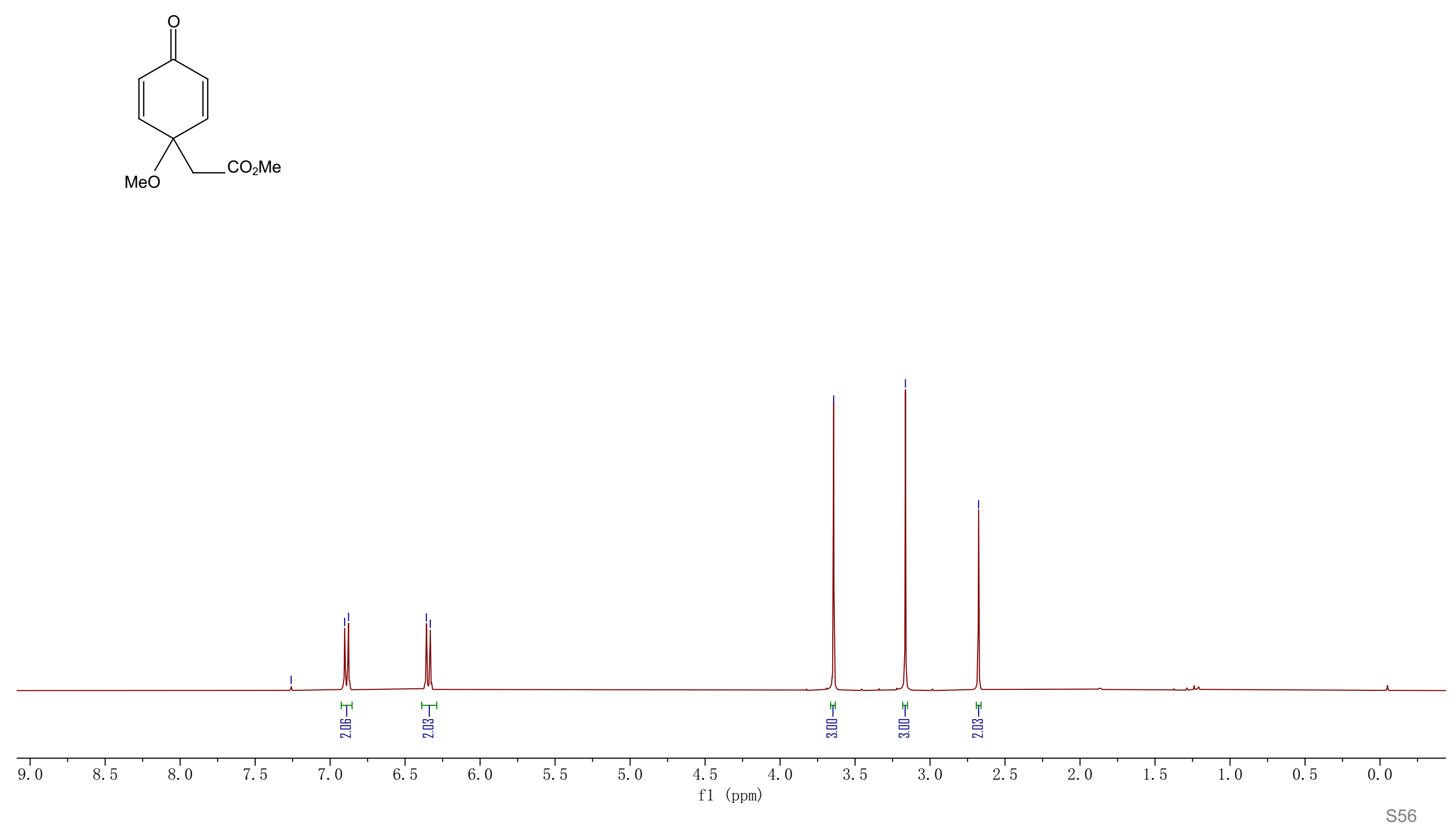
${ }^{13} \mathrm{C}\left\{{ }^{1} \mathrm{H}\right\}$ NMR of $\mathbf{1 k}\left(\mathrm{CDCl}_{3}, 100 \mathrm{MHz}\right)$
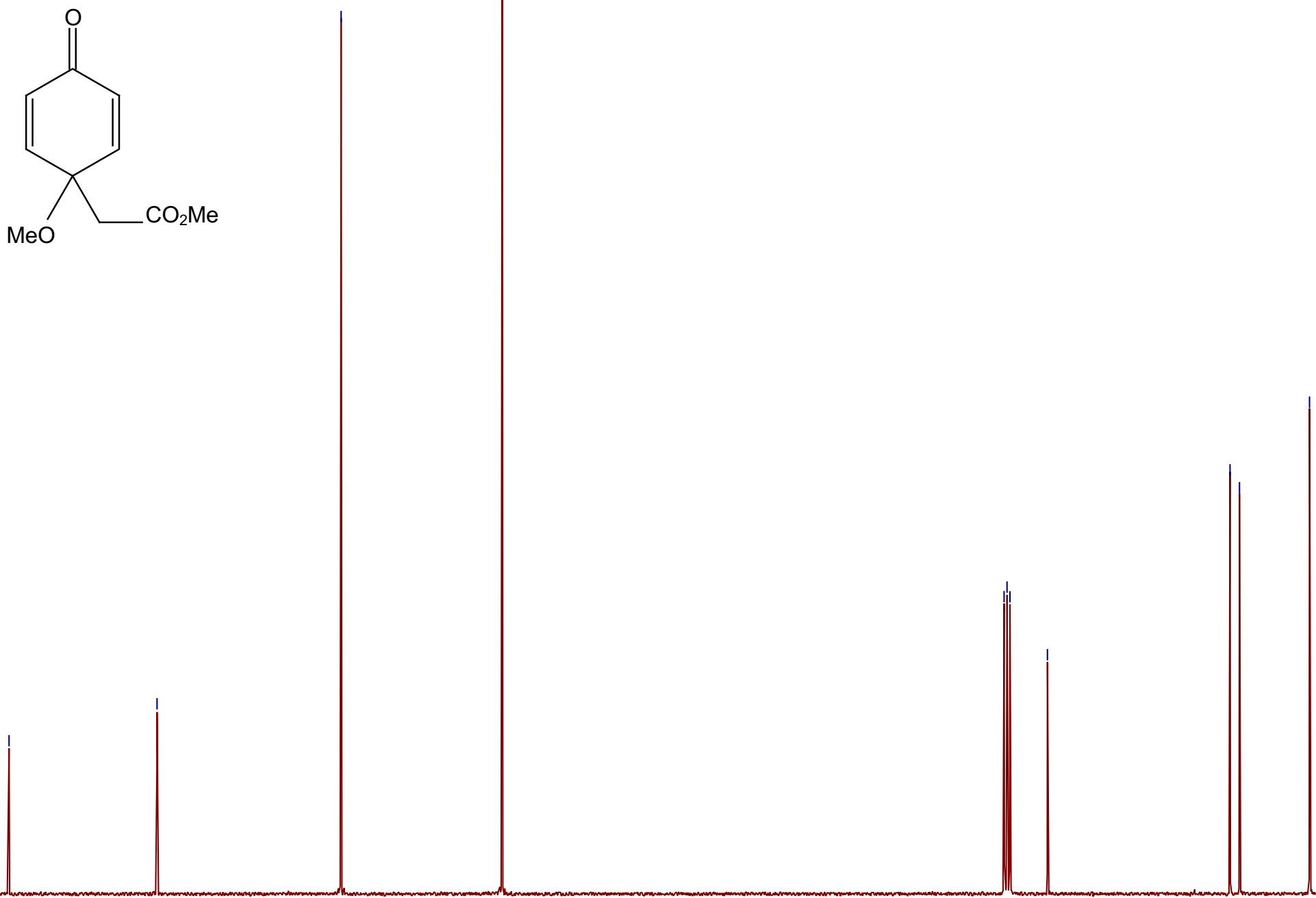